UNIVERSIDADE DE SÃO PAULO

ESCOLA DE ENGENHARIA DE SÃO CARLOS

DEPARTAMENTO DE GEOTECNIA

\title{
Aplicação da técnica da fotoelasticidade na análise de fundações por estacas helicoidais
}

\author{
JOSÉ ANTONIO SCHIAVON
}

\begin{abstract}
Dissertação apresentada à Escola de Engenharia de São Carlos da Universidade de São Paulo, como parte dos requisitos para obtenção do título de Mestre em Ciências, Programa de Pós Graduação em Geotecnia.
\end{abstract}

ORIENTADOR: PROF. DR. EDMUNDO ROGÉRIO ESQUIVEL 
AUTORIZO A REPRODUÇÃO E DIVULGAÇÃO TOTAL OU PARCIAL DESTE TRABALHO, POR QUALQUER MEIO CONVENCIONAL OU ELETRÔNICO, PARA FINS DE ESTUDO E PESQUISA, DESDE QUE CITADA A FONTE.

Ficha catalográfica preparada pela Seção de Tratamento da Informação do Serviço de Biblioteca - EESC/USP

Schiavon, José Antonio

Aplicação da técnica da fotoelasticidade na análise de fundações por estacas helicoidais / José Antonio Schiavon ; orientador Edmundo Rogério Esquivel. -- São Carlos, 2010 .

Dissertação (Mestrado-Programa de Pós-Graduação e Área de Concentração em Geotecnia) -- Escola de Engenharia de São Carlos da Universidade de São Paulo, 2010.

1. Fundações. 2. Estaca helicoidal. 3. Ancoragem. 4. Análise de tensões. 5. Fotoelasticidade. I. Título. 
FOLHA DE JULGAMENTO

Candidato: Engenheiro JOSÉ ANTONIO SCHIAVON.

Dissertação defendida e julgada em 23/07/2010 perante a Comissão Julgadora:

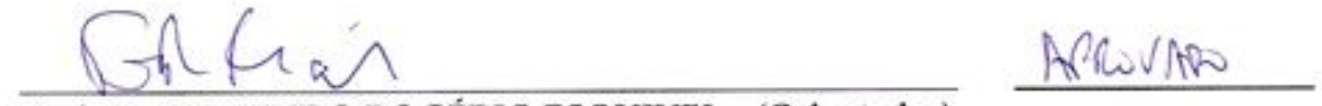

Prof. Dr. EDMUNDO ROGÉRIO ESQUIVEL - (Orientador)

(Escola de Engenharia de São Carlos/USP)

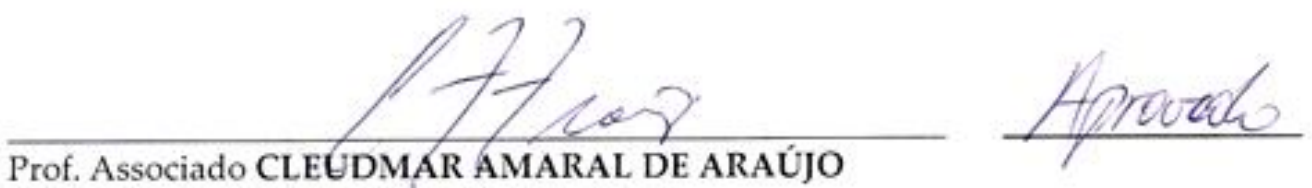
(Universidade Federal de Uberlândia/UFU)

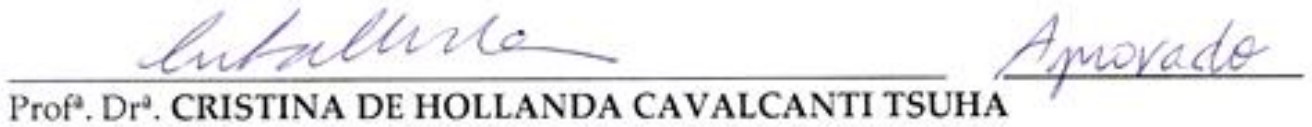

(Escola de Engenharia de São Carlos/USP)

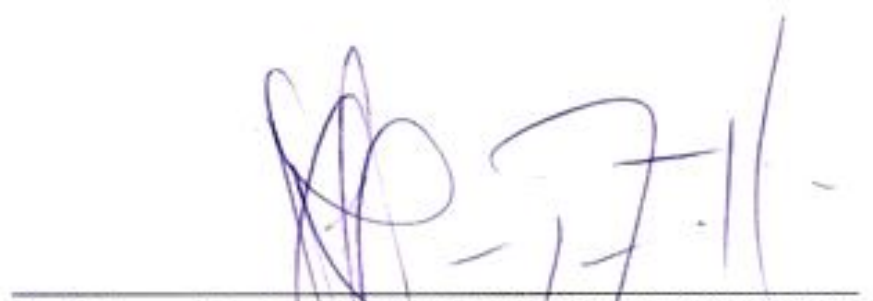

Prof. Associado LAZARO VALENTIN ZUQUETTE

Coordenador do Programa de Pós-Graduação em Geotecnia

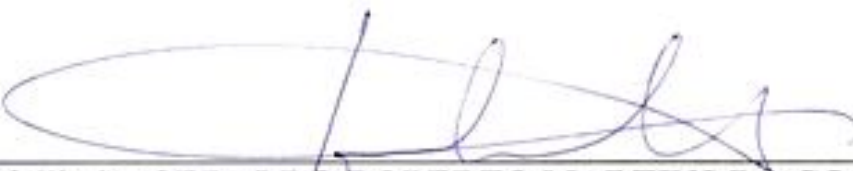

Prof. Titular GERALDO ROBERTO MARTINS DÀ COSTA

Presidente da Comissão da Pós-Graduação da EESC 


Aos meus pais, José Valentim e Maria José, pelo amor de todos os momentos. Ao Fábio, Andrea e Renata, pelo apoio incondicional. 



\section{AGRADECIMENTOS}

Ao Prof. Dr. Edmundo Rogério Esquivel pela orientação, companheirismo, conselhos, paciência e ao precioso tempo dedicado às correções e discussões.

À Profa. Dra. Cristina de Hollanda Cavalcanti Tsuha pelo fundamental apoio desde o início da pesquisa, sugestões, correções, grande atenção e paciência.

Ao Prof. Dr. Nelson Aoki pelos valiosos ensinamentos e conversas enriquecedoras.

Ao Prof. Dr. José C. A. Cintra pela amizade e grande aprendizado.

Ao Prof. Dr. Cleudmar Amaral de Araújo pelos conhecimentos transmitidos, sugestões e correções do presente trabalho.

Ao Prof. Dr. Alexandre Benetti Parreira pelas sugestões e correções do Exame de Qualificação.

Ao Prof. Dr. Antonio Antenor Tognon pela confiança e indicação para o mestrado.

A todos os professores do Departamento de Geotecnia da EESC por todo o conhecimento transmitido.

Aos funcionários do Departamento de Geotecnia, Álvaro, Maristela, Neiva, Antonio C. Carriel, Antonio Garcia, Benedito, Décio, Herivelto, José Luis e Oscar.

Aos amigos(as) pós-graduandos(as) e companheiros(as) durante as disciplinas, Damares, Felipe, Fernando Jamal, Fernando Portelinha, Giovana, Juliana Azoia, Juliana Maria, Junio, Karin, Luis Miguel, Márcia, Natália, Osvaldo Freitas, Vagner e Vinicius. Em especial ao amigo Victor Valdivia pela ajuda e companheirismo durante todo o curso. 

À CAPES - Coordenação de Aperfeiçoamento Pessoal de Nível Superior, pela bolsa de mestrado concedida.

À Escola de Engenharia de São Carlos e ao Departamento de Geotecnia pela oportunidade de realizar esta pesquisa.

Ao amigo Dênis Delázari da Silva, pelos valiosos conselhos, sugestões e sua amizade ímpar.

Ao Fábio, Andréa e Renata, queridos e amorosos irmãos.

Aos meus queridos pais, os alicerces da minha vida.

Em especial à Karen Fernanda Bompan pelo amor, companheirismo, compreensão, incentivo e todo o apoio nessa importante fase de minha vida.

A Deus, pois sem ele nada seria possível! 




\section{SUMÁRIO}

LISTA DE FIGURAS $v$

LISTA DE TABELAS $x i$

LISTA DE ABREVIATURAS, SIGLAS E SÍMBOLOS xiii

RESUMO $x v i i$

ABSTRACT xix

1. INTRODUÇÃO 1

1.1. Objetivo 2

2. REVISÃO BIBLIOGRÁFICA 5

2.1. Teoria da Fotoelasticidade de Transmissão Plana_______ 5

2.1.1. Teoria da Onda de Luz ___ 9

2.1.2. Luz Polarizada___ 12

2.1.3. Polarizador Plano ou Linear ___ 14

2.1.4. Propagação da Luz através de Meio Anisotrópico ___ 15

2.1.5. Retardadores de Onda___ 19

2.1.6. Polariscópio____ 21

2.1.6.1. Polariscópio Plano___ 21

2.1.6.2. Polariscópio Circular __ 23

2.1.7. Análise em Polariscópio Plano ___ _ _ _

2.1.8. Análise em Polariscópio Circular ____________ 28

2.1.9. Padrão de Franjas ___ 32

2.1.9.1. Linhas de Tensões Principais________ 33

2.1.9.2. Franjas Isocromáticas ___ 34 


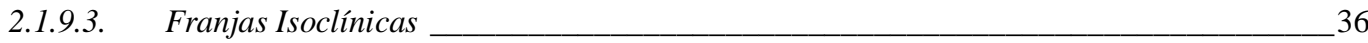

2.1.9.4. Comportamento das Franjas___ 40

2.1.10. Medida dos Parâmetros Fotoelásticos ___ 41

2.1.10.1. Compensação Tardy______ 41

2.1.11. Métodos de Calibração______ 43

2.2. Materiais Fotoelásticos ________________________

2.2.1. Propriedades do MateriaL Fotoelástico___ 45

2.2.1.1. Transparência ___ 46

2.2.1.2. Sensibilidade_____ 47

2.2.1.3. Isotropia e Homogeneidade ___ 47

2.2.1.4. Fluência___ 48

2.2.1.5. Módulo de Elasticidade e Limite de Proporcionalidade___ 49

2.2.1.6. Sensibilidade à Temperatura___ 50

2.2.1.7. Efeito de Borda pelo Tempo ___ 51

2.2.1.8. Efeito da Absorção Óptica ___ 51

2.2.2. Materiais Utilizados em Análises Fotoelásticas___ 51

2.3. Aplicações da Fotoelasticidade__________________________

2.3.1. Análises Fotoelásticas voltadas à Geotecnia ___ 53

2.3.2. Utilização da gelatina como material fotoelástico ___ 56

2.4. Estacas Helicoidais ___________ 61

3. MATERIAIS E MÉTODOS ___ 73

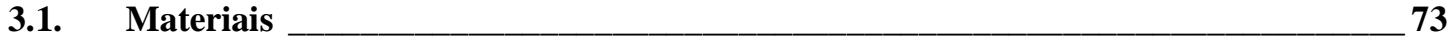

3.2. Ensaios Fotoelásticos__________________

3.3. Calibração do Material Fotoelástico_______________________ 77

3.3.1. Análises Fotoelásticas das Ancoragens ___ 81

3.3.1.1. Carregamentos Axiais___ 82

3.3.2. Análises Numéricas__________ 84 
4.1. Calibração da Gelatina

4.2. Ensaios Fotoelásticos 90

4.2.1. Ancoragem de Placa Circular Plana "AP” na profundidade igual a 2,5D (Ancoragem Rasa)_ 91

4.2.1.1. Modelagem Numérica Assumindo Estado Plano de Tensões 98

4.2.1.2. Modelagem Numérica Axi-simétrica 101

4.2.1.3. Estaca Helicoidal “EH1” na profundidade igual a 2,5D (Ancoragem Rasa) 105

4.2.2. Estaca Helicoidal “EH2” na profundidade igual a 1,6D (Ancoragem Rasa) 109

4.2.3. Estaca Helicoidal “EH2” na profundidade igual a 5,5D (Ancoragem Profunda) 112

5. CONCLUSÃO 117

5.1. Sugestões para Trabalhos Futuros 118 


\section{LISTA DE FIGURAS}

Figura 2.8 - Objeto e fatia em na técnica da fotoelasticidade de transmissão tridimensional. 8

Figura 2.9 - Representação de uma onda de luz (FLEURY, 2001). 11

Figura 2.10 - Diferença de fase linear entre duas ondas. 12

Figura 2.11 - (a) Elemento vibrante e (b) Luz natural. 13

Figura 2.12 - Luz polarizada (a) plana, (b) circular e (c) elíptica (HENDRY, 1966 modificado). 14

Figura 2.13 - Luz incidindo em um polarizador plano (ARAÚJO, 2006b - modificado).__ 15

Figura 2.14 - Luz polarizada plana incidindo em retardador de onda (ARAÚJO, 2006b modificado). 19

Figura 2.15 - Esquema de polariscópio plano (Measurements Group, 1981 - modificado)._22

Figura 2.16 - Esquema de polariscópio circular (Measurements Group, 1981 - modificado).24

Figura 2.17 - Modelo genérico sob carregamento em polariscópio plano (ARAÚJO, 2006b modificado). 26

Figura 2.18 - Modelo genérico carregado em polariscópio circular em campo escuro (ARAÚJO, 2006b - modificado). 29

Figura 2.19 - Franjas isocromáticas (a) em luz monocromatica e (b) em luz branca. 32

Figura 2.20 - Linhas de tensões principais em um modelo de pórtico (HENDRY, 1966). __ 33

Figura 2.21 - Construção para converter isoclínicas em isostáticas (DALLY; RILEY, 1991 modificado). 34

Figura 2.22 - Franjas isocromáticas em peça mecânica sujeita a tração axial (DALLEY; RILEY, 1991 - modificado). 35

Figura 2.23 - Padrão de isoclínicas em anel sob compressão diametral (MEASUREMENTS GROUP, 1981 - modificado). 37

Figura 2.24 - Família de isoclínicas em anel sob compresão diametral (DALLY; RILEY, 1991 - modificado).

Figura 2.25 - Traçado das linhas de tensões principais por meio das isoclínicas (HENDRY, 1966 - modificado). 
Figura 2.26 - Direção das tensões principais a partir da isoclínica (HENDRY, 1966 modificado).

Figura 2.27 - Ensecadeira sob carregamento de pressão de água (BURKI; RICHARDS JR, 1975). 40

Figura 2.28 - Locação dos pontos de interesse relativos às isoclínicas e isocromáticas (DALLY; RILEY, 1991 -modificado). 42

Figura 2.29 - Elipsóide índice. 45

Figura 2.30 - Curva típica de fluência fotoelástica (DALLY; RILEY, 1991 - modificado). 49

Figura 2.31 - Curva típica da variação da constante óptica com a temperatura (DALLY; RILEY, 1991 - modificado). 50

Figura 2.25 - Estrutura sobre duas camadas elásticas (CHANDRASHEKHARA; ANTONY, 1993). 55

Figura 2.26 - Variação do módulo de elasticidade e da constante óptica com $65 \%$ de água (FARQUHARSON; HENNES, 1940). 58

Figura 2.27 - Variação do módulo de elasticidade e da constante óptica com 15\% de gelatina (FARQUHARSON; HENNES, 1940). 58

Figura 2.28 - Isocromáticas em um modelo de fundação por sapata (PHILIPPE; MELLINGER, 1948). 59

Figura 2.29 - Isocromáticas em um modelo de estrutura de contenção (BURKI; RICHARDS, 1975). 60

Figura 2.30 - Contorno das isocromáticas (BURKI; RICHARDS, 1975). 60

Figura 2.31 - Estaca helicoidal com fuste de seção transversal (a) circular e (b) quadrada (A.B. CHANCE CO, 2010). 61

Figura 2.32 - Comportamento de ancoragens (MERIFIELD; SLOAN; YU, 2001). 64

Figura 2.33 - Comportamento de ancoragens multi-placas (MERIFIELD; SMITH, 2010). 65

Figura 2.34 - Superfície de ruptura idealizada à carga última $Q_{u(g)}$ em (a) ancoragem rasa (b) profunda em solo coesivo (DAS, 1990). 68

Figura 3.1 - (a) gelatina sem sabor; (b) glicerina pura. 74

Figura 3.2 - Dessecador conectado à bomba de vácuo utilizados para moldagem dos materiais fotoelásticos. 74 
Figura 3.3 - (a) pórtico, (b) trilho, (c) direcionador de luz, (d) medidor de força, (e) polarizadores com $205 \mathrm{~mm}$ de diâmetro, (f) polarizadores com diâmetro de $78 \mathrm{~mm}$ e (g) pesos. 76

Figura 3.4 - Polariscópio 76

Figura 3.5 - Esquema da calibração (FROCHT, 1941 - modificado). 78

Figura 3.6 - Moldes em (a) silicone, (b) acrílico e (c) aço, para moldagem da gelatina. 79

Figura 3.7 - Elementos de ancoragem utilizados. 82

Figura 3.8 -Esquema de carregamento axial: (a) vista frontal e (b) lateral; (c) dinamômetro digital 83

Figura 3.9 - (a) seções adotadas para análise; (b) determinação da profundidade das isocromáticas. 84

Figura 3.10 - Modelo numérico. 85

Figura 4.1 - (a) Modelo com bolhas e ruptura; (b) detalhe da ruptura da gelatina. 87

Figura 4.2 - Carregamentos em G1 com campo claro (acima) e escuro (abaixo) com luz verde $(\lambda=5461 \AA)$. 88

Figura 4.3 - Carregamentos em G2 com campo escuro com luz verde ( $\lambda=5461 \AA$ ). 89

Figura 4.4 - Curva de calibração da gelatina. 89

Figura 4.5 - Isocromáticas em campo escuro com AP lubrificada com graxa de silicone em: (a) arrancamento por 15,4 $\mathrm{N}\left(\sigma_{p}=3,11 c\right)$; (b) compressão de $10,0 \mathrm{~N}\left(\sigma_{p}=2,02 c\right)$. 92

Figura 4.6 - Isocromáticas em campo (a) claro e (b) escuro em carregamento de tração de $18,1 \mathrm{~N}\left(\sigma_{p}=3,66 c\right)$. 94

Figura 4.7 - Carregamentos de tração analisados na seção EE para ancoragem AP. 94

Figura 4.8 - Ancoragem AP com $\tau_{\operatorname{máx}}=0,15 \mathrm{kPa}\left(\tau_{\max }=0,02 c\right)$ por contorno sob carga de compressão de $10,9 \mathrm{~N}\left(\sigma_{p}=2,20 c\right)$. 96

Figura 4.9 - (a) Família de isoclínicas e (b) direção das tensões principais sob carregamento de compressão. 96

Figura 4.10 $-\tau_{\text {máx }}=0,15 \mathrm{kPa}\left(\tau_{\max }=0,02 c\right)$ por contorno sob carga de tração de $18,1 \mathrm{~N}\left(\sigma_{p}=\right.$ $3,66 c)$ em AP. 97

Figura 4.11 - (a) Família de isoclínicas e (b) direção das tensões principais sob carregamento de tração. 97 
Figura 4.12 - (a) arrancamento de AP com 15,5 N $\left(\sigma_{p}=3,13 c\right)$ e (b) compressão com $p=$ $13,3 \mathrm{~N}\left(\sigma_{p}=2,69 c\right)$.

Figura 4.13 - (a) arrancamento de AP com 15,5 N $\left(\sigma_{p}=3,13 c\right)$ e (b) compressão com $p=$ $13,3 \mathrm{~N}\left(\sigma_{p}=2,69 c\right)$. Carregamento "a".

Figura 4.14 - (a) arrancamento de AP com 15,5 N $\left(\sigma_{p}=3,13 c\right)$ e (b) compressão com $p=$ $13,3 \mathrm{~N}\left(\sigma_{p}=2,69 c\right)$. Carregamento "b". 100

Figura 4.15 - Análise experimental e numérica na seção EE no arrancamento de AP com $18,1 \mathrm{~N}\left(\sigma_{p}=3,66 c\right)$ em termos da (a) diferença das tensões principais e (b) tensões cisalhantes máximas. 101

Figura 4.16 - Análise experimental e numérica na seção EE com carga de compressão de $10,9 \mathrm{~N}\left(\sigma_{p}=2,20 c\right)$ em AP em termos da (a) diferença das tensões principais e (b) tensões cisalhantes máximas. 102

Figura 4.17 - Análise experimental e numérica na seção EE no arrancamento de AP com $15,5 \mathrm{~N}\left(\sigma_{p}=3,13 c\right)$ em termos da (a) diferença das tensões principais e (b) tensões cisalhantes máximas. 104

Figura 4.18 - Análise experimental e numérica na seção EE com carga de compressão de $13,3 \mathrm{~N}\left(\sigma_{p}=2,69 c\right)$ em AP em termos da (a) diferença das tensões principais e (b) tensões cisalhantes máximas. 104

Figura 4.19 - Isocromáticas em carregamento de: (a) tração com 9,0 N e (b) compressão com 9,2 $\mathrm{N}$ com EH1. 105

Figura 4.20 - Análise experimental e numérica em carregamento de $-15,0 \mathrm{~N}\left(\sigma_{p}=3,03 c\right)$ em AP e EH1. 106

Figura 4.21 - Tração de EH1 com variação da ordem de $2 \mathrm{~N}\left(\Delta \sigma_{p}=0,40 c\right)$ e nas seções EE e $\mathrm{DD}$, respectivamente. 107

Figura 4.22 - Comparação entre AP e EH1, nas seções EE e DD em carregamento de 9,0 N $\left(\sigma_{p}=1,82 c\right)$ de tração e compressão. 108

Figura 4.23 - Análise fotoelástica de tensões em seção horizontal nab compressão de 9,0 N $\left(\sigma_{p}=1,82 c\right)$ das ancoragens, onde o ponto $(0,0)$ é o centro da ponta da haste. 108

Figura 4.24 - Análise fotoelástica da estaca EH1 na posição a $0^{\circ}$ tração de $15,9 \mathrm{~N}\left(\sigma_{p}=\right.$ $3,21 c)$ e $90^{\circ}$ com tração de $15,7 \mathrm{~N}\left(\sigma_{p}=3,17 c\right)$. 109

Figura 4.25 - Sequência do carregamento de tração da haste de EH2 com isocromáticas em campo claro e escuro. 111 
Figura 4.26 $-\tau_{\text {máx }}=0,15 \mathrm{kPa}\left(\tau_{\max }=0,02 c\right)$ por contorno na tração de $\mathrm{EH} 2 \operatorname{com} 7,9 \mathrm{~N}\left(\sigma_{p}=\right.$ $4,97 c)$.

Figura 4.27 - Arrancamento por 10,5 $\mathrm{N}\left(\sigma_{p}=6,61 c\right)$ com $\tau_{\operatorname{máx}}=0,05 c\left(\tau_{\operatorname{máx}}=0,37 \mathrm{kPa}\right)$ por contorno. Captura da imagem (a) imediatamente após aplicação da carga e (b) após estabilização de isocromáticas, respectivamente. 113

Figura 4.28 - Isocromáticas em ensaio de tração de EH2. 114

Figura 4.29 - EH2 nas profundidades iguais a 1,6 e 5,5D com 8,0 N $\left(\sigma_{p}=5,03 c\right)$ de tração . 115

Figura 4.30 - (a) Família de isoclínicas e (b) direção das tensões principais sob carregamento de tração. 


\section{LISTA DE TABELAS}

Tabela 3.1- Dimensões utilizadas nos blocos de calibração (em mm). 78

Tabela 3.2 - Dimensões dos moldes de acrílico (em mm). 82

Tabela 4.1 - Valores de $f_{\sigma}$ determinados por meio de calibração. 


\section{LISTA DE ABREVIATURAS, SIGLAS E SÍMBOLOS}

$A$ - área;

$A_{1}$ - área da hélice do topo do conjunto;

AP - modelo de ancoragem em placa;

$C$ - constante óptica ou fotoelástica;

$D$ - diâmetro;

$D_{1}$ - diâmetro da lâmina menor em estacas com mais de uma lâmina;

$D_{a}-$ diâmetro médio das hélices;

DD - seção à direita da ancoragem, vista de frente;

$E$ - módulo de elasticidade;

$\vec{E}$ - componente vibrante;

$E_{0}$ - vetor de luz que sofreu uma polarização plana inicial;

$E_{1}-$ vetor luminoso que vibra na direção da tensão principal maior;

$E_{2}$ - vetor luminoso que vibra na direção da tensão principal menor;

$\vec{E}_{a}$ - componente vibrante absorvida;

$\vec{E}_{t}-$ componente vibrante transmitida;

$E_{L}-$ componente lenta transmitida;

$E_{R}$ - componente rápida transmitida;

$E_{f}-$ Energia do fóton;

$\mathrm{EE}$ - seção à esquerda da ancoragem, vista de frente;

EESC - Escola de Engenharia de São Carlos;

EH1 - modelo de estaca helicoidal 1;

EH2 - modelo de estaca helicoidal 2;

$G$ - módulo de elasticidade transversal ou cisalhante;

G1 e G2 - blocos utilizados na calibração da gelatina; 
$H$ - profundidade de lâmina de ancoragem;

$H_{1}$ - profundidade da hélice do topo do conjunto da ancoragem;

$\left(H / D_{l}\right)_{c r}$ - profundidade relativa crítica da ancoragem helicoidal;

$\left(H / h_{l}\right)_{c r}$ - profundidade relativa crítica da ancoragem;

$H_{c r}$ - profundidade crítica;

$H_{n}$ - profundidade da hélice da ponta do conjunto;

$I$ - intensidade luminosa;

$K_{u}$ - coeficiente de empuxo do solo no arrancamento (solos não coesivos);

MEF - Método dos Elementos Finitos;

$N$ - ordem de franja;

$N_{c u}$ - fator de capacidade de carga no arrancamento para solos coesivos;

$N_{q u}$ - fator de capacidade de carga no arrancamento para solos não coesivos;

$P$ - força aplicada;

$P_{S}$ - perímetro do fuste da ancoragem;

$Q_{c}$ - resistência ao longo da superfície de ruptura, admitida cilíndrica;

$Q_{f}$ - resistência do solo na superfície cilíndrica de ruptura;

$Q_{p}$ - capacidade de carga da hélice do topo;

$Q_{s h}$ - resistência de fuste;

$Q_{u}$ - capacidade de carga;

$Q_{u}^{*}$ - capacidade de carga em ancoragem profunda;

$R$ - raio da circunferência;

R1 e R2 - recipientes utilizados para moldagem dos modelos;

$S$ - tensão;

$S_{u}$ - resistência não drenada do solo;

$T$ - período;

USP - Universidade de São Paulo; 
$V$ - velocidade de propagação da luz;

$c$ - velocidade de propagação da luz no vácuo;

$c_{a}$ - adesão no fuste da ancoragem;

$c_{u}-$ coesão;

$f$ - frequência;

$f_{\varepsilon}-$ constante óptica em termos de deformação;

$f_{\sigma}-$ constante óptica em termos de tensão;

$h$ - espessura do modelo fotoelástico;

$h_{l}$ - raio ou lado menor da lâmina de ancoragem;

$h_{f}-$ Constante de Planck do fóton;

$k$ - constante;

$n$ - índice de refração;

$t$ - tempo;

$y_{(x, t)}$ - propagação da onda harmônica simples;

$\Delta$ - diferença de fase angular;

$\alpha$ - ângulo entre a direção de polarização e o vetor incidente;

$\alpha^{\prime}$ - ângulo de rotação do analisador;

$\beta$ - ângulo entre o vetor incidente e qualquer dos eixos de polarização;

$\gamma$ - ângulo de giro do vetor de luz;

$\gamma^{\prime}$ - peso específico efetivo do solo;

$\delta$ - diferença de fase linear;

$\varepsilon$ - deformação;

$\varepsilon_{1}$ - deformação principal maior;

$\varepsilon_{2}-$ deformação principal intermediária;

$\varepsilon_{3}$ - deformação principal menor;

$\theta$ - ângulo entre as tensões principais e o eixo de polarização; 
$\lambda$ - comprimento de onda;

$v$ - coeficiente de Poisson;

$\rho$ - massa específica;

$\sigma$ - tensão normal;

$\sigma_{l}-$ tensão principal maior;

$\sigma_{2}-$ tensão principal intermediária;

$\sigma_{3}-$ tensão principal menor;

$\sigma_{p}$ - tensão aplicada pela lâmina da ancoragem;

$\sigma_{p l}$ - tensão aplicada no limite da proporcionalidade entre tensão e deformação;

$\sigma_{\text {rup }}$ - tensão de ruptura do material;

$\sigma_{x}-$ tensão normal à direção $\mathrm{x}$;

$\sigma_{y}-$ tensão normal à direção $\mathrm{y}$;

$\sigma_{z}$ - tensão normal à direção z;

$\tau$ - tensão de cisalhamento;

$\tau_{m a ́ x}$ - tensão de cisalhamento máxima;

$\tau_{\text {oct }}-$ tensão de cisalhamento octaédrica;

$\tau_{x y}$ - tensão de cisalhamento no plano da direção x, variando ao longo da direção y;

$\tau_{x z}$ - tensão de cisalhamento no plano da direção x, variando ao longo da direção z;

$\tau_{y z}$ - tensão de cisalhamento no plano da direção y, variando ao longo da direção z;

$\omega$ - velocidade angular; 


\section{RESUMO}

Schiavon, J.A. Aplicação da técnica da fotoelasticidade na análise de fundações por estacas helicoidais. São Carlos, 2010. 153 p. Dissertação de Mestrado - Escola de Engenharia de São Carlos, Universidade de São Paulo, São Carlos, 2010.

A técnica da fotoelasticidade pode ser particularmente útil na análise de tensões em sistemas com geometrias complexas. Em um equipamento chamado polariscópio, um feixe de luz polarizada atravessa o modelo fotoelástico que representa o protótipo. Ao submeter este modelo a um carregamento, faixas de diferentes cores poderão ser visualizadas. Cada cor é associada a um nível de tensão. As tensões observadas no modelo fotoelástico podem ser comparadas com as tensões determinadas nos modelos numéricos ou analíticos. Em casos específicos, o problema da distribuição de tensões em uma fundação pode ser analisado com emprego da fotoelasticidade. A análise do comportamento de estacas helicoidais através da técnica da fotoelasticidade pode ser então de grande valia para estudos mais aprofundados deste sistema. O principal objetivo desta pesquisa foi viabilizar este método experimental para ser aplicado no Departamento de Geotecnia da EESC em análises de tensões em sistemas geotécnicos. Para validar as análises experimentais, tensões observadas em modelos de geometria simples foram comparadas com as tensões determinadas por meio de modelagem numérica com o método dos elementos finitos. O comportamento da fundação por estaca helicoidal observado pela técnica da fotoelasticidade mostrou semelhança ao observado na modelagem numérica. Por meio da distribuição de tensões, foi possível avaliar a influência da geometria helicoidal da lâmina e da profundidade de instalação da ancoragem no terreno.

PALAVRAS-CHAVE: Estaca Helicoidal, Ancoragem, Análise de Tensões, Fotoelasticidade. 
xviii 


\begin{abstract}
Schiavon, J.A. Aplication of the photoelastic method to the analysis of helical screw pile foundations. São Carlos, 2010. 153 p. Master Dissertation - School of Engineering at São Carlos, University of São Paulo, São Carlos, 2010.
\end{abstract}

The photoelastic method can be particularly useful for stress analysis with complex geometry systems. In equipment called polariscope, a polarized light beam crosses the photoelastic model that represents the prototype. Submitting this model to a load, fringes of different colors can be visualized. Each color is associated to a stress level. The stresses corresponding to the observed fringes on the photoelastic model can be compared to the stresses obtained through analytical or numerical models. In specific cases, the stress distribution problem can be analyzed with the use of photoelasticity. The photoelastic analysis of the helical pile behavior can then be valuable for further studies of this system. The main objective of this research was enabling this experimental method to be applied in the Department of Geotechnical Engineering of EESC in geotechnical systems stress analysis. To validate the experimental analysis, stresses observed in simple geometry models have been compared to those stresses determined by numerical modeling with the finite element method. The observed behavior of the helical pile foundation by photoelastic method showed similarity to that one observed through numerical modeling. Stress distribution analyses allowed evaluating the influence of helical blade geometry and the depth of installation.

KEY WORDS: Helical Pile, Anchor, Stress Analysis, Photoelasticity. 


\section{INTRODUÇÃO}

A maior parte dos trabalhos em Mecânica dos Solos é focada, ao menos indiretamente, quer com a distribuição de tensões em uma massa de solo ou com o comportamento do solo sob tensões impostas. Os problemas relacionados com a distribuição de tensões são complexos. Então quando a técnica da fotoelasticidade foi introduzida, para análise de tensões em estruturas, o interesse por sua aplicação na geotecnia foi rapidamente despertado.

As fundações por estacas helicoidais começaram a ser utilizadas no Brasil, no fim da década passada, primeiramente para resistir a esforços de tração (TSUHA, 2007). Mais recentemente tem-se observado a tendência de utilização desta fundação para resistir também a esforços de compressão. Este tipo de fundação tem grande aplicação em fundações de torres de transmissão de energia e telecomunicações que geram carregamentos de tração e também de compressão em sua base. A aplicação das estacas helicoidais tem aumentado, tendo em vista sua aplicabilidade também em fundações de obras residenciais, comerciais, industriais, trabalhos de reforço de fundações e locais de difícil acesso (CLEMENCE, 1985).

Na maioria dos estudos na Mecânica dos Solos e Engenharia de Fundações, o problema da distribuição de tensões pode ser analisado com emprego da técnica fotoelasticidade. A geometria tridimensional da hélice traz muitas dificuldades no tratamento teórico da distribuição de tensões no solo em fundações por estacas helicoidais, e modelagens numéricas refinadas demandam grandes esforços computacionais. Por meio da técnica da fotoelasticidade é possível visualizar o campo completo de tensões gerado quando a ancoragem é carregada, permitindo comparações com outros métodos de análise. A análise do comportamento de estacas helicoidais por meio dessa técnica é de grande importância para estudos mais aprofundados deste sistema. 
Embora existam pesquisas sobre fundações por estacas helicoidais na literatura geotécnica, poucos estudos sobre o mecanismo de distribuição de tensões no terreno têm sido apresentados na literatura. Por esta razão, foi realizado, com a utilização da técnica da fotoelasticidade, um estudo da distribuição de tensões por ancoragens e estacas helicoidais posicionadas com suas hastes nas verticais.

Para a realização do presente trabalho que é o primeiro que envolve pesquisas com aplicação da técnica fotoelasticidade no Departamento de Geotecnia da Escola de Engenharia de São Carlos (EESC), foi necessário fazer uma revisão bibliográfica abrangendo os conceitos fundamentais para a aplicação da técnica da fotoelasticidade em estudos geotécnicos. Essa revisão bibliográfica tem a finalidade de fornecer o conteúdo para a fundamentação conceitual de novos pesquisadores que iniciem suas atividades com utilização da técnica da fotoelasticidade.

A comparação entre os resultados numéricos e experimentais possibilitaram validar os resultados conseguidos com a técnica experimental. Esses resultados permitiram estabelecer simplificações em análises de projeto com carregamentos de compressão. Foi possível também avaliar as diferenças entre as situações de serviço com ancoragem rasa e ancoragem profunda. Dessa forma, os resultados obtidos com as análises fotoelásticas contribuem para o melhor conhecimento da distribuição e propagação de tensões nas fundações por estacas helicoidais.

\subsection{Objetivo}

O principal objetivo deste trabalho é viabilizar e testar a técnica da fotoelasticidade para aplicação em estudos de situações complexas de distribuição de tensões em fundações e outras obras geotécnicas. Considera-se também que com a técnica disponível seja possível aplicá-la a atividades didáticas no Departamento de Geotecnia da Escola de Engenharia de 
São Carlos - USP. Para que estes objetivos pudessem ser alcançados, foi necessário definir um problema geotécnico que pudesse ser estudado por meio da técnica da fotoelasticidade. Como pouco tem-se pesquisado o mecanismo de distribuição de tensões em fundações por estacas helicoidais, foram realizadas estudos em modelos dessa fundação.

A maneira como o terreno responde ao carregamento imposto a uma estaca helicoidal em serviço depende da geometria e deformabilidade da estaca e do terreno, profundidade de instalação da hélice, resistência dos materiais envolvidos, entre outros. Portanto, os objetivos da aplicação da técnica da fotoelasticidade em fundações por estacas helicoidais são:

1) Analisar, por meio da técnica da fotoelasticidade, a distribuição de tensões, devido a carregamentos axiais, em uma ancoragem constituída por estaca helicoidal, em função da profundidade da hélice.

2) Comparar os resultados obtidos pelas análises experimentais com análises numéricas pelo método dos elementos finitos (MEF), afim de validar as análises fotoelásticas. 


\section{REVISÃO BIBLIOGRÁFICA}

Várias técnicas experimentais são hoje utilizadas para a determinação da distribuição de tensões, como a técnica por eletro-resistividade (strain gages), transdutores de força e deslocamento, holografia e interferometria e a técnica da fotoelasticidade. Dentre elas, podese destacar a modelagem fotoelástica, técnica que permite uma rápida análise qualitativa do nível de tensões através de efeitos ópticos. Especificamente, a fotoelasticidade de transmissão pode ser usada na solução de problemas do estado plano e tridimensional de tensões.

As estacas helicoidais são elementos de fundação com geometrias complexas. Na literatura, não se têm registros de estudos sobre a influência dessa geometria na transferência de carga desse tipo de estaca para um meio de comportamento elástico-linear. A técnica da fotoelasticidade, neste caso, pode ser uma útil ferramenta, uma vez que a aplicação de métodos numéricos pode ser trabalhosa em estudos deste tipo, demandando o uso de computadores com alta capacidade de processamento para análise de um modelo numérico refinado.

\subsection{Teoria da Fotoelasticidade de Transmissão Plana}

A fotoelasticidade é uma técnica de análise óptica de tensões que se baseia em propriedades ópticas de certos materiais sensíveis a variações de tensões internas. Tais materiais possuem a capacidade de exibir efeitos ópticos que retratam níveis de mesma tensão quando submetidos a um carregamento.

A técnica da fotoelasticidade é muito utilizada na validação ou verificação experimental de soluções numéricas, no estudo de distribuição de tensões em problemas de geometria e carregamentos complexos, bem como na otimização de formas (PEREIRA; SMITH NETO; ALMEIDA, 2007). 
Uma das grandes vantagens da análise de tensões por fotoelasticidade é a facilidade de visualizar imediatamente as magnitudes de tensões e deformações, os gradientes de deformação e a sua distribuição global, incluindo áreas sob alta ou baixa concentração de tensões e ainda verificar a importância relativa dos vários modos de aplicação de cargas. Essa capacidade é chamada de análise de campo completo e é única da fotoelasticidade dentre os métodos de análise de tensões (DALLEY; RILEY, 1991).

Certos materiais na natureza que são submetidos a tensões internas apresentam características anisotrópicas. Em 1816 através de experiências realizadas com o vidro, David Brewster notou a presença de franjas coloridas em um pedaço de vidro quando tensionado e examinado à luz polarizada (TIMOSHENKO; GOODIER, 1980). Brewster notou então que as propriedades ópticas de certos materiais se alteravam com a variação do estado de tensão que o corpo se encontrava submetido. Mas somente em $1891 \mathrm{C}$. Wilson utilizou a sugestão de Brewster em estudos de tensão em vigas com carga concentrada. A. Mesnager também utilizou a mesma técnica numa investigação sobre arcos de pontes (FLEURY, 2001). A técnica da fotoelasticidade foi aprimorada e extensivamente aplicada por E. G. Coker em 1925, que introduziu a celulóide como material para modelos fotoelásticos (TIMOSHENKO; GOODIER, 1980).

Posteriormente, muitos pesquisadores como Gomide (1975), Peng (1976), Oliveira e Gomide (1989), Chandrashekhara e Antony (1996), Chandrashekhara, Antony e Reddy (1996) e Ravi (1998) experimentaram novos materiais, e.g., resinas epoxy e poliéster, baquelite $^{1}$, misturas com resinas epoxy, poliéster, trietilamina ${ }^{2}$, fibra de vidro, entre outros. Algumas dessas combinações podem ser utilizadas para fabricação de modelos de materiais granulares ou materiais ortotrópicos. O objeto de estudo pode ser produzido ou reproduzido

\footnotetext{
${ }^{1}$ Resina sintética, quimicamente estável e resistente ao calor, que foi o primeiro produto plástico.

${ }^{2}$ Composto químico com a fórmula $\mathrm{N}\left(\mathrm{CH}_{2} \mathrm{CH}_{3}\right)_{3}$, geralmente abreviada $\mathrm{Et}_{3} \mathrm{~N}$. É comumente encontrado em síntese orgânica.
} 
na forma de modelos transparentes bidimensionais ou tridimensionais, ou ainda ser revestido com uma película de material fotoelástico (FLEURY, 2001).

\section{a) Fotoelasticidade de transmissão plana}

A fotoelasticidade de transmissão plana consiste no estudo de tensões pela transmissão da luz através de um molde plano. Esse molde deve ser confeccionado com um material, denominado material fotoelástico, que proporcione o aparecimento das franjas ópticas. Em pontos no interior do modelo bidimensional, pode-se obter apenas a leitura da tensão cisalhante máxima. Os valores individuais das tensões principais somente podem ser obtidos com a utilização de dados suplementares ou emprego de métodos numéricos.

\section{b) Fotoelasticidade de transmissão tridimensional}

A melhor maneira de analisar problemas tridimensionais é por meio do método de congelamento de tensões. Este método é restrito a casos de carregamento estático ou forças de massa (FLEURY, 2001). Vários polímeros, quando carregados sob altas temperaturas e em seguida resfriados, retêm a configuração das franjas como se ainda estivessem carregados em regime elástico (ARAUJO, 2006b). De acordo com Kuske e Robertson (1974), a anisotropia óptica pode ser fixada no material por meio de um tratamento térmico especial, que não é trocada mesmo se a carga for removida. Desta forma, as tensões podem ser congeladas no modelo, que poderá ser posteriormente cortado em fatias, para que as mesmas sejam analisadas (Figura 2.1). 


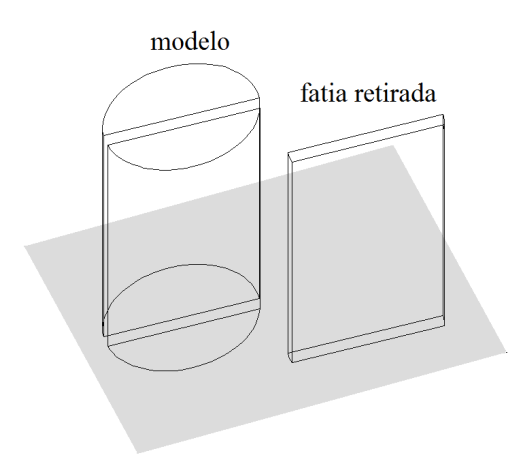

Figura 2.1 - Objeto e fatia em na técnica da fotoelasticidade de transmissão tridimensional.

O estado de tensões que produziu o efeito óptico na fatia não é plano, mas caracterizado pelas tensões principais secundárias no plano em consideração. Assim, pode-se examinar uma fatia interna ao modelo, com qualquer direção normal e espessura, de forma similar à usada para modelos planos (ARAÚJO, 2006b).

c) Fotoelasticidade de reflexão

É uma técnica usada para a determinação de tensões e/ou deformações em superfícies planas ou irregulares. É uma técnica que tem como principal vantagem o fato de não ser necessária a confecção de modelos. Pode ser utilizada em problemas envolvendo deformações elásticas ou plásticas, bem como em problemas envolvendo materiais anisotrópicos. A obtenção dos parâmetros ópticos pode ser feita diretamente no objeto real, quando estes estão sob o efeito dos carregamentos reais (ARAÚJO, 2006b).

Na fotoelasticidade por reflexão, uma película fotoelástica é colada na superfície do objeto de estudo com uma cola que possui propriedade reflexiva. Quando o objeto sob carregamento é analisado com um polariscópio que permite a observação da luz polarizada refletida, é possível visualizar o padrão de franjas diretamente da superfície do objeto. 


\subsubsection{Teoria da Onda de Luz}

A compreensão de certos fenômenos ópticos, que algumas vezes não são familiares ao geotécnico, é fundamental para o estudo da fotoelasticidade. O fenômeno da luz tem atraído a atenção desde tempos remotos na história. Os gregos antigos consideravam que a luz seria uma emissão de pequenas partículas provenientes de um corpo luminoso que incide nos olhos e retorna ao corpo luminoso. Empédocles (484-424 A.C.) sugeriu que a luz levaria algum tempo para viajar de um ponto a outro, mas Aristóteles (384-322 A.C.) rejeitou posteriormente esta idéia como sendo muito difícil de assumi-la (DALLY; RILEY, 1991).

Hendry (1966) relata que Newton e outros elaboraram a primeira teoria sistemática da luz, baseada na hipótese de que a fonte de luz emite minúsculas partículas em todas as direções. Tal teoria foi denominada teoria corpuscular da luz. Enquanto que vários fenômenos eram explicados satisfatoriamente, haviam efeitos que eram completamente incompatíveis com tal teoria. Isso levou a seu abandono em favor de uma teoria da onda chamada éter.

Ao mesmo tempo que Newton, Huygens (1629-1695) e Hooke (1635-1703) explicaram os fenômenos da luz com base na teoria que assume a idéia de que uma substância hipotética de massa zero, chamada o éter, ocupe todo o espaço. Huygens e Hooke consideravam a onda de luz uma vibração transversa que vibra em ângulos retos na direção da propagação através do éter (HENDRY, 1966).

O seguinte passo importante na evolução da teoria da luz é atribuído a Maxwell (18311879). Sua teoria eletromagnética considerava a presença de dois campos vetoriais nas ondas de luz, um campo elétrico e um campo magnético. Desde que esses campos possam se propagar através do espaço, ausente de matéria conhecida, a teoria do éter estava eliminada (DALLY; RILLEY, 1991).

Embora a teoria ondulatória seja geralmente correta na descrição da propagação da luz, não é capaz de explicar todas as propriedades da luz, especialmente as propriedades da 
interação da luz com meios materiais. Esses fenômenos só poderiam ser explicados por um modelo corpuscular de luz. Assim, o modelo de partículas de luz foi reintroduzido.

As partículas de luz são denominadas fótons. A energia de um fóton $E_{f}$ está relacionada à frequência $f$ da onda de luz que lhe é associada. Segundo Einstein, $E_{f}=h_{f} f$, onde $h_{f}$ é uma constante denominada constante de Planck. O completo entendimento da natureza dual da luz não se fez até 1920, quando experiências de C. J. Davisson e L. Germer, e também G. P. Thompson, mostraram que os elétrons também têm natureza dual e também exibem propriedades ondulatórias, que levam à interferência e à difração (TIPLER, 1995).

O desenvolvimento da teoria quântica dos átomos e moléculas por Rutherfor, Bohr, Schrödinger e outros, no século XX, levou ao entendimento da emissão e da absorção da luz pela matéria. A luz emitida ou absorvida pelos átomos, como se admite nos dias de hoje, é conseqüência das alterações da energia dos elétrons mais externos dos átomos. Em virtude de estas variações de energia serem quantizadas, e não contínuas, os fótons emitidos têm energias discretas. Isso implica em ondas de luz com um conjunto discreto de freqüencias e de comprimentos de onda, com espaçamentos e intensidades característicos do elemento emissor (TIPLER, 1995).

Segundo Frocht (1941), Hendry (1966), Kuske e Robertson (1974) e Dally e Rilley (1991) todos os fenômenos encontrados na fotoelasticidade podem ser adequadamente representados através do campo elétrico da luz. Para a interpretação dos fenômenos fotoelásticos, a luz pode ser representada como um trem de ondas sinusoidais que se propagam mediante vibrações inteiramente desorganizadas. A propagação do vetor descrita pela onda harmônica simples é representada pela seguinte expressão:

$$
y(x, t)=y_{m} \cdot \operatorname{sen}\left[\frac{2 \pi}{\lambda}(x-v t)\right]
$$

onde,

$y_{m}=$ amplitude do vetor luminoso; 
$\lambda=$ comprimento de onda;

$V=$ velocidade de propagação da luz;

$x=$ coordenada ao longo da direção de propagação;

$t=$ tempo

Os parâmetros utilizados para diferenciar as várias radiações são o comprimento de onda $\lambda$ (Figura 2.2) e frequência $f$. Esses dois parâmetros podem ser relacionados com a velocidade de propagação $v$ (Equação (2.2).

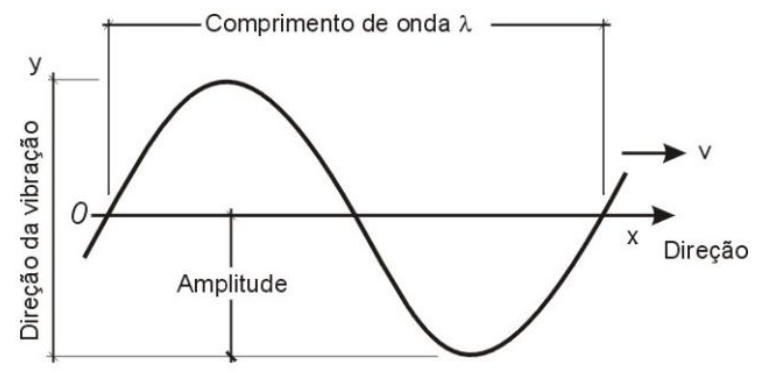

Figura 2.2 - Representação de uma onda de luz (FLEURY, 2001).

$$
f=\frac{v}{\lambda}=\frac{1}{T}
$$

A frequência consiste, então, do número de oscilações por unidade de tempo, medida em $\operatorname{Hertz}(\mathrm{Hz})$. A frequência pode ser expressa como o inverso do período $T$, que é o tempo gasto pela luz ao percorrer a distância de um comprimento de onda.

A luz é usualmente definida como a radiação que pode afetar o olho humano. Os limites do espectro visível não são bem definidos, pois o olho deixa de ser sensível a curtos e longos comprimentos de onda. De acordo com Dally e Riley (1991), o campo normal de visão é situado entre comprimentos de onda de 400 a $700 \mathrm{~nm}$. Nesse intervalo, o olho humano interpreta os diferentes comprimentos de onda dando origem às cores. 
A luz proveniente de uma fonte que emite um espectro contínuo com energias aproximadamente iguais para todo comprimento de onda é denominada luz branca. Um trem de ondas luminoso que possui um único comprimento de onda é chamado de luz monocromática. Para certos gases, quase todo o espectro visível é concentrado em um comprimento de onda. Lâmpadas de sódio, por exemplo, exibem brilho de cor amarelada (FROCHT, 1941).

A distância entre duas coordenadas $x_{1}$ e $x_{2}$ de duas ondas em cada instante, é por definição, a diferença de fase linear entre as duas ondas, ou seja, $d=x_{1}-x_{2}$ (Figura 2.3).

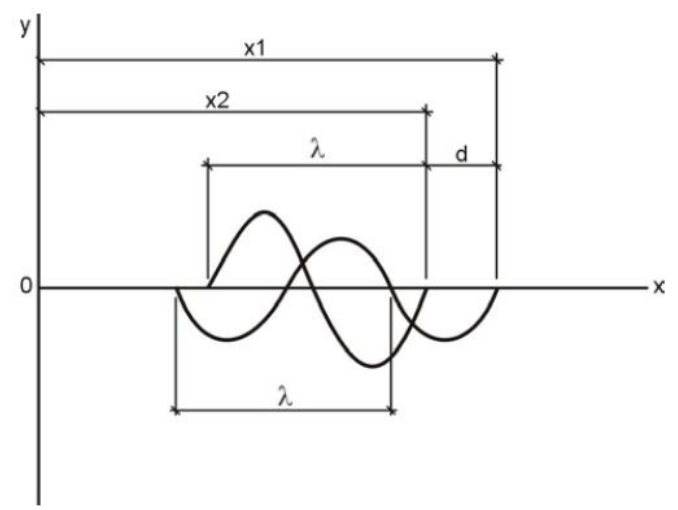

Figura 2.3 - Diferença de fase linear entre duas ondas.

O comprimento da onda e a velocidade de propagação da luz dependem das características ópticas do meio através do qual ela se propaga. Já a freqüência da vibração é uma característica que permanece constante, independentemente do meio através do qual a luz se propaga.

\subsubsection{Luz Polarizada}

Um raio de luz natural será admitido como um conjunto de ondas independentes com frequência e planos de orientação aleatórios em torno da direção de propagação. $O$ elemento vibrante pode ser caracterizado por um vetor variável (Figura 2.4a). A origem deste vetor é 
sempre a mesma e a extremidade define a posição ocupada pelo elemento vibrante, é o chamado vetor luminoso (VASCONCELOS, 1947). No caso da luz natural, o lugar geométrico descrito pela extremidade deste vetor em função do tempo é uma curva irregular situada no plano normal à direção de propagação (Figura 2.4b).
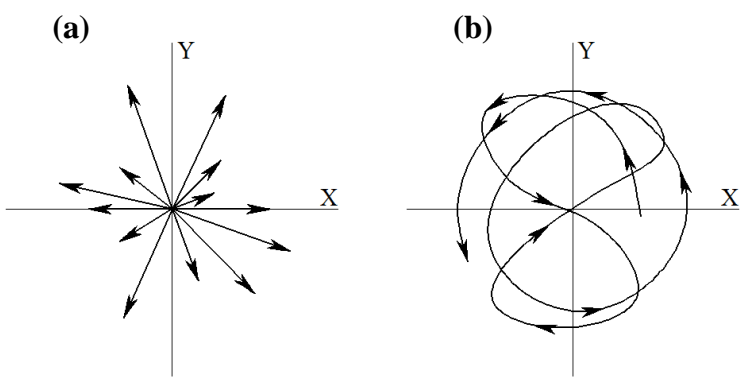

Figura 2.4 - (a) Elemento vibrante e (b) Luz natural.

É possível, no entanto, introduzir ordem nessas ondas caóticas. Com isso, o lugar geométrico da extremidade do vetor luminoso é uma reta, e poderá apenas ocupar posições sobre essa reta. Se a direção do plano de propagação e o vetor luminoso se tornam fixos de instante para instante, a luz é dita plano polarizada, ou seja, a luz apresentará ondas vibrantes em apenas um plano de propagação (Figura 2.5a).

Se o vetor luminoso em qualquer ponto permanece com amplitude constante enquanto altera continuamente a inclinação de seu plano de polarização de maneira que suas extremidades descrevam um padrão de trajetória circular, o trem de ondas está polarizado circularmente (Figura 2.5b). Se a extremidade do vetor luminoso descreve uma trajetória elíptica, a luz sofreu polarização elíptica (Figura 2.5c). 

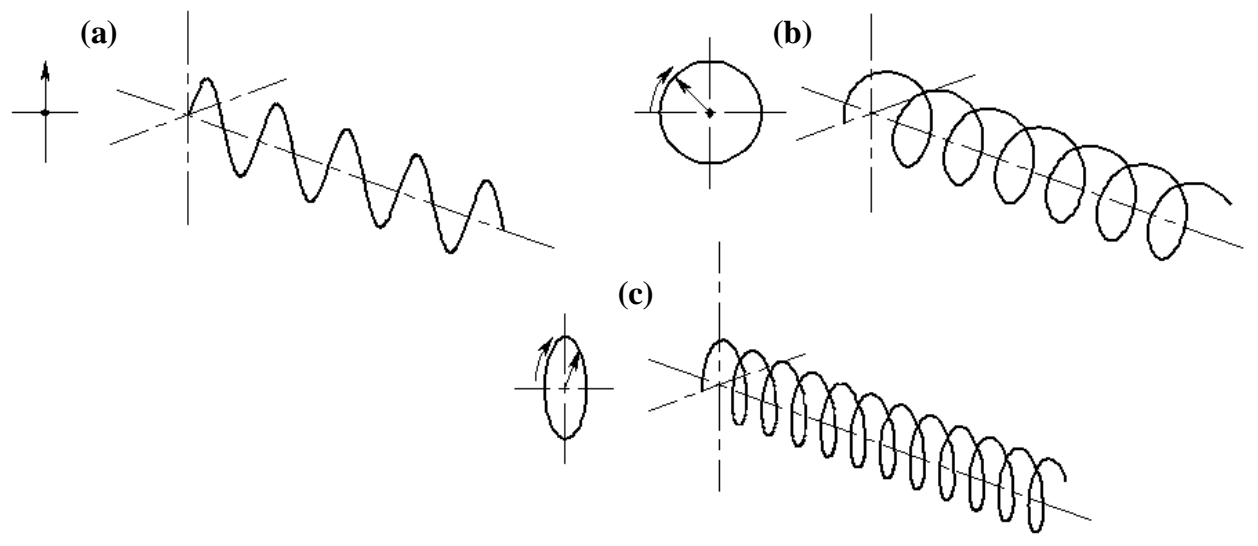

Figura 2.5 - Luz polarizada (a) plana, (b) circular e (c) elíptica (HENDRY, 1966 - modificado).

Para transformar a luz natural em luz polarizada, são utilizadas lentes ou placas denominadas filtros polarizadores ou polaróides e também retardadores de onda. Esses filtros têm a característica de absorver as componentes da luz que não vibram na mesma direção de seu eixo de polarização. Já os retardadores de onda são utilizados para introduzir um atraso na vibração da onda.

\subsubsection{Polarizador Plano ou Linear}

São elementos utilizados para absorver as componentes do vetor de luz que não vibram na direção de seu eixo de polarização. Quando a luz atravessa um polarizador plano, ele a divide em duas componentes de onda que vibram em planos mutuamente ortogonais. A componente que vibra paralelamente ao eixo de polarização é transmitida $\left(E_{t}\right)$, enquanto que a componente perpendicular é absorvida ou totalmente refletiva $\left(\mathrm{E}_{\mathrm{a}}\right)$. Portanto, tem-se que:

$$
\begin{aligned}
& \vec{E}=\vec{E}_{a}+\vec{E}_{t} \\
& E_{t}=a \cos \omega t \cos \alpha
\end{aligned}
$$




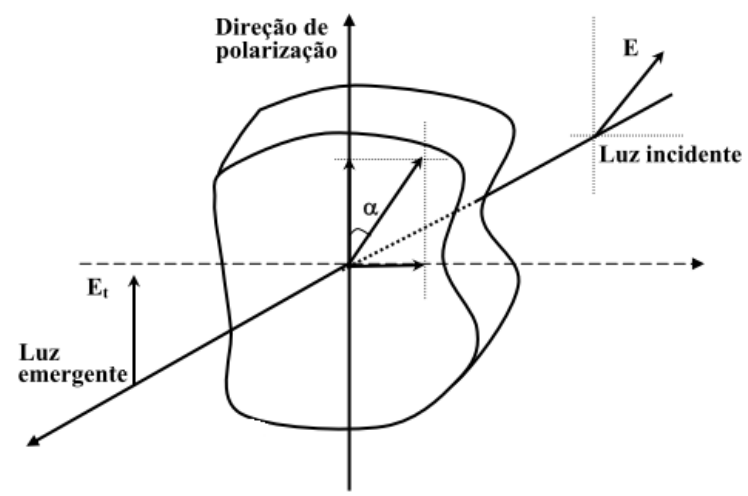

Figura 2.6 - Luz incidindo em um polarizador plano (ARAÚJO, 2006b - modificado).

\subsubsection{Propagação da Luz através de Meio Anisotrópico}

Meios oticamente isotrópicos são aqueles que têm a propriedade de transmitir ondas de luz com velocidades iguais em todas as direções. Alguns exemplos de meios oticamente isotrópicos são o ar, água e alguns plásticos. Se o meio que recebe o raio de luz incidente for anisotrópico, a velocidade de transmissão da luz dependerá da direção de propagação.

Um único raio incidente sobre o meio opticamente anisotrópico geralmente resultará em dois raios emergentes, ambos polarizados e decompostos em planos normais entre si. Como os raios emergentes possuem direções diferentes, a velocidade de propagação dos raios não é a mesma. Tal fato proporciona o surgimento de um evento peculiar, chamado de dupla refração temporária, que deriva da impossibilidade das duas vibrações caminharem no interior do meio com a mesma velocidade (FIALHO, 1969). Os materiais transparentes que possuem a propriedade de dividir o vetor luminoso em duas componentes ortogonais transmitindo-as a velocidades diferentes são denominados bi-refringentes (FLEURY, 2001).

Segundo Fialho (1969), certos materiais transparentes possuem a propriedade de exibir o fenômeno de dupla refração quando submetidos a um estado de deformação. Tal fenômeno, denominado dupla refração temporária, é a base das técnicas da fotoelasticidade. Os materiais que exibem aquela propriedade são denominados fotoelásticos. 
As duas componentes em que as vibrações da luz podem atravessar uma lâmina opticamente anisotrópica são os eixos de transmissão. O eixo no qual a velocidade de propagação da onda é a maior é chamado de eixo rápido, e o outro, eixo lento.

Maxwell associou a variação dos índices de refração com os níveis das tensões principais em objetos de materiais bi-refringentes. Em regime elástico linear, as variações dos índices de refração de um corpo transparente em função dos esforços aplicados podem ser determinadas por meio das seguintes equações:

$$
\begin{aligned}
& n_{1}-n_{0}=C_{1} \sigma_{1}+C_{2} \sigma_{2} \\
& n_{2}-n_{0}=C_{1} \sigma_{2}+C_{2} \sigma_{1}
\end{aligned}
$$

onde, $n_{0}$ é o índice de refração do sólido no vácuo antes da aplicação dos esforços; $n_{l}$ e $n_{2}$ são os índices de refração para as vibrações que atravessam o sólido solicitado nas direções da tensão principal maior $\sigma_{1}$ e principal menor $\sigma_{2}$, respectivamente; $C_{1}$ e $C_{2}$ são constantes fotoelásticas, denominadas constantes ópticas.

Tais relações são válidas para um intervalo considerável de variação de tensões, ultrapassando em geral o limite de proporcionalidade do material (DALLY; RILEY, 1991). A constante fotoelástica $C$ é definida a partir da combinação das Equações (2.5) e (2.6):

$$
n_{1}-n_{2}=\left(C_{1}-C_{2}\right)\left(\sigma_{1}-\sigma_{2}\right)=C\left(\sigma_{1}-\sigma_{2}\right)
$$

Devido à diferença de velocidade entre os eixos rápido (1) e lento (2), as duas componentes transmitidas emergirão do meio anisotrópico em tempos diferentes. $\mathrm{O}$ atraso de uma componente de luz em relação à outra no eixo de propagação é denominado diferença de fase linear $\delta$, dada por:

$$
\delta=\delta_{1}-\delta_{2}=h\left(n_{1}-n_{2}\right)
$$


sendo que, $\delta_{1}$ e $\delta_{2}$ são as diferenças de fase linear nos eixos da tensão principal maior e menor, respectivamente:

$$
\begin{aligned}
& \delta_{1}=h\left(n_{1}-n_{0}\right) \\
& \delta_{2}=h\left(n_{2}-n_{0}\right)
\end{aligned}
$$

onde, $h$ é a espessura do modelo.

Se as intensidades de tensão nas direções principais são $\sigma_{1}$ e $\sigma_{2}$ e as velocidades da vibração da luz nestas direções são $v_{l}$ e $v_{2}$, respectivamente, o tempo necessário para transpor a placa para cada componente será $h / v$, e a retardação relativa $\delta$ entre os dois eixos será:

$$
\delta=c\left(\frac{h}{v_{1}}-\frac{h}{v_{2}}\right)=h\left(n_{1}-n_{2}\right)
$$

onde:

$c=$ velocidade de propagação da luz no vácuo, igual a $3,0 \times 10^{8} \mathrm{~m} / \mathrm{s}$.

Combinando-se as Equações (2.7) e (2.8) obtém-se a diferença de fase linear em função da diferença das tensões principais $\left(\sigma_{1}-\sigma_{2}\right)$ :

$$
\frac{\delta}{h}=C\left(\sigma_{1}-\sigma_{2}\right)
$$

A diferença de fase angular $\Delta$ pode ser obtida a partir da diferença de fase linear $\delta$, uma vez que $\Delta$ é equivalente ao vetor luz que gira ao longo do eixo de propagação com uma frequência angular $\omega$, podendo ser expressa em função da diferença de fase linear e do comprimento de onda $\lambda$ :

$$
\Delta=\frac{2 \pi}{\lambda} \delta=\frac{2 \pi}{\lambda} h\left(n_{1}-n_{2}\right)
$$


Combinando-se as Equações (2.12) e (2.13), é possível escrever uma expressão que fornece a diferença de fase angular $\Delta$ em função da diferença das tensões principais.

$$
\frac{\Delta}{2 \pi} \frac{\lambda}{C} \frac{1}{h}=\left(\sigma_{1}-\sigma_{2}\right)
$$

A ordem de franja $N$ é a ordem de aparecimento do efeito óptico chamado franja isocromática, contada em números ordinais $1,2,3 \ldots$ (Equação (2.15). A constante óptica $f_{\sigma}$ quantifica o nível de tensão de uma dada isocromática (Equação (2.16).

$$
\begin{aligned}
& \frac{\Delta}{2 \pi}=N \\
& \frac{\lambda}{C}=f_{\sigma}
\end{aligned}
$$

Assim, a diferença das tensões principais pode ser determinada em função de variáveis de fácil obtenção (ARAÚJO, 2006b):

$$
\begin{aligned}
& \left(\sigma_{1}-\sigma_{2}\right)=\frac{N \cdot f_{\sigma}}{h} \\
& \tau_{\text {máx }}=\frac{N \cdot f_{\sigma}}{2 h}
\end{aligned}
$$

De forma análoga, é determinada uma expressão que fornece a diferença de deformações principais:

$$
\left(\varepsilon_{1}-\varepsilon_{2}\right)=\frac{N \cdot f_{\varepsilon}}{h}
$$

O parâmetro $\mathrm{f}_{\varepsilon}$, é a constante óptica em termos de deformação:

$$
f_{\varepsilon}=\frac{1+v}{E} f_{\sigma}
$$

onde, $E$ é o módulo de elasticidade do material e $v$ é o coeficiente de Poisson. 


\subsubsection{Retardadores de Onda}

Os retardadores de onda são elementos que decompõe o vetor de luz em duas componentes ortogonais que são transmitidas com velocidades diferentes. Portanto, são materiais bi-refringentes. Estes elementos possuem dois eixos principais: eixo rápido (1) e eixo lento (2). Se a placa é colocada em um campo de luz polarizada plana com o vetor luz transmitido $\left(E_{t}\right)$ fazendo um ângulo $\beta$ igual a $0^{\circ}$ com qualquer um de seus eixos, este vetor não será decomposto. No entanto, se o vetor transmitido $\left(E_{t}\right)$ fizer um ângulo $\beta$ diferente de $0^{\circ}$ ou $90^{\circ}$ com um dos eixos do retardador, este vetor é decomposto em duas componentes que são transmitidas, $E_{R}$ e $E_{L}$ (Figura 2.7). Devido à diferença de velocidade ao longo destes dois eixos, as duas componentes transmitidas emergem da placa em tempos diferentes. Portanto, uma estará retardada em relação à outra.

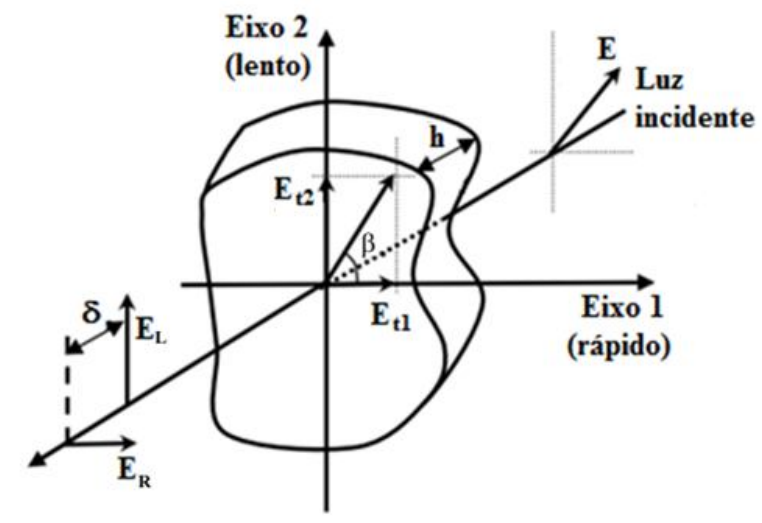

Figura 2.7 - Luz polarizada plana incidindo em retardador de onda (ARAÚJO, 2006b - modificado).

Quando uma placa proporciona uma retardação angular $\Delta=\pi / 2$, ela é chamada placa de um quarto de onda. As componentes do vetor luz transmitidas ao longo dos eixos rápido e lento na saída da placa, são dados, respectivamente, pelas seguintes expressões:

$$
E_{R}=k \cos \omega t \cos \beta
$$




$$
E_{L}=k \cos (\omega t-\Delta) \operatorname{sen} \beta
$$

onde, $k=a \cos \alpha$.

O módulo do vetor de luz resultante $\left(E_{t}^{r}\right)$ e o ângulo $\gamma$ que faz com o eixo rápido são dados, respectivamente, pelas seguintes expressões:

$$
\begin{aligned}
& E_{t}^{r}=\sqrt{E_{R}^{2}+E_{L}^{2}}=k \sqrt{\cos ^{2} \beta \cos ^{2} \omega t+\operatorname{sen}^{2} \beta \cos ^{2}(\omega t-\Delta)} \\
& \tan \gamma=\frac{E_{R}}{E_{L}}=\frac{\cos (\omega t-\Delta)}{\cos \omega t}-\tan \beta
\end{aligned}
$$

Desta forma, tanto a amplitude quanto a rotação da luz emergente podem ser controladas pela placa retardadora, podendo ser obtidos os tipos de polarização plana, circular ou elíptica. Os fatores que controlam estes tipos são a diferença de fase relativa ( $\Delta$ ) e o ângulo de orientação $(\beta)$. São apresentados os três casos possíveis:

\section{a) Luz Polarizada Plana}

Para $\beta=0$ não há efeito retardador, independentemente de $\Delta$. Desde que o vetor de luz não gire $(\gamma=0)$, ele passa através da placa retardadora e emerge com luz polarizada plana. Ocorre apenas uma retardação de onda que depende de sua espessura e do índice de refração associado com o eixo rápido. Resultado similar é obtido para $\beta=\pi / 2$.

$$
E_{t}=k \cos \omega t
$$




\section{b) Luz Polarizada circular}

Para o caso de $\beta=\pi / 4\left(45^{\circ}\right)$ e $\Delta=\pi / 2$, a ponta do vetor de luz gira com uma velocidade angular constante no sentido anti-horário e uma magnitude constante, descrevendo uma trajetória circular:

$$
E_{t}=k \frac{\sqrt{2}}{2}
$$

onde, $\gamma=\omega t$.

\section{c) Luz Polarizada elíptica}

A extremidade do vetor tem uma magnitude que varia com a posição angular formando uma elipse, cuja forma e orientação são controlados pelo ângulo $\beta$.

$$
k \sqrt{\cos ^{2} \beta \cos ^{2} \omega t+\operatorname{sen}^{2} \beta \cos ^{2} \omega t}
$$

onde, $\tan \gamma=\tan \omega t \times \tan \beta$.

\subsubsection{Polariscópio}

O polariscópio é o instrumento utilizado nas análises fotoelásticas. Este equipamento é comumente utilizado para medir a diferença de fase ou a retardação relativa produzida quando a luz polarizada atravessa um modelo fotoelástico sob tensão. $\mathrm{Na}$ análise de tensões, duas configurações são mais frequentemente empregadas: o polariscópio plano e o polariscópio circular (DALLY; RILEY, 1991). Os polariscópios podem ser ainda divididos em polariscópios de transmissão e de reflexão.

\subsubsection{Polariscópio Plano}

Foi visto que é possível ordenar um raio de luz natural de forma que a inclinação e a direção do vetor luminoso permaneçam as mesmas ao longo do tempo. O dispositivo utilizado 
para se observar os efeitos ópticos produzidos pela passagem da luz polarizada plana através de um modelo fotoelástico carregado é chamado de polariscópio de transmissão plana ou simplesmente polariscópio de transmissão.

O polariscópio plano é um dispositivo que consiste essencialmente de um conjunto de dois filtros polarizadores (Figura 2.8). O primeiro filtro é chamado de polarizador e tem a capacidade de absorver as ondas de luz que não são paralelas ao eixo do polarizador (DALLY; RILEY, 1991). O segundo filtro, o analisador, é geralmente colocado com seu eixo de polarização perpendicular ao do polarizador. Então, o raio de luz que atravessar o primeiro filtro não atravessará o segundo. Diz-se que os dois filtros estão cruzados (HENDRY, 1966).

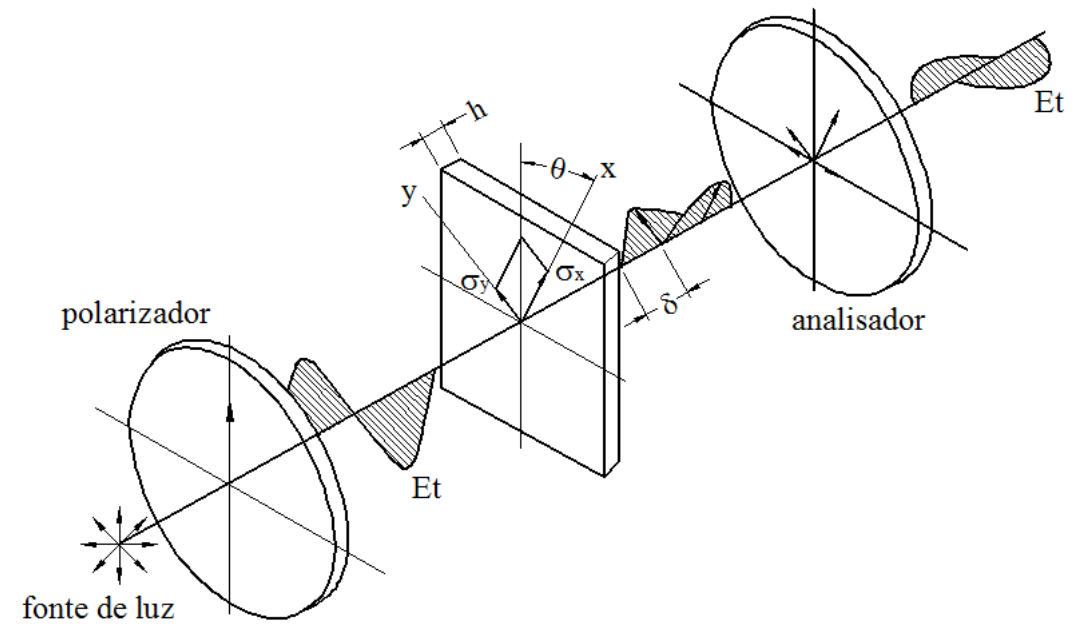

Figura 2.8 - Esquema de polariscópio plano (Measurements Group, 1981 - modificado).

No polariscópio plano, a intensidade da luz emergente é dada por (Gomes, 1984):

$$
I=K \operatorname{sen}^{2} 2 \theta \cdot \operatorname{sen}^{2}\left(\frac{\pi \delta}{\lambda}\right)
$$

onde:

$\theta=$ ângulo entre o eixo de polarização do polarizador e a direção das tensões principais.

Portanto, a intensidade luminosa ( $I$ ) observada na saída do analisador depende dos parâmetros $\theta$ e $\delta$ anteriormente definidos, uma vez que $K$ é constante. 
Existem duas condições para a extinção da luz polarizada que passa através da amostra e do analisador. A primeira condição é encontrada em todo ponto no modelo fotoelástico onde a direção das tensões principais está alinhada com o eixo do polarizador. Assim, nos locais do modelo fotoelástico onde há extinção de luz aparecerá uma série de linhas escuras. Estas linhas são denominadas franjas isoclínicas e definem as direções principais em cada ponto no modelo.

A segunda condição de extinção ocorre quando a diferença de fase entre os dois componentes de vibração, que emergem do modelo fotoelástico, for um número inteiro de comprimento de onda. A intensidade $I$ da luz composta por um comprimento de onda $\lambda$ transmitida por um polariscópio em campo escuro é dada por:

$$
I=\operatorname{sen}^{2}\left(\frac{\pi \delta}{\lambda}\right)
$$

Cada comprimento de onda, ou cor, será extinto então quando $\delta=N \lambda=0,1 \lambda, 2 \lambda, 3 \lambda, \ldots$ Isto produz uma franja denominada de isocromática, que aparece nos pontos do modelo fotoelástico onde ocorre a mesma diferença de fase, ou seja, o mesmo nível de tensão.

Se a luz branca for usada no polariscópio, as franjas isocromáticas serão faixas coloridas, pois somente uma cor correspondente a um $\lambda$ será extinta de cada vez. Quando essa cor é extinta, em seu lugar aparece uma nova cor chamada de cor complementar.

No caso da utilização de luz monocromática, a ausência de luz ocorre propriamente dita. Como a luz monocromática apresenta apenas um comprimento de onda, a cada valor inteiro de $N$, a luz se extinguirá e as isocromáticas serão visualizadas como faixas negras.

\subsubsection{Polariscópio Circular}

O polariscópio circular é obtido com a inserção de duas placas de um quarto de onda $(\lambda / 4)$ entre os filtros polaróides do polariscópio plano. Essas placas são posicionadas com seus 
eixos principais fazendo $45^{\circ}$ com o eixo das polaróides (Figura 2.9). Neste caso, ao entrar na placa de um quarto de onda, a onda é dividida em duas componentes de igual amplitude.

O primeiro elemento do conjunto, assim como no polarizador plano, é o filtro polarizador, que transforma a luz ordinária em luz plano-polarizada. A placa quarto de onda instalada após o polarizador é posicionada de forma que o eixo rápido esteja com inclinação de $45^{\circ}$ em relação ao eixo do polarizador. Dessa maneira, a luz polarizada plana será transformada em luz polarizada circular (FLEURY, 2001).

O terceiro elemento é outra placa quarto de onda orientada de modo que o eixo rápido esteja paralelo ao eixo lento da primeira placa quarto de onda. Assim, a segunda placa anulará o efeito da primeira e transformará novamente em polarização plana.

O analisador, último elemento do conjunto, pode estar orientado de modo que o eixo de polarização seja perpendicular ao eixo do polarizador, ou de modo que seu eixo esteja orientado paralelamente à direção do eixo do polarizador. O primeiro arranjo corresponde ao polariscópio circular em campo escuro e o segundo ao polariscópio de eixos paralelos ou em campo iluminado.

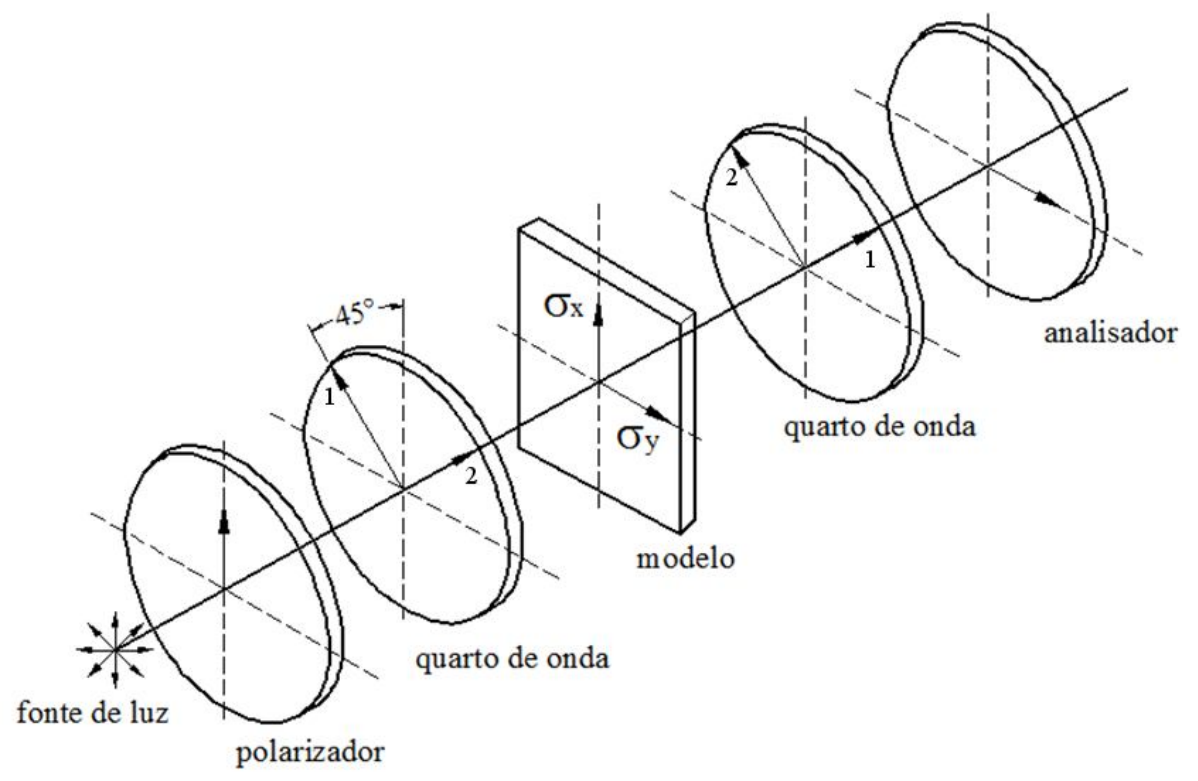

Figura 2.9 - Esquema de polariscópio circular (Measurements Group, 1981 - modificado). 
Com a utilização do polariscópio circular é possível eliminar as isoclínicas, visualizando-se apenas as franjas isocromáticas. A intensidade da luz no polariscópio circular é dada então por:

$$
I=K \operatorname{sen}^{2}\left(\frac{\pi \delta}{\lambda}\right)
$$

Se no polariscópio circular em campo escuro o analisador for girado de $90^{\circ}$, equipamento estará configurado como polariscópio em campo claro. Assim a intensidade luminosa é dada pela Equação (2.31). Esta equação mostra que a extinção da luz ocorrerá quando $\delta=1 / 2 \lambda, \delta=1 \frac{1}{2} \lambda, \delta=2 \frac{1}{2} \lambda, \delta=N \lambda$, obtendo-se as franjas isocromáticas de meia

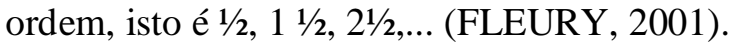

$$
I=K \cos ^{2}\left(\frac{\pi \delta}{\lambda}\right)
$$

\subsubsection{Análise em Polariscópio Plano}

Quando um modelo fotoelástico é carregado em um polariscópio plano, ele funciona como um retardador de onda, com a característica de que os eixos ópticos desse modelo sejam coincidentes com as direções das tensões principais (Figura 2.10). Nesta configuração, o vetor de luz sofre uma polarização plana. Ao vibrar na direção do eixo de polarização, a luz fornecerá um vetor campo elétrico da seguinte forma:

$$
E_{0}=\cos \alpha \cos \varpi t=k \cos \omega t
$$




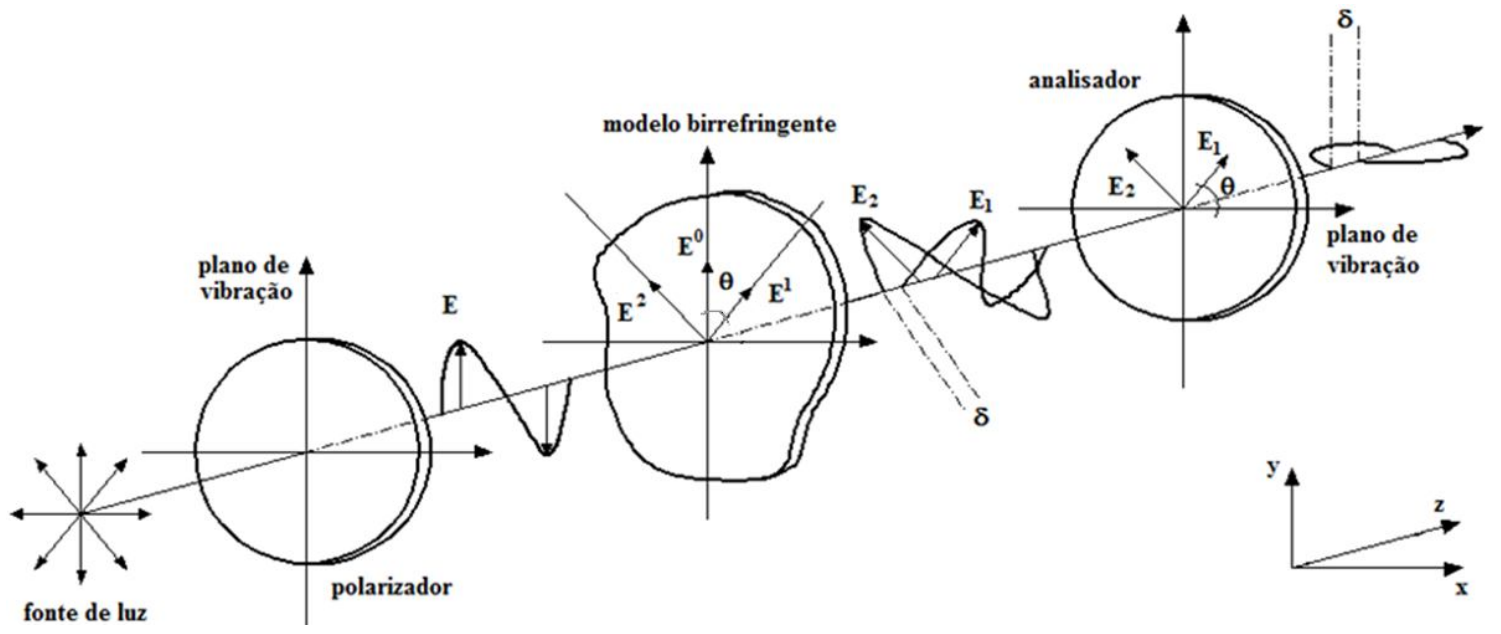

Figura 2.10 - Modelo genérico sob carregamento em polariscópio plano (ARAÚJO, 2006b - modificado).

Ao encontrar o modelo fotoelástico, este vetor de luz será decomposto em duas componentes que vibram ao longo das direções das tensões principais no ponto específico. Quando as componentes emergirem do modelo de espessura $h$, elas estarão defasadas de uma fase $\Delta$ :

$$
\begin{aligned}
& E_{1}=k \cos \left(\omega t-\Delta_{1}\right) \cos \theta \\
& E_{2}=k \cos \left(\omega t-\Delta_{2}\right) \operatorname{sen} \theta
\end{aligned}
$$

onde, $E_{1}$ e $E_{2}$ e são os vetores luminosos que vibram na direção das tensões principais maior e menor, respectivamente.

Se o polarizador estiver configurado em um arranjo em campo escuro, ao encontrar o analisador, os dois vetores emergentes do modelo fotoelástico serão decompostos em duas parcelas. Uma componente será absorvida e a outra será transmitida. O vetor transmitido terá como resultante:

$$
E_{x}=E_{2}^{\prime}-E_{1}^{\prime}=k \cos \theta \operatorname{sen} \theta\left[\cos \left(\omega t-\Delta_{2}\right)-\cos \left(\omega t-\Delta_{1}\right)\right]
$$


Após algumas transformações, esta equação pode ser reescrita da seguinte forma:

$$
E_{x}=\frac{k}{2} \operatorname{sen} 2 \theta \operatorname{sen}\left(\frac{\Delta_{2}-\Delta_{1}}{2}\right) \operatorname{sen}\left(\omega t-\frac{\Delta_{2}+\Delta_{1}}{2}\right)
$$

A diferença de fase angular média $\left[\left(\Delta_{2}+\Delta_{1}\right) / 2\right]$ afeta apenas a fase da luz que emerge do analisador e não a amplitude do vetor luz. Sabendo-se que a intensidade luminosa (I) é proporcional ao quadrado da amplitude, a intensidade luminosa depende apenas dos parâmetros $\theta$ e $\Delta$, pois $k$ é constante:

$$
I=k \operatorname{sen}^{2} 2 \theta \operatorname{sen}^{2} \frac{\Delta}{2}
$$

A intensidade luminosa depende do ângulo $\theta$ que as tensões principais do modelo fotoelástico fazem com o eixo de polarização. No caso em que $I=O$ tem-se que:

$$
\begin{aligned}
& \operatorname{sen}^{2} 2 \theta=0 \\
& \theta=\frac{n \pi}{2}
\end{aligned}
$$

A intensidade da luz se anula nos pontos em que as direções das tensões principais coincidirem com o eixo do polarizador $(\theta=0$ ou $\theta=\pi / 2)$. Portanto, estas franjas, definidas anteriormente como isoclínicas, são os lugares geométricos da direção das tensões principais. O ângulo $\theta$ é denominado de parâmetro das isoclínicas e identifica a direção das tensões principais no modelo em um ponto específico.

A intensidade luminosa $(I)$ também depende da retardação angular $(\Delta)$, de forma que quando $I=0$,

$$
\operatorname{sen}^{2} \frac{\Delta}{2}=0
$$




$$
\Delta=2 n \pi=\frac{2 \pi}{\lambda} \delta
$$

A ordem de franja $(N)$ pode então ser determinada da seguinte forma:

$$
n=N=\frac{\Delta}{2 \pi}=\frac{\delta}{\lambda}
$$

A intensidade da luz (I) será nula quando a retardação angular $(\Delta)$ for zero ou múltiplo inteiro do comprimento de onda $2 \pi$ ou $\lambda$. Assim, os lugares geométricos destas franjas indicam os pontos onde os comprimentos de onda da luz resultante são iguais. Tais lugares geométricos são chamados de isocromáticas.

\subsubsection{Análise em Polariscópio Circular}

Da mesma forma que no polariscópio plano, um modelo fotoelástico sob carregamento em um polariscópio circular funciona como um retardador de onda (Figura 2.11). Os eixos ópticos do modelo coincidem com a direção das tensões principais devido ao efeito de birefringência.

O polariscópio da Figura 2.11 está configurado em campo escuro. O polarizador e o analisador estão com seus eixos cruzados entre si, e os retardadores de onda com seus eixos cruzados um em relação ao outro e posicionados a $45^{\circ}$ em relação ao eixo do polarizador. Nesta posição, tem-se luz polarizada circular entre as duas placas quarto de onda. Se o modelo não estiver submetido a carregamento, nenhuma intensidade de luz é observada na saída do analisador. 


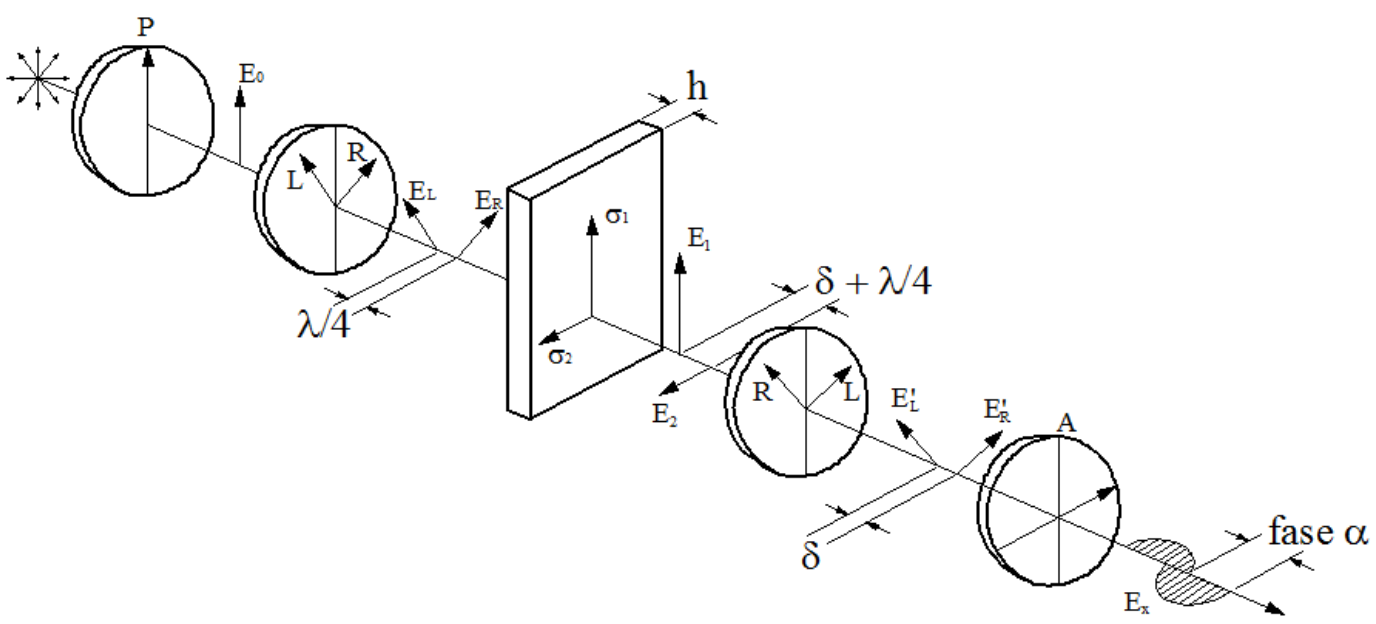

Figura 2.11 - Modelo genérico carregado em polariscópio circular em campo escuro (ARAÚJO, 2006b modificado).

O vetor de luz que parte da fonte atravessa o polarizador e sofre uma polarização plana, de modo que a luz vibra na direção de seu eixo de polarização. O campo elétrico desse vetor resultante da polarização plana é expresso por:

$$
E_{0}=\cos \alpha \cos \omega t=k \cos \omega t
$$

Ao encontrar a primeira placa quarto de onda, este vetor de luz polarizada plana será decomposto em duas componentes que vibram ao longo dos eixos rápido (1) e lento (2), em cada ponto específico desse retardador. Quando emergirem da primeira placa quarto de onda, as duas componentes estarão defasadas de uma fase $\pi / 2$ (um quarto de onda), que passam a descrever uma trajetória de vibração circular:

$$
\begin{aligned}
& E_{R}=k \frac{\sqrt{2}}{2} \cos \omega t \\
& E_{L}=k \frac{\sqrt{2}}{2} \cos \left(\omega t-\frac{\pi}{2}\right)=k \frac{\sqrt{2}}{2} \operatorname{sen} \omega t
\end{aligned}
$$


Ao encontrar o modelo fotoelástico, os dois vetores de luz serão decompostos em duas componentes que vibram ao longo da direção das tensões principais do modelo fotoelástico. Essas componentes fazem um ângulo $\theta$ com relação ao eixo de polarização, e emergem com uma retardação angular relativa de $\Delta$, ou seja:

$$
\begin{aligned}
& E_{1}=E_{R} \cos \left(\frac{\pi}{4}-\theta\right)+E_{L} \operatorname{sen}\left(\frac{\pi}{4}-\theta\right) \\
& E_{2}=E_{R} \operatorname{sen}\left(\frac{\pi}{4}-\theta\right)+E_{L} \cos \left(\frac{\pi}{4}-\theta\right)
\end{aligned}
$$

Combinando-se as Equações (2.44), (2.45), (2.46) e (2.47) e considerando a retardação relativa entre os dois vetores, tem-se que:

$$
\begin{aligned}
& E_{1}=k \frac{\sqrt{2}}{2} \cos \left[\omega t+\left(\theta-\frac{\pi}{4}\right)\right] \\
& E_{2}=k \frac{\sqrt{2}}{2} \operatorname{sen}\left\{\left[\omega t+\left(\theta-\frac{\pi}{4}\right)\right]-\Delta\right\}
\end{aligned}
$$

A segunda placa quarto de onda possui seus eixos rápido (1) e lento (2) cruzados em relação ao primeiro retardador. Aos encontrar essa segunda placa quarto de onda, os dois vetores emergentes do modelo fotoelástico serão novamente decompostos em dois vetores segundo a orientação da segunda placa quarto de onda. Assim é somado mais uma diferença de fase igual a $\pi / 2$. Logo, tem-se:

$$
\begin{aligned}
& E_{R}^{\prime}=E_{1} \operatorname{sen}\left(\frac{\pi}{4}-\theta\right)+E_{2} \cos \left(\frac{\pi}{4}-\theta\right) \\
& E_{L}^{\prime}=E_{1} \cos \left(\frac{\pi}{4}-\theta\right)+E_{2} \operatorname{sen}\left(\frac{\pi}{4}-\theta\right)
\end{aligned}
$$


Com as Equações (2.48) e (2.49) e a retardação de um dos vetores relativo ao outro, tem-se:

$$
\begin{aligned}
& E_{R}^{\prime}=k \frac{\sqrt{2}}{2}\left\{\cos \left[\omega t+\left(\theta-\frac{\pi}{4}\right)\right] \operatorname{sen}\left(\theta-\frac{\pi}{4}\right)+\right. \\
& +\operatorname{sen}\left[\omega t+\left(\theta-\frac{\pi}{4}\right)-\Delta\right] \cos \left(\theta-\frac{\pi}{4}\right) \\
& E_{L}^{\prime}=k \frac{\sqrt{2}}{2}\left\{\cos \left[\omega t+\left(\theta-\frac{\pi}{4}\right)\right] \cos \left(\theta-\frac{\pi}{4}\right)-\right. \\
& -\operatorname{sen}\left[\omega t+\left(\theta-\frac{\pi}{4}\right)-\Delta\right] \operatorname{sen}\left(\theta-\frac{\pi}{4}\right)
\end{aligned}
$$

Estes dois vetores, emergentes da segunda placa quarto de onda, encontram o analisador. O eixo de polarização do analisador está posicionado a $90^{\circ}$ em relação ao eixo do polarizador. Além disso, os eixos rápido e lento também fazem um ângulo de $45^{\circ}$ em relação ao eixo de polarização do analisador. Desta forma, apenas as componentes ao longo do eixo de polarização do analisador serão transmitidas e observadas. O vetor de luz resultante será então:

$$
E_{x}=\frac{\sqrt{2}}{2}\left(E_{2}^{\prime \prime}-E_{1}^{\prime \prime}\right)=k \operatorname{sen} \frac{\Delta}{2} \operatorname{sen}\left(\omega t+2 \theta-\frac{\Delta}{2}\right)
$$

Como a intensidade luminosa é proporcional ao quadrado da amplitude do vetor luz resultante, tem-se:

$$
I=K \operatorname{sen}^{2} \frac{\Delta}{2}
$$

Ao se comparar a Equação (2.37) com a Equação (2.55), observa-se que quando o modelo é carregado em um polariscópio circular, a intensidade luminosa é apenas função da retardação relativa. As únicas famílias de franjas presentes no modelo são as isocromáticas. 
Assim, a utilização do polariscópio circular é importante para se avaliar as tensões com maior facilidade e precisão, uma vez que não há superposição das franjas isoclínicas.

\subsubsection{Padrão de Franjas}

Através da análise fotoelástica é possível visualizar simultaneamente dois diferentes sistemas de faixas ou franjas. Na luz branca, estes dois sistemas podem ser facilmente distinguíveis, uma vez que as isoclínicas são negras enquanto que as isocromáticas são coloridas, com exceção da isocromática de ordem zero. Na luz monocromática, ambos os sistemas são negros (Figura 2.12a).

Em um corpo de prova submetido a um acréscimo de carregamento, quando examinado em luz branca, exibirá uma série de cores (Figura 2.12b). Para cada valor de $\sigma_{1}-\sigma_{2}$ haverá uma cor correspondente. Portanto, nos pontos do objeto sob carregamento em que for possível visualizar faixas com a mesma cor, o valor de $\sigma_{l}-\sigma_{2}$ nesses pontos será o mesmo. Os contornos de $\sigma_{1}-\sigma_{2}$ aparecerão como bandas coloridas e por essa razão elas são chamadas franjas isocromáticas (HENDRY, 1966).

(a)

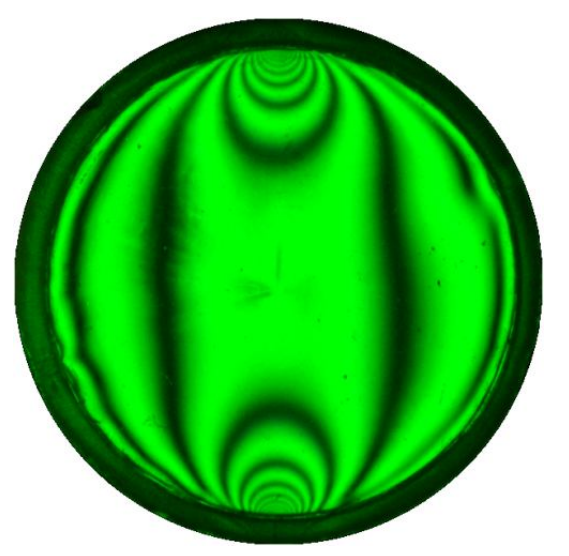

(b)

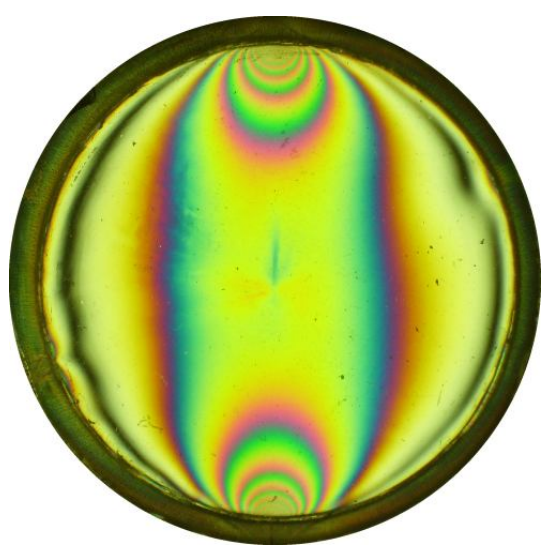

Figura 2.12 - Franjas isocromáticas (a) em luz monocromatica e (b) em luz branca. 


\subsubsection{Linhas de Tensões Principais}

No campo de tensões não-uniformes, a direção das tensões principais varia de ponto para ponto. Se for possível desenhar uma curva de maneira que a direção de uma das tensões principais seja tangencial a ela em todo ponto ao longo de sua extensão, tal curva será denominada linha de tensão principal, trajetória de tensão ou isostática (KUSKE; ROBERTSON, 1974).

A Figura 2.13 traz o traçado de uma rede de tensões principais para um pórtico. As linhas finas são as linhas de tensão principal maior $\sigma_{l}$, e as grossas são as de tensão principal menor $\sigma_{3}$. O diagrama mostrado na Figura 2.13 exibe as trajetórias das tensões principais em um modelo de pórtico. Pode-se observar a concentração de linhas de tensões mínimas no interior da borda à direita do modelo, o que indica uma concentração de tensões nessa região. É possível também visualizar o cruzamento entre as linhas, indicando a variação de tensões de compressão para tração (HENDRY, 1966)

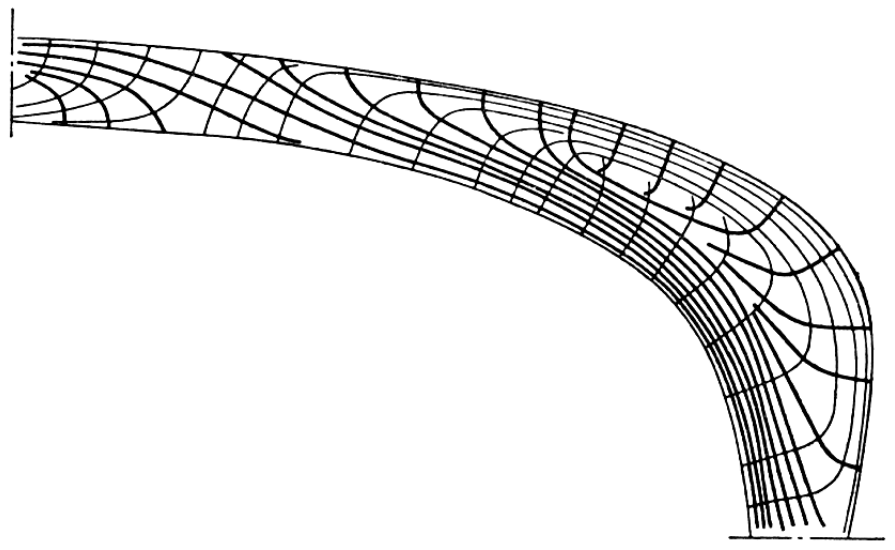

Figura 2.13 - Linhas de tensões principais em um modelo de pórtico (HENDRY, 1966).

O traçado das isostáticas pode ser feito diretamente das isoclínicas. Conforme Dally e Rilley (1991), em uma das técnicas, a trajetória de tensão é iniciada normal à isoclínica $0^{\circ}$ (Figura 2.14). Esta linha normal (1) é desenhada até interceptar a isoclínica $10^{\circ}$. A linha (1) então é dividida ao meio, e uma nova linha (2) é desenhada a partir da divisão de (1) até a 
isoclínica $20^{\circ}$, com inclinação de $10^{\circ}$ com a vertical. Assim como na linha (1), a linha (2) é dividida ao meio, de onde se dará origem à linha (3), que será traçada com uma inclinação de $20^{\circ}$ em relação à vertical. O processo é repetido até que todo o campo esteja coberto.

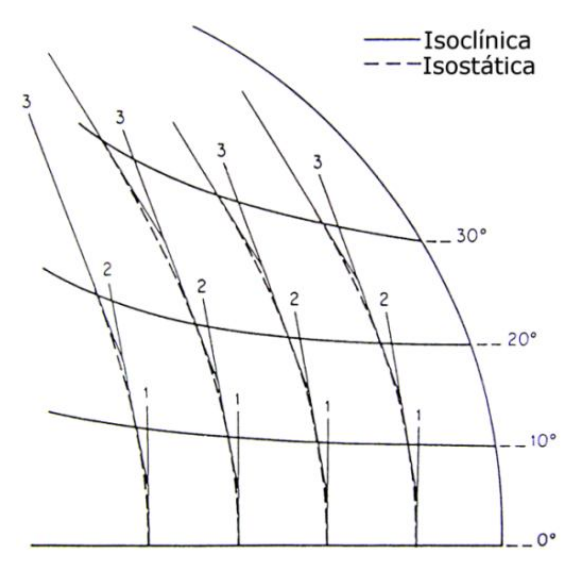

Figura 2.14 - Construção para converter isoclínicas em isostáticas (DALLY; RILEY, 1991 - modificado).

\subsubsection{Franjas Isocromáticas}

$\mathrm{Na}$ análise fotoelástica plana, um modelo é adequadamente preparado e colocado em um polariscópio. Após ser carregado, o seu padrão de franjas é fotografado e examinado. O padrão de franjas isocromáticas obtidos de um modelo bidimensional exibe linhas ao longo do modelo onde a diferença das tensões principais $\left(\sigma_{1}-\sigma_{2}\right)$ é constante.

Ao aplicar um carregamento em incrementos de carga em uma peça inicialmente descarregada, as franjas aparecerão primeiramente nos pontos com maior nível de tensão. Ao aumentar a carga, novas franjas aparecem e as anteriores são redistribuídas para áreas de menor tensão. Com a sucessão de carregamentos, franjas adicionais são geradas nas regiões de maior tensão e redistribuídas em direção às regiões de menor tensão até que se atinja a carga máxima. 
As franjas podem ser designadas por números ordinais (primeira, segunda, terceira etc.) de acordo com o seu surgimento, e elas possuirão uma identidade individual (ordem) durante a seqüência de carregamento. As franjas são contínuas, não se interceptam em nenhum ponto e sempre seguem uma determinada sequência (KUSKE; ROBERTSON, 1974).

A Figura 2.15 foi utilizada por Dally e Riley (1991) para ilustrar a determinação da ordem de franjas. Primeiramente é necessário determinar a ordem da franja em cada ponto de interesse no modelo. Neste modelo, a determinação é relativamente simples, pois se tratam de ordens de meias-franjas que podem ser rapidamente identificadas.

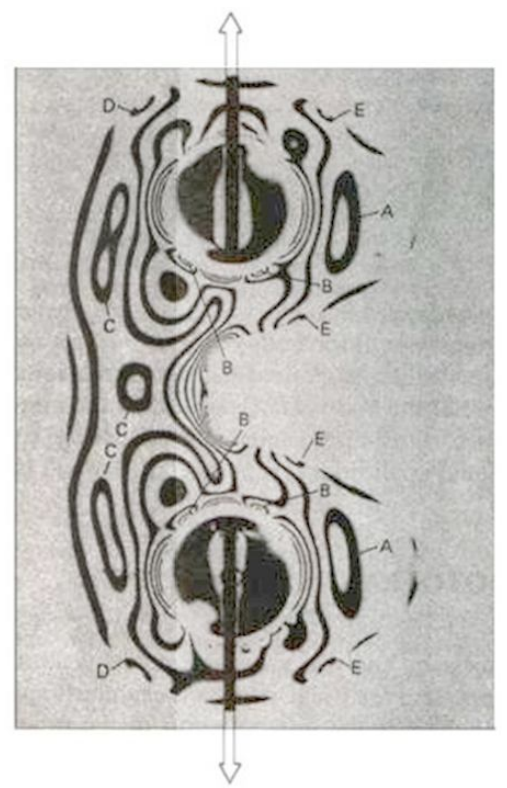

Figura 2.15 - Franjas isocromáticas em peça mecânica sujeita a tração axial (DALLEY; RILEY, 1991 modificado).

Com a luz branca, os pontos de ordem zero são facilmente reconhecidos por serem faixas ou manchas de cor negra. A direção do crescimento da ordem das franjas é determinada pelas cores das franjas que possuem uma variação de tons em função do gradiente de tensões, que geralmente se inicia pelo tom de vermelho, em seguida, amarelo, azul e/ou verde (KUSKE; ROBERTSON, 1974). 
Quando a ordem de franja é determinada no ponto em análise, é possível determinar a diferença entre as tensões principais $\sigma_{1}-\sigma_{2}$ através da Equação (2.56). A máxima tensão de cisalhamento $\tau_{\text {máx }}$ é então dada pela Equação (2.57).

$$
\begin{aligned}
& \sigma_{1}-\sigma_{2}=\frac{N \cdot f_{\sigma}}{h} \\
& \tau_{\text {máx }}=\frac{1}{2}\left(\sigma_{1}-\sigma_{2}\right)=\frac{N \cdot f_{\sigma}}{2 h}
\end{aligned}
$$

onde,

$N=$ ordem da franja

$h=$ espessura do modelo

$f_{\sigma}=\lambda C=$ valor da franja do material (constante) onde:

$\lambda=$ comprimento de onda

$C=$ constante fotoelástica do material

$\tau_{\text {máx }}=$ tensão de cisalhamento máxima.

\subsubsection{Franjas Isoclínicas}

Como visto ao examinar modelos fotoelásticos em um polarizador plano, haverão pontos escuros onde a direção de uma das tensões principais coincide com a direção de polarização da luz incidente. No lugar geométrico dos pontos onde a direção das tensões principais coincide com a direção de polarização aparecerão as franjas isoclínicas.

A utilização das isoclínicas pode ser feita de duas maneiras. Na primeira, franjas isoclínicas podem ser obtidas e combinadas para formar uma imagem global no campo completo do modelo (Figura 2.16), i.e., a família de isoclínicas (Figura 2.17). Para isso é necessário obter as isoclínicas para diversas inclinações das lentes polarizadoras. Portanto gira-se o polarizador e o analisador juntos, em pequenos incrementos angulares na faixa de 0 a $90^{\circ}$. 
A outra maneira de se utilizar as isoclínicas consiste em determinar a direção das tensões principais em um ponto de interesse. Neste caso gira-se as lentes polarizadoras até uma franja isoclínica passar sobre o ponto de interesse. Ao interceptar o ponto, o parâmetro da isoclínica $(\theta)$ indicará a inclinação das direções principais. O ângulo que os polarizadores foram girados é chamado de parâmetro da isoclínica.
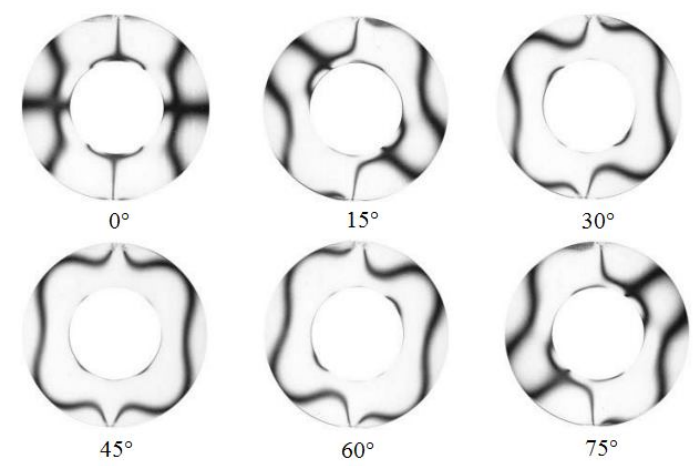

Figura 2.16 - Padrão de isoclínicas em anel sob compressão diametral (MEASUREMENTS GROUP, 1981 modificado).

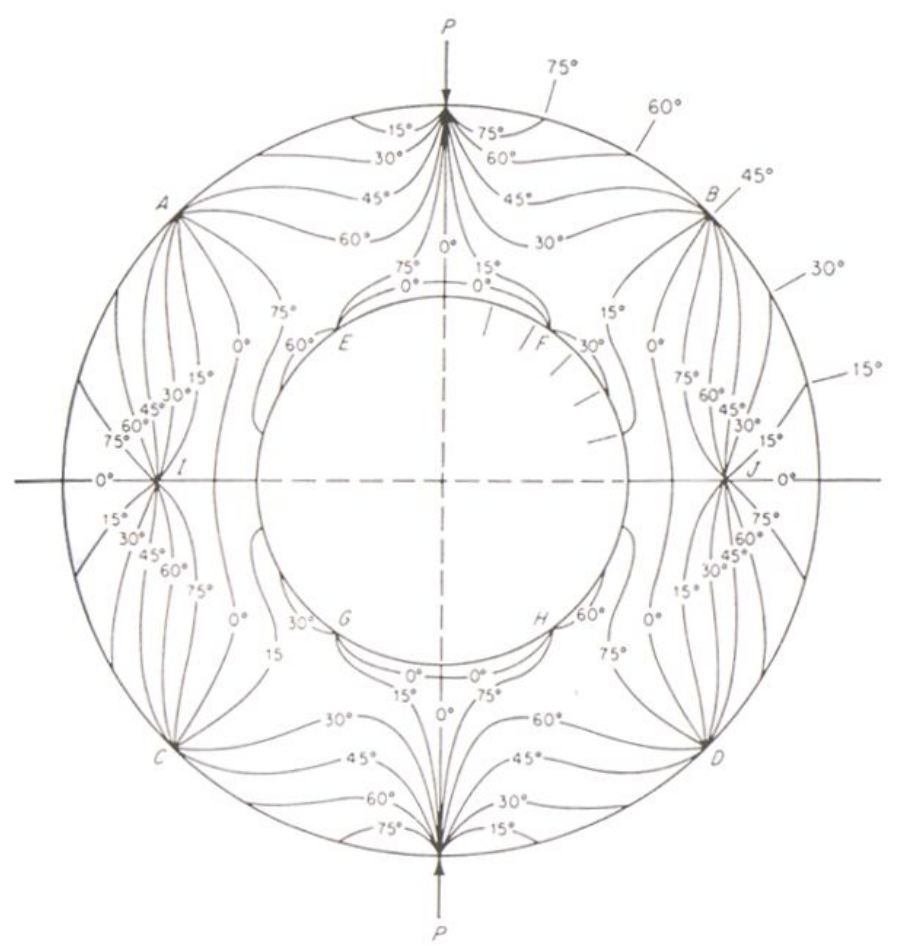

Figura 2.17 - Família de isoclínicas em anel sob compresão diametral (DALLY; RILEY, 1991 - modificado). 
Algumas regras devem ser seguidas durante a composição do padrão de isoclínicas através de padrões individuais:

- As isoclínicas de todos os parâmetros devem passar através de pontos singulares ou isotrópicos;

- Uma isoclínica de um parâmetro deve coincidir com qualquer eixo de simetria que exista;

- O parâmetro de uma isoclínica que intercepta uma borda livre é determinado pelo ângulo da divisa no ponto de interseção;

- As isoclínicas de todos os parâmetros passam através de pontos de carregamento concentrado, desde que sejam pontos singulares.

HENDRY (1966) cita que com a obtenção das linhas isoclínicas pelo ensaio fotoelástico, fica fácil construir o desenho das linhas de tensões principais. A Figura 2.18 apresenta o exemplo de traçado das linhas das tensões principais obtidos a partir de isoclínicas. Nesse caso, o ângulo $\phi$ que a direção da tensão principal faz com um eixo de referência é parâmetro da isoclínica (Figura 2.18).

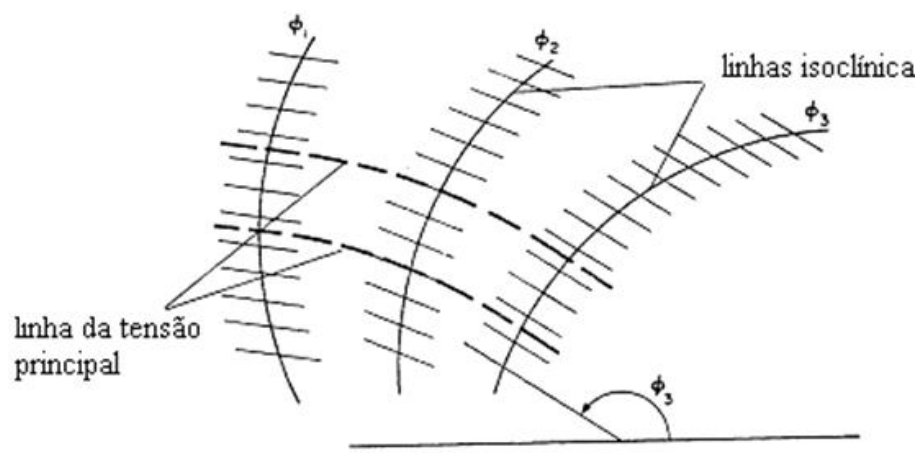

Figura 2.18 - Traçado das linhas de tensões principais por meio das isoclínicas (HENDRY, 1966 - modificado). 
A direção das tensões principais varia de ponto a ponto. A direção de umas das tensões principais é a reta tangente em cada ponto da isoclínica (Figura 2.19).

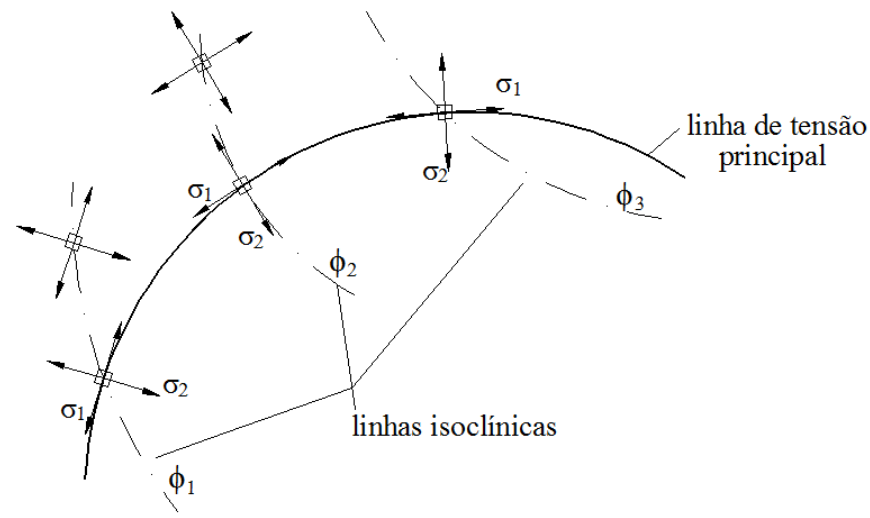

Figura 2.19 - Direção das tensões principais a partir da isoclínica (HENDRY, 1966 - modificado).

Os parâmetros das isoclínicas também são empregados para determinar tensões de cisalhamento em um plano arbitrário. Sabe-se que o parâmetro de isoclínica proporciona a direção entre o eixo $x$ do sistema de coordenadas e a direção de $\sigma_{l}$ ou $\sigma_{2}$, de forma que:

$$
\begin{gathered}
\tau_{x y}=-\frac{\sigma_{1}-\sigma_{2}}{2} \operatorname{sen} 2 \theta_{2}=\frac{N f_{\sigma}}{2 h} \operatorname{sen} 2 \theta_{2} \\
\tau_{x y}=-\frac{\sigma_{1}-\sigma_{2}}{2} \operatorname{sen} 2 \theta_{1}=\frac{N f_{\sigma}}{2 h} \operatorname{sen} 2 \theta_{1}
\end{gathered}
$$

onde, $\theta_{1}$ ou $\theta_{2}$ são os ângulos entre o eixo $x$ e a direção de $\sigma_{1}$ ou $\sigma_{2}$ dada pelo parâmetro da isoclínica.

Burki e Richards Jr. (1975) apresentaram a composição de uma família de isoclínicas em um estudo fotoelástico sobre um modelo de ensecadeira sob pressão de água (Figura 
2.20). O modelo fotoelástico foi feito em gelatina e construído com o objetivo de determinar as tensões em campo completo sob carregamento de gravidade e pressão de água.

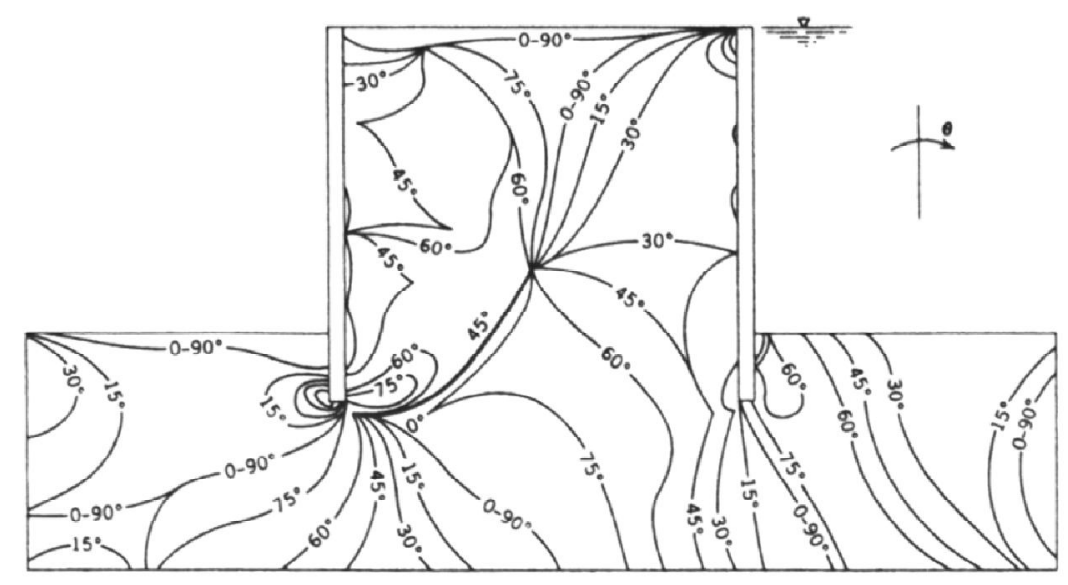

Figura 2.20 - Ensecadeira sob carregamento de pressão de água (BURKI; RICHARDS JR, 1975).

\subsubsection{Comportamento das Franjas}

As franjas fotoelásticas possuem características que podem ser úteis na interpretação do padrão fotoelástico. As isocromáticas nunca se interceptam e, a ordem da franja e o nível de tensão são os mesmos em todo ponto da franja. As franjas negras de ordem zero são usualmente manchas isoladas, linhas, ou áreas circundadas por franjas de ordem superior.

As franjas existem em uma seqüência contínua tanto no número como na cor, ou seja, se as franjas de primeira e terceira ordem são identificadas, a franja de segunda ordem deverá encontrar-se entre elas (FLEURY, 2001).

Quando não existe franja de ordem zero evidente, a franja de primeira ordem pode sempre ser reconhecida devido ao brilho das cores de passagem adjacentes à matiz púrpura. Como alternativa, quando o carregamento pode ser realizado em incrementos a partir do modelo descarregado, a franja de ordem zero pode geralmente ser acompanhada até desaparecer. 
Ao reconhecer uma franja, a ordem de outras franjas pode ser identificada, pois sabese que a direção de aumento da ordem das franjas corresponde a uma determinada seqüência de cores. Por este processo o observador pode rapidamente localizar as franjas de maior ordem e geralmente as regiões mais tensionadas ou deformadas (FLEURY, 2001). Áreas de franjas finas com pequenos espaçamentos significam regiões de gradientes excessivos de tensões e de altas tensões. Grandes áreas onde o padrão é quase uniformemente negro ou cinza geralmente indicam uma região não tensionada.

\subsubsection{Medida dos Parâmetros Fotoelásticos}

Como já discutido, o método mais simples para determinação da ordem das franjas é através da contagem do ponto conhecido de ordem zero em direção ao acréscimo de ordem. A Equação (2.56) mostra que a diferença entre as tensões principais ou a máxima tensão de cisalhamento em qualquer ponto do modelo fotoelástico é diretamente proporcional à franja isocromática de ordem $N$.

Por vezes é necessário determinar a fração da franja em ponto em análise onde nenhuma isocromática passa por ele. Casos estes que o número ou a distribuição de franjas é tal que por si própria não forma uma base satisfatória para a determinação da distribuição de tensões. Para determinar medidas pontuais de tensões, melhorando a precisão nas leituras, utiliza-se técnicas de compensação. Há vários métodos propostos por diferentes autores, como por exemplo, em Kuske e Robertson (1974).

\subsubsection{Compensação Tardy}

De acordo com Kuske e Robertson (1974), ordens fracionárias de franja são mais frequentemente determinadas com o uso de compensações de um quarto de onda, como a de 
Tardy. Tais métodos combinam um elevado grau de exatidão com a vantagem de utilizar o polariscópio.

Primeiramente um polariscópio plano é empregado para que as isoclínicas possam ser usadas para estabelecer as direções dos eixos das tensões principais em um ponto de interesse (Figura 2.21). Gira-se então o conjunto polarizador/analisador até que uma isoclínica passe sobre o ponto em questão. Os eixos de polarização ficam então alinhados com a direção das tensões principais.

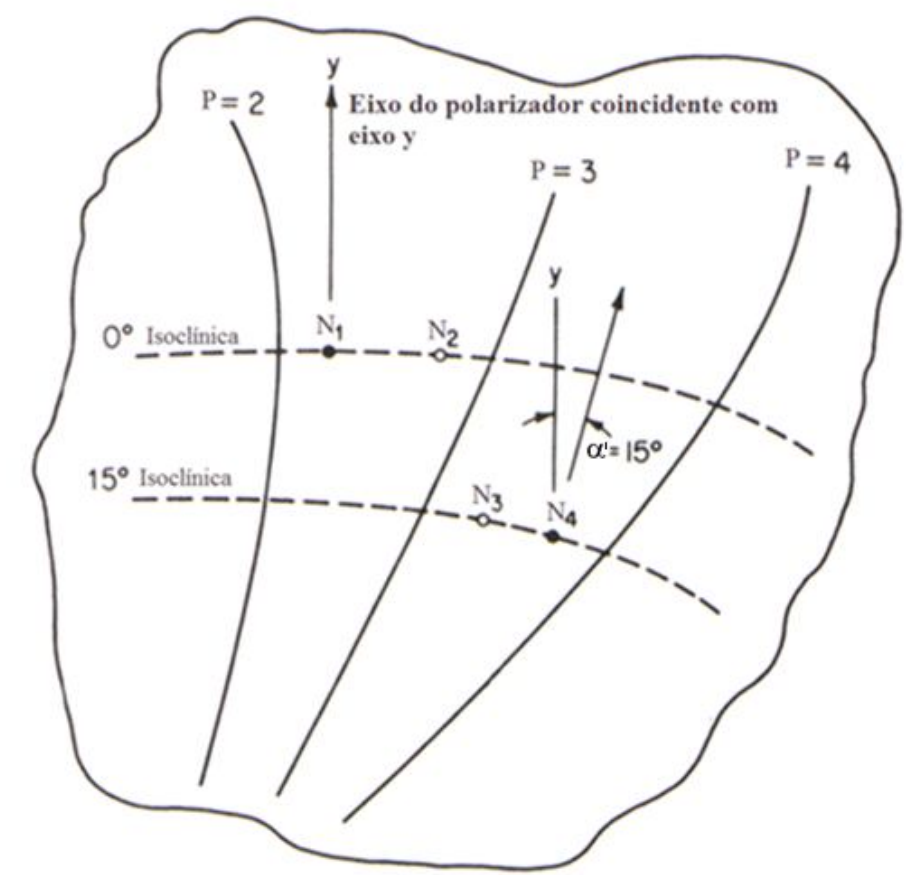

Figura 2.21 - Locação dos pontos de interesse relativos às isoclínicas e isocromáticas (DALLY; RILEY, 1991 modificado).

Em seguida, rotaciona-se as placas de um quarto de onda para transformar o polariscópio plano em circular. As placas de um quarto de onda então devem formar um ângulo de $45^{\circ}$ com os eixos de polarização.

Observa-se o espectro, assinalando as ordens de franja de valores inteiros adjacentes ao ponto de interesse. As franjas próximas ao ponto de interesse estarão identificadas. O 
analisador deverá ser rotacionado, observando o movimento das franjas, até que uma das franjas de ordem inteira passe pelo ponto. No transferidor do polariscópio, o ângulo de rotação $\left(\alpha^{\prime}\right)$ é lido.

Se a franja que se moveu em direção ao ponto for a de ordem menor, tem-se que a ordem de franja fracionária no ponto é dada pela Equação (2.60). Se a franja que se moveu for a de ordem mais alta, tem-se que a ordem fracionária da franja é dada pela Equação (2.61).

$$
\begin{aligned}
& N=\frac{\Delta}{2 \pi}=n+\frac{\gamma}{\pi} \\
& N=\frac{\Delta}{2 \pi}=n-\frac{\gamma}{\pi}
\end{aligned}
$$

onde,

$n=0,1,2, \ldots$

$\alpha^{\prime}=$ ângulo de rotação do analisador

O grau de exatidão do método independe do operador e é influenciado pela qualidade das placas quarto de onda utilizadas no polariscópio. No entanto, medidas de $\pm 0,02$ franjas são usualmente alcançadas (DALLY; RILEY, 1991).

\subsubsection{Métodos de Calibração}

$\mathrm{Na}$ maioria das análises fotoelásticas o objeto de estudo é a distribuição de tensões num modelo em função dos carregamentos. Para determinar a distribuição de tensões com boa exatidão, é necessária uma cuidadosa calibração da constante óptica $f_{\sigma}$. Alguns valores de $f_{\sigma}$ são listados em Frocht (1941), Vasconcelos (1947), Hendry (1966), Kuske e Robertson (1974), Gomes (1984), Gomide e Smith (1984), Chandrashekhara e Antony (1995), Araújo; Neves; Bernardes (2004), entre outros. Essa constante pode se alterar com a idade do material 
e com a temperatura ambiente. Por essa razão é conveniente que se faça a calibração do material quando da realização do ensaio (FLEURY, 2001).

Em qualquer técnica de calibração deve-se escolher um corpo cuja distribuição de tensões teórica seja conhecida com exatidão. O modelo deve ser fácil de confeccionar e simples de se aplicar carregamentos. O modelo para calibração deverá ser carregado em estágios com as ordens de franjas fotografadas e carregamentos anotados. A partir destes dados será possível determinar o valor da constante óptica $f_{\sigma}$ do material.

Um modelo empregado frequentemente para a obtenção da calibração do material fotoelástico é o disco comprimido diametralmente (Figura 2.12, por exemplo). Um exemplo de calibração do disco pode ser encontrado em Dally e Riley (1991).

\subsection{Materiais Fotoelásticos}

Muitos materiais transparentes não cristalinos são oticamente isotrópicos quando não estão sob carregamento, livre de tensão, e ao se tornarem oticamente anisotrópicos exibem características similares às de cristais sob tensão. Essas características persistem durante o carregamento, mas desaparecem quando o carregamento é removido. Tal comportamento é chamado de dupla refração temporária, como tratada em 2.1.4.

O efeito de anisotropia óptica pode ser representado através do elipsóide índice (Figura 2.22). Os semi-eixos do elipsóide representam os índices de refração principais no ponto de um material. Qualquer raio do elipsóide representa uma direção de propagação da luz no ponto. A interseção do elipsóide com um plano que passe pela sua origem e que seja ortogonal a dois eixos caracteriza uma elipse. Os semi-eixos da elipse representam então os índices de refração associados com as ondas de luz cujos planos de vibração contenham o vetor raio e um eixo da elipse (DALLY e RILEY, 1991). Nos materiais isotrópicos, os três 
índices de refração são iguais e o elipsóide índice se tornará uma esfera e o índice de refração será o mesmo em todas as direções.

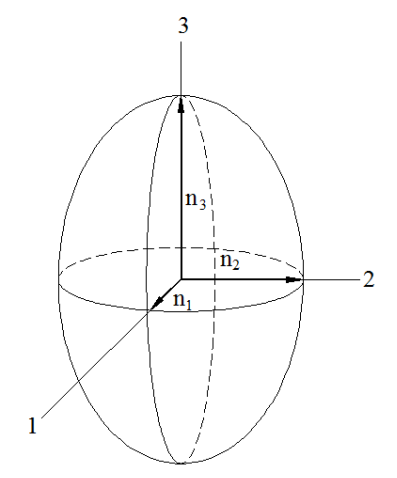

Figura 2.22 - Elipsóide índice.

Embora uma das vantagens do método fotoelástico seja a improbabilidade de erros grosseiros nos resultados dos ensaios, a exatidão da análise depende em grande parte da preparação cuidadosa do modelo e da atenção nos procedimentos de ensaio (HENDRY, 1966).

\subsubsection{Propriedades do MateriaL Fotoelástico}

Um dos fatores mais importantes na análise fotoelástica é a seleção do material adequado para um modelo fotoelástico. Infelizmente, um material ideal não existe. Então o pesquisador deve escolher um material que atenda às necessidades da pesquisa (KUSKE; ROBERTSON, 1974).

A quantidade de plásticos fotoelásticos utilizados a cada ano não é suficiente para que toda uma companhia química se dedique ao desenvolvimento e produção de polímeros dedicados a aplicações fotoelásticas (DALLY; RILLEY, 1991). Como conseqüência, é comum o pesquisador escolher um material que é usualmente empregado para outras finalidades não inerentes à fotoelasticidade. 
A lista seguinte aborda algumas propriedades interessantes que um material fotoelástico ideal deveria exibir. Em seguida, alguns critérios serão discutidos separadamente.

- Ser transparente à luz empregada no polariscópio;

- Ser sensível à tensão e deformação;

- Apresentar comportamento elástico-linear

- Apresentar relação linear do tipo $\left(\sigma_{1}-\sigma_{2}\right)=$ aN entre as diferentes ordens de franja e seus níveis de tensão, onde a é o coeficiente angular da reta de ajuste e $\mathrm{N}$ é a ordem de franja;

- Exibir homogeneidade e isotropia mecânica e óptica;

- Não exibir comportamento viscoelástico;

- Apresentar alto módulo de elasticidade e ter um alto limite de proporcionalidade em relação aos níveis de tensão esperados;

- As constantes ópticas não devem variar com pequenos gradientes de temperatura;

- Ser livre de efeitos de borda;

- Ser possível de se manufaturar por forma convencional;

- Não apresentar tensões residuais;

- Ser de baixo custo.

\subsubsection{Transparência}

A maioria dos materiais utilizados nos modelos fotoelásticos são plásticos transparentes. É necessário que estes plásticos sejam transparentes para que seja possível visualizar a luz, mas não necessariamente precisam ser cristalinos (DALLY; RILLEY, 1991).

De acordo com Ravi (1998), a análise fotoelástica que utiliza a fotoelasticidade de transmissão requer a necessidade do material fotoelástico ser transparente e possuir boas propriedades ópticas. Segundo Pipes e Rose (1974), a tonalidade amarelada das epoxies é um 
inconveniente para seu uso como material fotoelástico, embora alguns pesquisadores tentem usá-lo.

A perda da transparência ocorre por duas razões: (1) a diminuição dos índices de refração dos materiais constituintes e (2) ar aprisionado. Em ambos os casos, há uma modificação das propriedades do meio fotoelástico, e então ocorre a dispersão de luz, reduzindo a transparência do material (RAVI, 1998).

\subsubsection{Sensibilidade}

Um material apresenta alta sensibilidade fotoelástica quando o número de franjas que são observadas no modelo são superiores aos de outro material de mesmas características mecânicas. Se o valor de $f_{\sigma}$ é baixo para o material do modelo, um padrão de franjas satisfatório pode ser alcançado com pequenos níveis de carregamento para o modelo. Esta característica reduz a complexidade e tamanho do suporte de carga e limita a distorção do modelo. Existem materiais fotoelásticos disponíveis com valores de $f_{\sigma}$ variando de 0,035 a $350 \mathrm{kN} / \mathrm{m}$.

\subsubsection{Isotropia e Homogeneidade}

Quando um polímero é preparado por um processo de fundição, suas cadeias moleculares orientam-se aleatoriamente, tornando-o essencialmente isotrópico e homogêneo. Porém, alguns plásticos são laminados, tracionados ou extrudados durante seu processo de fabricação. Nesses processos, as cadeias moleculares são orientadas na direção do esforço e consequentemente, estes materiais irão exibir propriedades anisotrópicas. Para torná-los isotrópicos, estes materiais deverão ser submetidos a um tratamento para orientar suas cadeias moleculares de forma aleatória (KUSKE; ROBERTSON, 1974). 


\subsubsection{Fluência}

A maioria dos polímeros associados à análise fotoelástica podem apresentar fluência. Mindlin (1949) considerou modelos elásticos e viscoelásticos em sua análise. Ao assumir que o efeito fotoelástico resultava apenas de deformação dos elementos elásticos do modelo, o autor mostrou que a retardação relativa poderia ser representada da mesma forma que na Equação (2.62), onde $f_{\sigma}$ é escrita em função do tempo, e não como constante.

$$
\sigma_{1}-\sigma_{2}=\frac{N}{h} f_{\sigma}(t)
$$

A Equação (2.62) é importante para mostrar que modelos com materiais viscoelásticos podem ser empregados para se fazer análises de tensões elásticas. Devido à natureza viscoelástica do material, as tensões e deformações do valor de franja são dados em função do tempo. Porém, como o intervalo de tempo necessário para fotografar o modelo é pequeno, $f_{\sigma}$ pode ser tratado como se fosse uma constante (MINDLIN, 1949).

Para a maioria dos polímeros, o valor de $f_{\sigma}$ decresce rapidamente com o tempo, imediatamente após o carregamento, tendendo-se a estabilizar após cerca de 30 a 60 minutos (DALLY; RILLEY, 1991). A configuração das franjas é então registrada e o valor da franja do material associado com o tempo da fotografia é usado para a análise (Figura 2.23). 


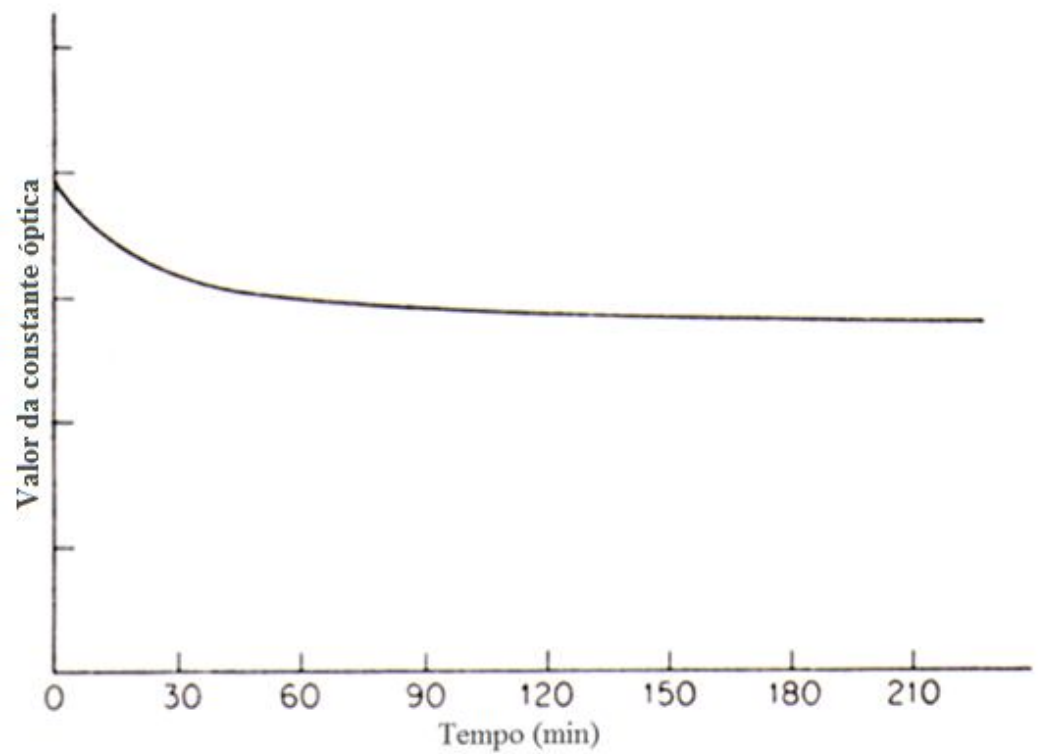

Figura 2.23 - Curva típica de fluência fotoelástica (DALLY; RILEY, 1991 - modificado).

\subsubsection{Módulo de Elasticidade e Limite de Proporcionalidade}

A importância do módulo de elasticidade na escolha do material para a análise fotoelástica se deve à necessidade de controle da distorção resultante do carregamento aplicado. Se as condições de borda se alteram devido à distorção, a solução fotoelástica apresentará erros (DALLY; RILEY, 1991). Um fator que pode ser usado para julgar os diferentes materiais fotoelásticos, considerando sua capacidade de não sofrer distorções é ( $E$ / $\left.f_{\sigma}\right) \times(1+v)$. Quanto maior esse valor, menor será a distorção que o material fotoelástico poderá sofrer.

A tensão no limite de proporcionalidade $\sigma_{p l}$ de um material fotoelástico é importante sob dois aspectos. Primeiro, um material com um alto limite de proporcionalidade pode ser carregado a um alto nível de tensão sem comprometer a integridade do modelo. Segundo, um material com um alto limite de proporcionalidade pode produzir uma alta ordem de padrão de franja, tendendo a melhorar a exatidão do processo de determinação de tensões. O índice de sensibilidade $(S)$ para um material é definido pela seguinte equação: 


$$
S=\frac{\sigma_{p l}}{f_{\sigma}}
$$

A constante $S$ poderá fornecer quantas ordens de franja $N$ poderão ser esperadas para um material com um dado $\sigma_{p l}$.

\subsubsection{Sensibilidade à Temperatura}

O valor de franja $f_{\sigma}$ é sensível à temperatura, e isto pode gerar algum erro no experimento. Para a maioria dos polímeros, a constante óptica $f_{\sigma}$ sofre uma pequena diminuição (Figura 2.24). Essa variação é linear até um determinado valor de temperatura. Para um epóxi comumente utilizado, a alteração de $f_{\sigma}$ é de apenas $0,0022 \mathrm{kN} /\left(\mathrm{m} \times{ }^{\circ} \mathrm{C}\right)$ nessa região linear. No entanto, para temperaturas superiores a $\mathrm{T}_{2}$, o valor de $f_{\sigma}$ cai bruscamente com qualquer acréscimo na temperatura (DALLY; RILEY, 1991). Para estudos fotoelásticos conduzidos à temperatura ambiente, a inclinação da curva na região linear é uma característica importante.

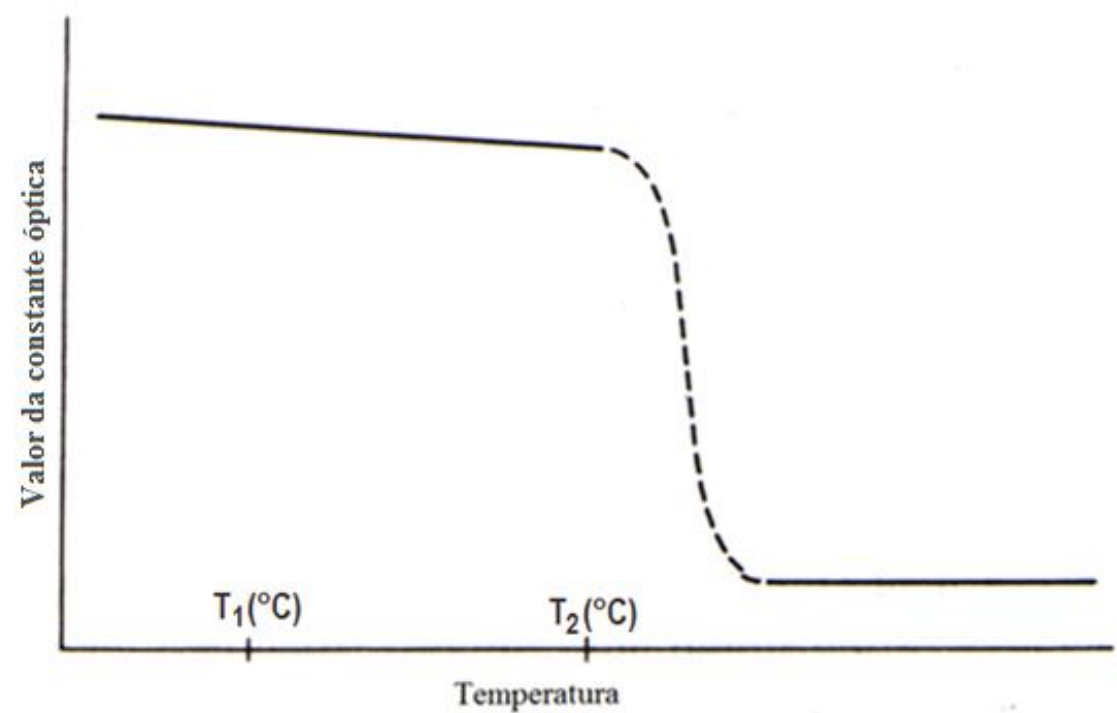

Figura 2.24 - Curva típica da variação da constante óptica com a temperatura (DALLY; RILEY, 1991 modificado). 


\subsubsection{Efeito de Borda pelo Tempo}

Quando um modelo constituído por uma placa de material fotoelástico é examinado sob condição de não-carregamento por um período de tempo, observa-se o surgimento de tensões de borda. Essas tensões produzem uma ou uma série de franjas paralelas à borda do modelo.

De acordo com Kuske e Robertson (1974), esse fenômeno é geralmente devido à evaporação ou absorção de água que causa alteração de volume. Essas variações volumétricas resultam em tensões de tração ou compressão em uma estreita zona próxima às bordas do modelo.

\subsubsection{Efeito da Absorção Óptica}

Os efeitos da absorção óptica devem ser considerados em estudos do campo de tensões quando o meio fotoelástico possui valores de coeficientes de absorção da luz não negligenciáveis. Bhowmik (2002) apresenta resultados de estudos do efeito da absorção óptica em materiais fotoelásticos. Segundo esse autor, os resultados mostrar que o contraste das franjas isoclínicas se apresenta degradado para altos valores de ordem de franjas. No entanto, a influência da absorção óptica na interpretação das franjas para medidas de tensão não tem sido suficientemente investigada.

\subsubsection{Materiais Utilizados em Análises Fotoelásticas}

Apesar de muitos materiais transparentes exibirem bi-refringência, a maioria não apresenta sensibilidade suficiente para a sua aplicação em fotoelasticidade. Alguns dos materiais utilizados na técnica da fotoelasticidade são:

- Bakelite - resina gliptálica que se obtém através da reação da glicerina com anidrido fitálico. É fácil de ser usinada e possui excelentes propriedades ópticas e mecânicas. A 
sua desvantagem está no fato de ser difícil a sua moldagem sem o surgimento de tensões residuais (GOMES, 1984).

- Resina Epóxi - possui elevada sensibilidade óptica, excelentes propriedades mecânicas e são fáceis de a trabalhar (GOMES, 1984).

- Borracha de poliuretano - possui excepcional sensibilidade óptica (cerca de cinqüenta vezes mais sensível que as resinas epóxi) e reduzido módulo de elasticidade. É utilizado para fabricação de modelos demonstrativos e em modelos onde as tensões são provocadas por forças de volume, como em determinados problemas de Mecânica dos Solos (GOMES, 1984).

- Gelatina - é extremamente sensível aos efeitos fotoelásticos. Modelos em gelatina são usados particularmente em casos de análise de tensões de peso próprio e problemas de distribuição de tensões Mecânica dos Solos. O valor de $f_{\sigma}$ é muito variável, dependendo da concentração de glicerina usada na gelatina (HENDRY, 1966).

\subsection{Aplicações da Fotoelasticidade}

Desde o final do século XIX estudos fotoelásticos de análises de tensões e deformações são empregados nas mais variadas áreas de desenvolvimento científico. Algumas áreas de concentração da medicina têm desenvolvido estudos com a utilização da fotoelasticidade (JONES; HUNGERFORD, 1985, GRECULA et al., 2000, MORRIS et al., 2004, FAKHOURI, 2008 e FAKHOURI et al., 2009).

Vários trabalhos na Odontologia têm utilizado a técnica da fotoelasticidade para avaliar tensões induzidas por carregamentos em implantes (ASUNDI; KISHEN, 2000, BERNARDES et al., 2006, DAMACENO, 2007, OLIVEIRA, 2007 e SIMAMOTO JÚNIOR, 2008). 
Estudos de Mecânica da Fratura, Engenharia dos Materiais, Engenharia Mecânica e Engenharia Civil também têm sidos realizados com o auxílio da técnica da fotoelasticidade (CHANDRASHEKHARA; JACOB, 1976, AGARWAL; CHATURVEDI, 1978, SMITH, 1979, JONES; POULOSE; LIEBOWITZ, 1986, PRABHKARAN; SAWYER, 1986, MAHMOUD; HOSSEINI, 1986, EPSTEIN; LLOYD, 1991, MEGUID; GONG, 1993, SHUKLA et al., 2003, KHANA; ELLINGSEN; WINTER, 2004, GUAGLIANO; SANGIRARDI; VERGANI, 2006 e PATTERSON; BRAILLY; TARONI, 2006).

\subsubsection{Análises Fotoelásticas voltadas à Geotecnia}

A maior parte dos problemas de Mecânica dos Solos está relacionada, ao menos indiretamente, com a distribuição de tensões em uma massa de solo ou com o comportamento do solo para um dado carregamento imposto. A distribuição das tensões em um maciço de solo é difícil de ser determinada. Quando o método fotoelástico foi introduzido para a análise de tensões em outros problemas, a sua aplicação em problemas de Mecânica dos Solos foi rapidamente assimilada.

Um problema de interação solo-estrutura bem conhecido e estudado é a determinação de tensões de contato de uma placa carregada sobre um maciço de solo. Müller (1996) realizou uma série de testes em um modelo fotoelástico de placa rígida de fundação assente sobre areia. Esses ensaios objetivaram determinar as tensões de contato sob a fundação. Os modelos testados foram carregados com diferentes níveis de carga, tanto centralizados como excêntricos. Esse autor verificou que a distribuição das tensões no contato apresenta formato de um sino invertido. Entretanto, para altos níveis de carregamento, ocorre o surgimento tensões na borda da placa, diferentemente de valores nulos que são comumente considerados.

Utilizando a técnica da fotoelasticidade tridimensional, Durelli, Parks e Norgards (1973) analisaram a distribuição de tensões em um meio contínuo, elástico e linear que 
suporta uma placa circular carregada no seu centro. O deslocamento radial e axial da superfície de contato também foi avaliado. Esses autores também realizaram comparações dos resultados obtidos com soluções teóricas.

O material usado para o modelo de fundação era um composto epóxi preparado especialmente para esse fim. A placa foi feita de outra resina epóxi, Hysol 4290, e tratada em todas as superfícies. Segundo os autores, a combinação particular de resinas epóxi utilizada na análise tornou o método fotoelástico facilmente aplicável para a solução de muitos problemas de fundações.

Chandrashekhara e Antony (1993) realizaram uma investigação teórica e experimental relacionada a problemas de interação solo-estrutura em meios estratificados. Uma estrutura com formato quadrado foi moldada com material fotoelástico representando uma viga de fundação (Figura 2.25). Essa estrutura foi apoiada sobre o meio estratificado, também preparado com material fotoelástico, suportada por um molde rígido. Os resultados experimentais, obtidos com a técnica da fotoelasticidade de transmissão plana, foram comparados com uma solução analítica de um meio semi-infinito estratificado e com os resultados de uma análise pelo método dos elementos finitos. O material fotoelástico utilizado no molde rígido foi um composto de Araldite CY230 e endurecedor HY951, enquanto que o maciço estratificado foi feito de Araldite AY103 com diferentes porcentagens de endurecedor fabricado por CIBA-GEIGY (Índia) Ltd. Segundo esses autores, os resultados experimentais se ajustaram bem aos resultados analíticos, permitindo tal problema de interação soloestrutura ser efetivamente resolvido pela técnica da fotoelasticidade. 


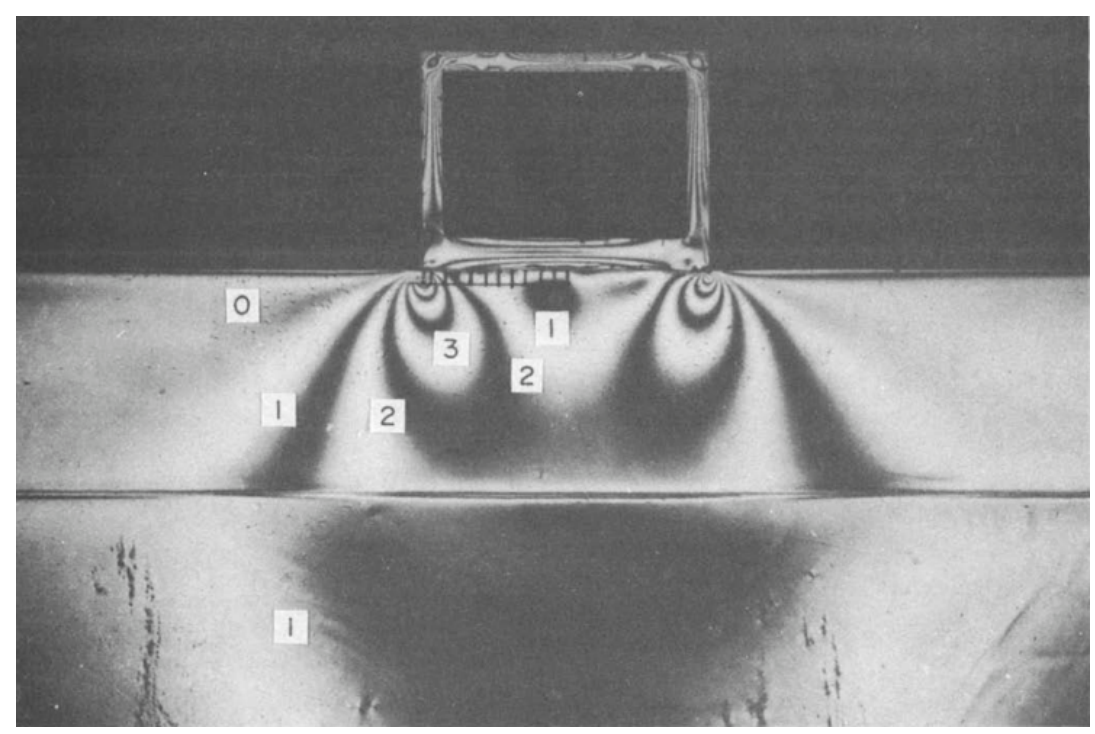

Figura 2.25 - Estrutura sobre duas camadas elásticas (CHANDRASHEKHARA; ANTONY, 1993).

Chandrashekhara e Antony (1996) apresentaram uma proposta para a solução do problema de interação de sapatas apoiadas em (i) meios elásticos não homogêneos e (ii) camadas elásticas não homogêneas apoiadas em um estrato rígido. A solução é apresentada para um estado plano de tensões. As análises foram realizadas com a utilização do MEF e métodos analíticos para minimizar os esforços computacionais. Para validar as soluções numéricas e analíticas, foram realizadas análises experimentais por meio da técnica da fotoelasticidade. Os experimentos foram realizados em um modelo de sapata apoiada em maciço elástico estratificado cujo módulo de elasticidade aumenta com a profundidade. As pressões de contato obtidas experimentalmente foram então comparadas com os resultados numéricos, mostrando uma boa compatibilidade entre as análises.

Ashford e Sitar (2001) avaliaram a exatidão dos resultados obtidos através do método dos elementos finitos $(\mathrm{MEF})$ para a distribuição de tensões próximas à superfície de taludes verticais. Afim de comparar os resultados obtidos com o MEF, foram realizadas análises fotoelásticas com a utilização da gelatina como material fotoelástico. Os resultados indicaram boa compatibilidade entre tensões de cisalhamento determinadas por meio da modelagem 
experimental (gelatina) e numérica (MEF). Observou-se também e uma boa compatibilidade global entre as tensões principais determinadas experimental e numericamente.

$\mathrm{Na}$ Mecânica das Rochas, a avaliação da resistência ao cisalhamento de descontinuidades encontra-se satisfatoriamente resolvida. No entanto, ainda permanece um relativo grau de incerteza na estimativa da área real de contato e seu efeito na variação da distriubição e concentração de tensões. Fleury e Assis (2002) procuraram avaliar como a fotoelasticidade poderia ser utilizada na análise do efeito da rugosidade em descontinuidades rochosas. Os modelos foram fabricados artificialmente em resina epóxi e submetidos a ensaios de cisalhamento direto. Como conclusão, esses autores afirmam que a técnica da fotoelasticidade pode ser utilizada como ferramente para auxílio na avaliação dos efeitos da rugosidade em descontinuidades rochosas.

A utilização de materiais fotoelásticos granulares encontra aplicação direta em problemas geotécnicos. Dijkstra, Broere e van Tol (2006) apresentaram um estudo da penetração de uma ponta em forma de cunha em um material fotoelástico granular composto por partículas de vidro. De acordo com esses autores, a utilização deste material permitiu a determinação das tensões, no material fotoelástico, na região próxima à ponta da cunha que penetrou entre as partículas de vidro. Sympadian (1970), Rossmanith e Shukla (1982) e Alersma (1988) também utilizaram materiais granulares em análises experimentais por meio da técnica da fotoelasticidade.

\subsubsection{Utilização da gelatina como material fotoelástico}

Modelos de gelatina têm sido utilizados em estudos fotoelásticos de problemas de distribuição de tensão em Mecânica dos Solos, como por exemplo, na investigação da distribuição de tensões em aterros e em fundações de barragens de gravidade. Embora existam diferenças óbvias entre solo e gelatina, as informações obtidas de experimentos fotoelásticos 
têm sido muito úteis e têm colaborado para o estudo do comportamento das massas de solos (FARQUHARSON; HENNES, 1940). Por ser a gelatina um material coesivo e de módulo de elasticidade constante, os estudos fotoelásticos com esse material podem ser usados para solucionar problemas relacionados com solos argilosos coesivos de comportamento elástico linear.

O material é obtido dissolvendo-se gelatina em água à temperatura entre 50 e $60^{\circ} \mathrm{C}$. Para evitar a rápida evaporação da água da superfície, adiciona-se glicerina à mistura. Uma composição típica da mistura é 15\% gelatina, $25 \%$ glicerina e $60 \%$ água (KUSKE; ROBERTSON, 1974). Segundo estes autores, o módulo de elasticidade dessa mistura é aproximadamente $10^{5} \mathrm{~N} / \mathrm{m}^{2}$. O valor da constante óptica $f_{\sigma}$ obtida com luz verde $(\lambda=5461 \AA)$ foi igual a $90 \mathrm{~N} / \mathrm{m}$.

Segundo Frocht (1941), para uma mistura de 13\% de gelatina e sem adição de glicerina, obtém-se um valor do módulo de elasticidade de aproximadamente $41 \times 10^{3} \mathrm{~N} / \mathrm{m}^{2}$. De acordo com o mesmo autor, quando se utiliza a luz verde, é obtém-se uma constante óptica $f_{\sigma}$ igual a $12,25 \mathrm{~N} / \mathrm{m}$.

As propriedades mecânicas e ópticas do material dependem da composição da gelatina. Segundo Farquharson e Hennes (1940), o módulo de elasticidade cresce e a constante óptica do material diminui quando aumenta-se o conteúdo de gelatina (Figura 2.26 e Figura 2.27). 


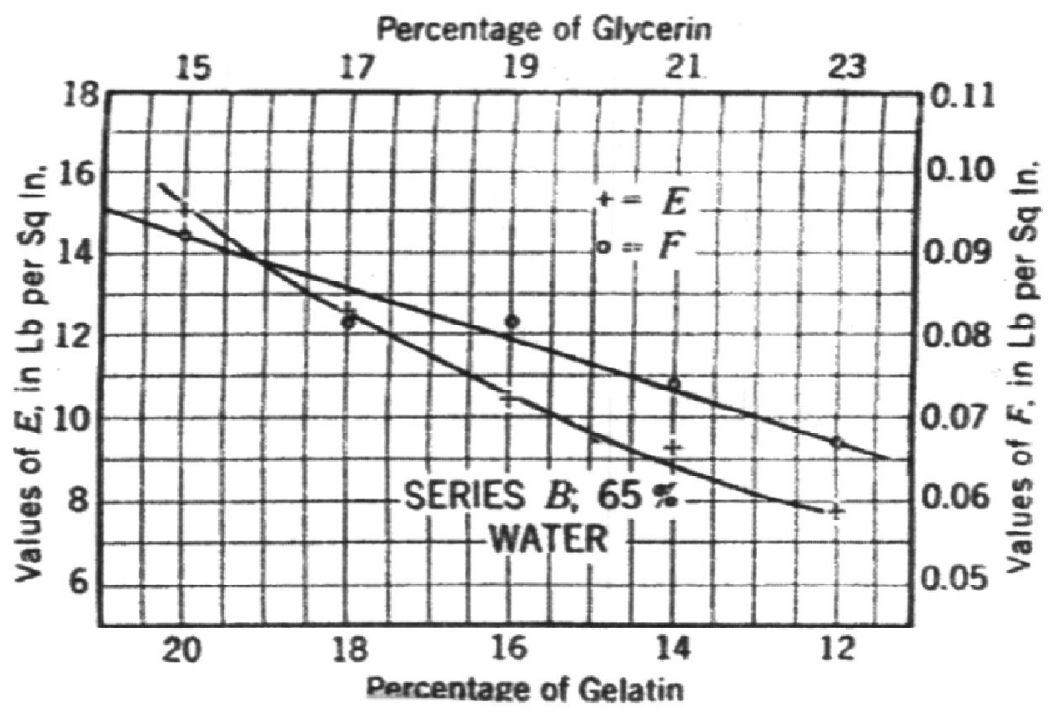

Figura 2.26 - Variação do módulo de elasticidade e da constante óptica com 65\% de água (FARQUHARSON;

HENNES, 1940).

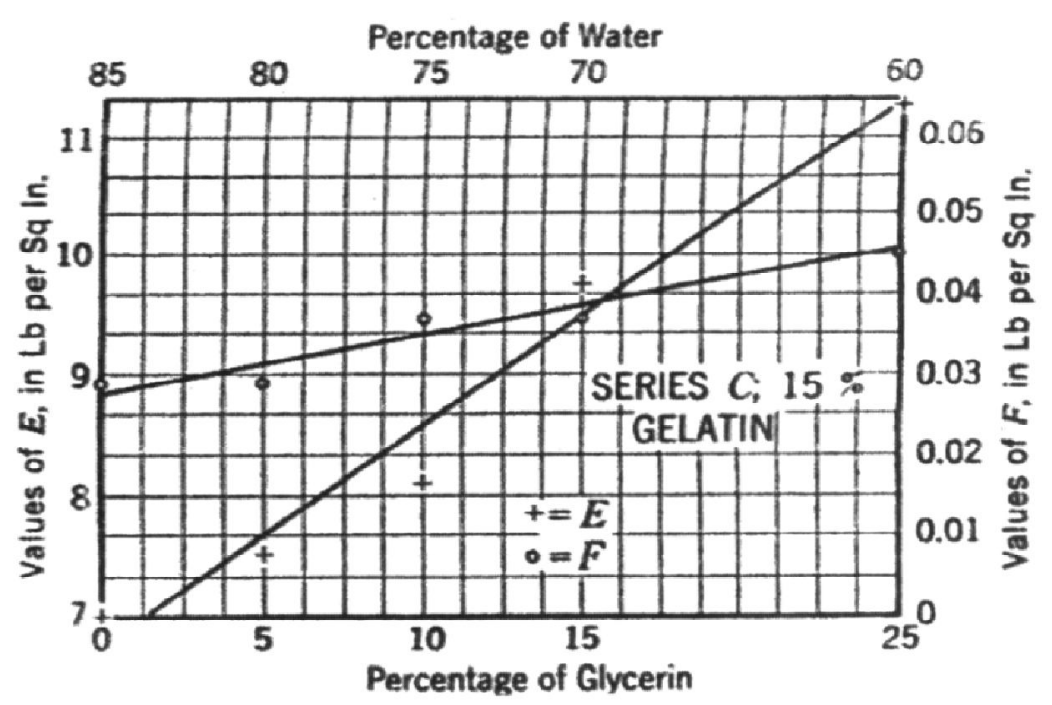

Figura 2.27 - Variação do módulo de elasticidade e da constante óptica com 15\% de gelatina (FARQUHARSON; HENNES, 1940).

Hendry (1966) propõe, para misturas com 13\% em peso de gelatina, o valor da constante óptica $f_{\sigma}=0,15 \mathrm{lb} / \mathrm{in}^{2}\left(1034,21 \mathrm{~N} / \mathrm{m}^{2}\right)$ em modelos com 1 in $(0,0254 \mathrm{~m})$ de 
espessura. Isso resultará num valor de $f_{\sigma}=26,27 \mathrm{~N} / \mathrm{m}$. Esse mesmo autor afirma que para a referida mistura, o módulo de elasticidade $E$ será igual a 41,39kPa.

Um dos primeiros estudos de análises de tensões em solos utilizando-se gelatina foi realizado em 1937 para o estudo de um projeto de barragem pelo Prof. F. C. Smith da Universidade de Washington. Em 1938, na Universidade de Washington, foram realizados estudos fotoelásticos com gelatina para analisar as tensões ao redor de um túnel, e os resultados obtidos foram satisfatórios (FARQUHARSON; HENNES, 1940).

Philippe e Mellinger (1948) realizaram um estudo de tensões no solo ao redor de uma sapata, utilizando um modelo fotoelástico com gelatina que representava o maciço de solo. $\mathrm{Na}$ Figura 2.28, as franjas isocromáticas, obtidas utilizando fonte de luz monocromática, representam o lugar geométrico de igual tensão cisalhante máxima.

Para analisar e comparar os resultados de ensaios fotoelásticos com previsões analíticas do comportamento de estruturas de gravidade, Richards Jr. e Mark (1966) utilizaram a gelatina como material fotoelástico. Segundo esses autores, há muito se conhece o potencial da gelatina, mas raramente é utilizada. $\mathrm{O}$ trabalho descreve uma série de ensaios fotoelásticos, mostrando a distribuição de tensões em modelos de estruturas de contenção com o solo representado pela gelatina.

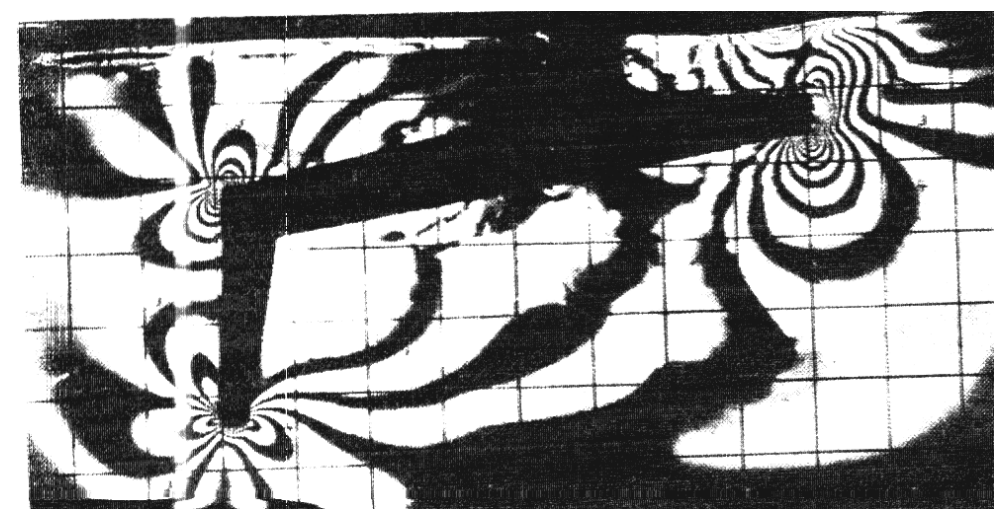

Figura 2.28 - Isocromáticas em um modelo de fundação por sapata (PHILIPPE; MELLINGER, 1948). 
Burki e Richards (1975) analisaram as tensões em solos junto a estruturas de contenção, utilizando a técnica de fotoelasticidade, com modelos em gelatina. O módulo de elasticidade da gelatina utilizada foi de $34 \times 10^{3} \mathrm{~N} / \mathrm{m}^{2}$ e a constante óptica obtida foi igual a 143,60 N/m. Na Figura 2.29 têm-se as isocromáticas obtidas neste estudo. A Figura 2.30 apresenta o desenho das isocromáticas feito a partir da foto da Figura 2.29.

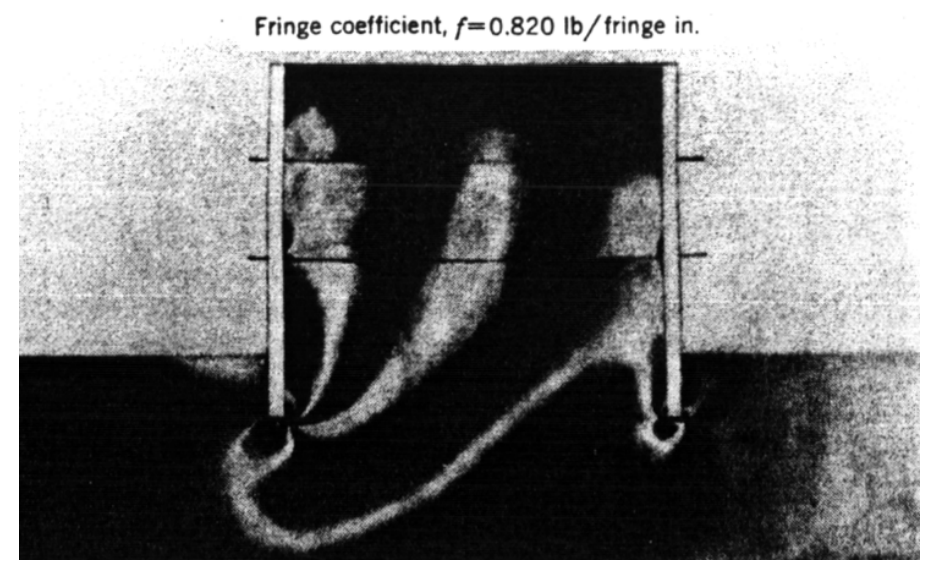

Figura 2.29 - Isocromáticas em um modelo de estrutura de contenção (BURKI; RICHARDS, 1975).

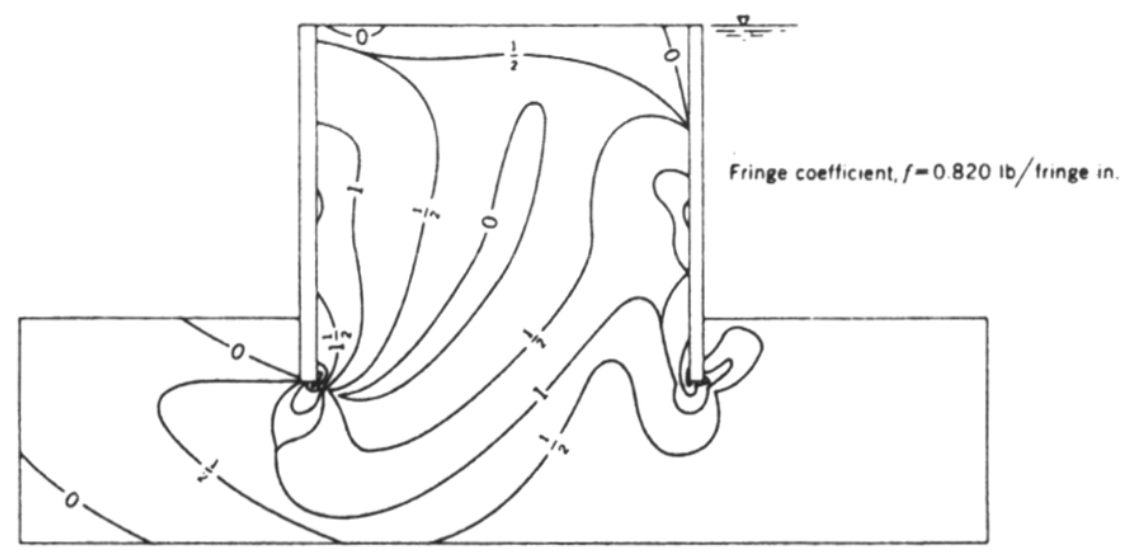

Figura 2.30 - Contorno das isocromáticas (BURKI; RICHARDS, 1975).

Richter, Demars e Richard Jr. (1984) estudaram a ocorrência de deslizamento na interface entre o meio fotoelástico, representado pela gelatina, e uma estaca rígida. A análise fotoelástica empregou o método de congelamento de tensões para analisar tridimensionalmente o estado de tensões imposto no meio ao carregar a estaca 
transversalmente. Os resultados mostraram que uma porção significativa do carregamento lateral é transferida ao meio circundante por tensões de cisalhamento horizontais ao longo da lateral da estaca quando existe adesão na interface.

\subsection{Estacas Helicoidais}

As estacas helicoidais são constituídas de uma haste central de seção transversal circular (Figura 2.31a) ou quadrada (Figura 2.31b), com uma ou mais placas de metal em forma de hélice soldadas nesta haste (PRASAD; RAO, 1996). Tais hélices podem apresentar o mesmo diâmetro ou aumentar o diâmetro conforme se aproxima da superfície do terreno. $\mathrm{O}$ lado da seção transversal quadrada varia de 40 a $50 \mathrm{~mm}$, enquanto que o diâmetro da seção transversal circular comumente varia entre 70 a $320 \mathrm{~mm}$, chegando a casos relatados de até 915 mm (SCHMIDT; NASR, 2004). O diâmetro das lâminas pode variar de 2 a 4 vezes o diâmetro da haste (KURIAN; SHAH, 2009). O número de placas helicoidais de uma estaca depende das condições do solo e da capacidade de carga requerida.

(a)

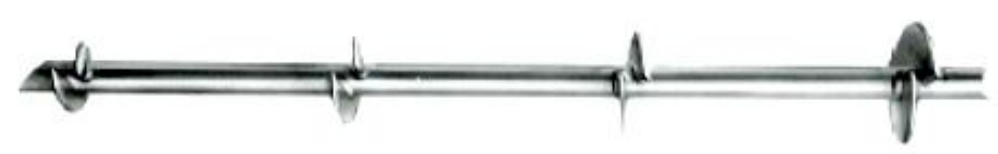

(b)

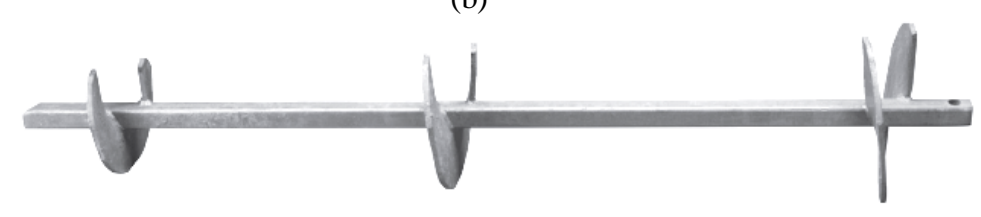

Figura 2.31 - Estaca helicoidal com fuste de seção transversal (a) circular e (b) quadrada (A.B. CHANCE CO, 2010).

De acordo com Clemence et al. (1994), as estacas metálicas helicoidais são instaladas no solo por meio da aplicação de torque rotacional no sentido horário. Na maioria dos casos esse torque é aplicado por sistema de motor hidráulico de trados mecânicos. O torque é aplicado à haste central por meio de um dispositivo de acoplamento, e as hélices são 
rotacionadas para dentro do terreno. Inicialmente é empregada uma pequena força para baixo para auxiliar a penetração da estaca no solo. A taxa de avanço é igual ao passo da hélice em cada revolução completa. A haste é prolongada emendando-se extensões com a extremidade alargada para o encaixe e aparafusamento. A estaca é rotacionada no terreno até encontrar uma cota com a resistência procurada.

As ancoragens são sistemas de fundação primeiramente desenvolvidos para resistir cargas de tração (KULHAWY, 1985). Recentemente, há uma tendência de crescimento no uso de estacas helicoidais para oferecer resistência à compressão (LI, 2006). No Brasil, as estacas helicoidais tem sido aplicadas quase que unicamente em torres de transmissão de energia elétrica e de telecomunicações cujas fundações resistem a esforços ora de tração, ora de compressão (TSUHA, 2007).

Em países como os EUA e Canadá, as estacas helicoidais são usadas extensivamente em edificações residenciais, comerciais e instalações industriais (CLEMENCE, 1985). Uma resenha histórica do desenvolvimento e aplicação deste tipo de fundação foi feita por Tsuha (2007).

O uso de estacas helicoidais oferece certas vantagens. Dentre elas, a adequação à construção em locais de difícil acesso, instalação abaixo do nível do lençol freático e alta capacidade de carga, tanto em compressão como em tração. Outra vantagem consiste na possibilidade da adição de novas hélices à composição para superação de imprevistos quando a capacidade de carga prevista não é alcançada. Muitas vezes, este imprevisto é devido à variabilidade, não detectada durante as investigações, dos materiais do terreno . Segundo Sakr (2009), a capacidade de carga desta fundação pode ser de 3 a 5 vezes maior do que a das tradicionais estacas de aço cravadas com o mesmo diâmetro do fuste e comprimento.

Ênfase tem sido dada ao estudo do mecanismo de ruptura em ancoragens em placa, e fundações por estacas helicoidais (tração e compressão do fuste). Meyerhof e Adams (1968) 
apresentaram uma proposta para se estimar a capacidade de carga à tração de ancoragens com placas horizontais circulares e quadradas em solos granulares. Nesta proposta, o comportamento do sistema é avaliado em termos de resistência última, que por sua vez é função da profundidade de instalação da placa.

Vesic (1965) admite que, na condição de carregamento último de uma ancoragem em placa circular, a superfície de ruptura em um solo granular se desenvolva segundo a teoria de expansão de cavidades. Desta forma, a capacidade de carga também dependerá da profundidade de instalação da placa.

Usando a analogia da expansão de cavidades, Vesic (1971) propõe uma estimativa da capacidade de carga de uma ancoragem em placa circular instalada em solo argiloso em carregamento na condição não-drenada. O autor apresenta uma variação teórica do fator de capacidade de carga $F_{c}$ em função da profundidade relativa de instalação da placa.

O comportamento de ancoragens por estacas helicoidais e ancoragens planas na ruptura pode ser classificado em comportamento de ancoragem rasa ou profunda. Na situação de carregamento último, a ancoragem será rasa quando a profundidade de instalação da estaca permita que a superfície de ruptura que se forma no solo atinja a superfície do terreno (Figura 2.32a e b). Se a profundidade de instalação da hélice é tal que a superfície de ruptura não se prolongue até a superfície do terreno, a ancoragem terá comportamento de ancoragem profunda (Figura 2.32c). Para que seja possível estimar a capacidade de carga de uma ancoragem, deverá ser adotado um critério que defina tal comportamento em função da profundidade. 


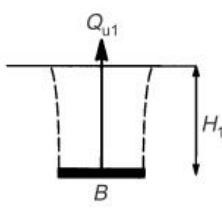

(a)

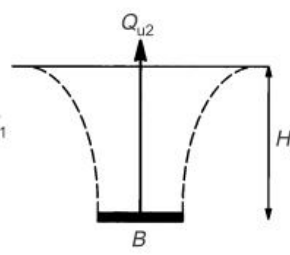

(b)

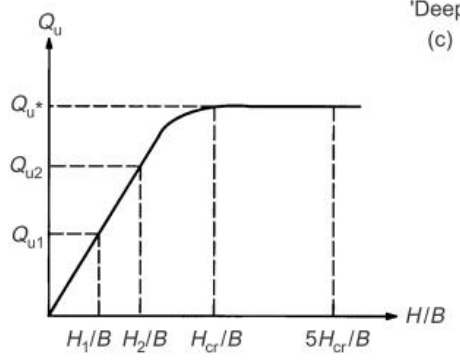

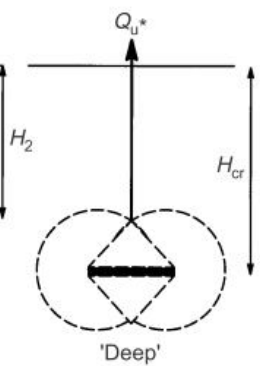

Figura 2.32 - Comportamento de ancoragens (MERIFIELD; SLOAN; YU, 2001).

No caso de ancoragens por placa isoladas instaladas em solos coesivos, há uma profundidade crítica $H_{c r}$ a partir da qual a zona de ruptura não se prolonga até a superfície do terreno. A zona de ruptura se concentrará ao redor da ancoragem. Quando isso ocorre, tanto para ancoragens com uma ou múltiplas placas (Figura 2.33), a capacidade de carga última do sistema terá alcançado seu valor máximo $Q_{u}^{*}$ (o asterisco denota a capacidade de carga em ancoragem profunda).Fisicamente, isso ocorre pois assume-se que a resistência ao cisalhamento não-drenada seja independente do confinamento. Do ponto de vista prático, este resultado é importante porque a instalação da ancoragem além de $H_{c r}$ não levará a um aumento sensível na capacidade de carga do sistema (MERIFIELD; SMITH, 2010). 


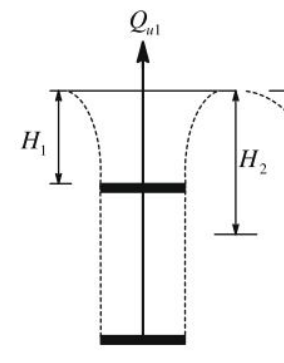

(a)

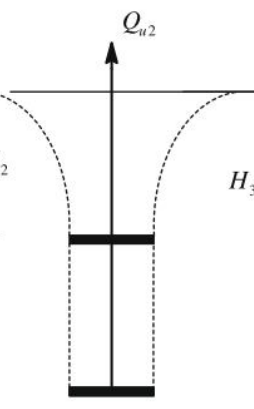

(b)

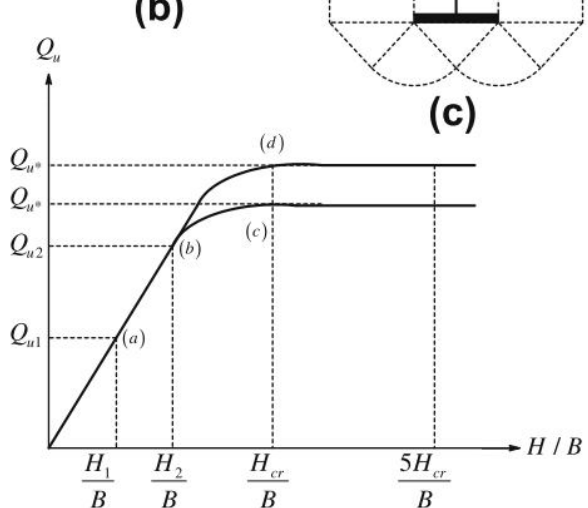

Figura 2.33 - Comportamento de ancoragens multi-placas (MERIFIELD; SMITH, 2010).

Das e Seeley (1975) realizaram ensaios em laboratório com placas retangulares rasas afim de verificar a influência dos fatores de capacidade de carga e profundidade crítica. Posteriormente, Das (1978), através dos resultados de ensaios em ancoragens quadradas e retangulares, propôs um critério de profundidade relativa crítica $(H / D)_{c r}$. Este critério representa o limite entre os comportamentos de ancoragem rasa ou profunda por placa em solos coesivos:

$$
\left(\frac{H}{D}\right)_{c r}=0,107 S_{u}+2,7 \leq 7
$$

onde, $H$ é a profundidade enterrada da placa, $D$ é o raio ou o lado menor da placa e $S_{u}$ é a resistência não drenada do solo dada em $\mathrm{kPa}$.

Segundo Das (1980), a mesma expressão proposta para ancoragens em placa pode ser aplicada como critério de profundidade crítica para estacas helicoidais, com a nomenclatura $\operatorname{de}\left(\mathrm{H} / \mathrm{D}_{1}\right)_{\mathrm{cr}}$ : 


$$
\left(\frac{H}{D_{1}}\right)_{c r}=0,107 S_{u}+2,7 \leq 7
$$

onde, $D_{l}$ é o diâmetro da lâmina menor em estacas com mais de uma lâmina.

Rowe e Davis (1982) realizaram estudos teóricos do comportamento na ruptura de ancoragens por placas. Estes estudos foram comparados com análises numéricas e dados obtidos com ensaios de campo. De acordo com os autores, houve uma concordância encorajadora entre os resultados das diversas formas de análise dos casos estudados. Com os resultados teóricos, foram apresentadas cartas a serem utilizadas em estimativas de ancoragem com uma ampla gama de tipos de solos e geometrias da ancoragem.

Merifield et al. (2003) realizaram análises numéricas, baseadas no método do equilíbrio limite, para avaliar o efeito da geometria da ancoragem sobre a capacidade de carga em argila não-drenada. Como resultado, os autores apresentam fatores de forma baseados em diferentes geometrias e profundidades, propondo uma aproximação sistemática para projetos de ancoragens.

No caso das estacas helicoidais com hélices de diferentes tamanhos, Mooney, Adamczak e Clemence (1985) mostraram que o tipo de ruptura depende também da razão de profundidade $H_{1} / D_{1}$, onde $H_{1}$ é a profundidade da hélice maior, mais próxima à superfície, e $D_{l}$ é o diâmetro dessa hélice. Portanto, se $H_{l} / D_{l}$ é relativamente grande, a superfície de ruptura no solo sobre a hélice superior não se prolonga até a superfície do terreno. Essa superfície de ruptura em solo coesivo é mostrada na Figura 2.34.

A capacidade de carga última da ancoragem helicoidal $Q_{u}$ pode ser dada pela soma:

$$
\begin{aligned}
& Q_{u}=Q_{p}+Q_{c}+Q_{s h}+Q_{f} \text { (siltes) } \\
& Q_{u}=Q_{p}+Q_{c}+Q_{s h} \text { (argilas) }
\end{aligned}
$$

onde,

$Q_{p}=$ capacidade de carga da hélice do topo; 
$Q_{c}=$ resistência ao longo da superfície de ruptura, admitida cilíndrica;

$Q_{s h}=$ resistência de fuste;

$Q_{f}=$ resistência do solo na superfície cilíndrica de ruptura.

Em solos coesivos e com ângulo de atrito interno (siltes, por exemplo) a capacidade de carga do sistema pode ser dada como proposto por:

$$
\begin{aligned}
& Q_{u}=\gamma^{\prime} H_{1} A_{1} N_{q u}+A_{1} c_{u} N_{c u}+\frac{\pi}{2} D_{a} \gamma^{\prime}\left(H_{n}^{2}-H_{1}^{2}\right) K_{u} \tan \phi^{\prime}+ \\
& +\pi D_{a} c_{u}\left(H_{n}-H_{1}\right)+P_{S} H_{1} \frac{\gamma^{\prime}}{2} H_{1} K_{u} \tan \phi^{\prime}+P_{S} H_{1} C_{a}
\end{aligned}
$$

Admitindo uma condição não-drenada com $\phi^{\prime}=0$ tem-se:

$$
Q_{u}=A_{1} c_{u} N_{c u}+\pi D_{a} c_{u}\left(H_{n}-H_{1}\right)+P_{S} H_{1} C_{a}
$$

onde,

$\gamma^{\prime}=$ peso específico efetivo do solo;

$\phi^{\prime}=$ ângulo de atrito efetivo do solo;

$H_{l}=$ profundidade da hélice do topo do conjunto da ancoragem;

$A_{l}=$ área da hélice do topo do conjunto.

$N_{q u}=$ fator de capacidade de carga no arrancamento para solos não coesivos;

$c_{u}=$ coesão;

$N_{c u}=$ fator de capacidade de carga no arrancamento para solos coesivos;

$D_{a}=$ diâmetro médio das hélices;

$H_{n}=$ profundidade da hélice da ponta do conjunto;

$K_{u}=$ coeficiente de empuxo do solo no arrancamento (solos não coesivos);

$P_{S}=$ perímetro do fuste da ancoragem;

$c_{a}=$ adesão no fuste da ancoragem, que varia de $0,3 c_{\mathrm{u}}$ a $0,9 \mathrm{c}_{\mathrm{u}}$; 


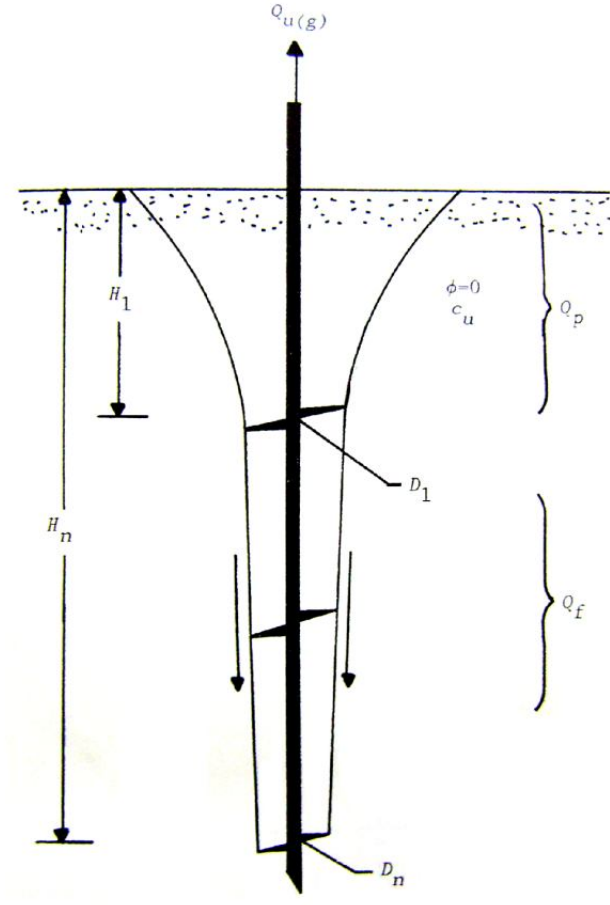

(a)

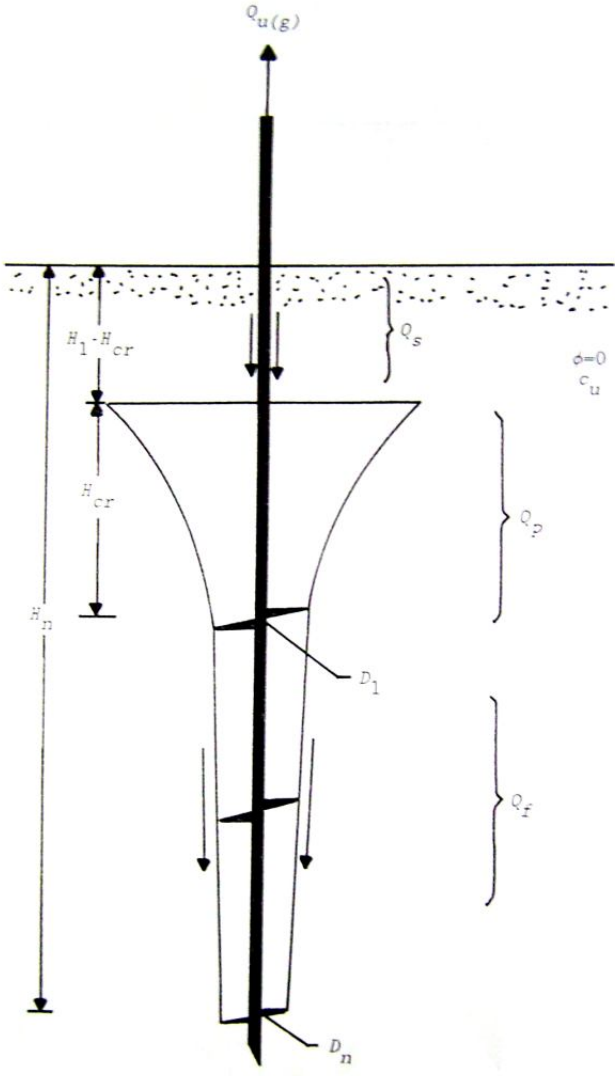

(b)

Figura 2.34 - Superfície de ruptura idealizada à carga última $Q_{u(g)}$ em (a) ancoragem rasa (b) profunda em solo coesivo (DAS, 1990).

De acordo com Hoyt e Clemence (1989), os métodos mais utilizados para previsão da capacidade de carga à tração de fundações por estacas helicoidais multi-hélices são baseados no método de ruptura do cilindro e no método das capacidades de carga individuais. No primeiro método, a resistência à tração do sistema depende da resistência ao cisalhamento de um cilindro formado entre as hélices da ponta e do topo. No segundo método, é admitido que a ruptura ocorra acima de cada hélice isoladamente, e a resistência à tração do sistema seja a soma das capacidades de carga individuais. Naquele trabalho, os autores concluem que ambos os métodos produzem resultados similares na estimativa da capacidade de carga de uma ancoragem multi-hélices cujo espaçamento inter-hélice seja usual. 
Rao, Prasad e Shetty (1991) estudaram o comportamento de fundações por estacas helicoidais em solos coesivos por meio de curvas carga-recalque. Segundo os autores, a diminuição do teor de umidade do solo leva a um aumento significativo da capacidade de carga. Adicionalmente, com base nos resultados obtidos, esses autores relatam que, em fundações por estacas helicoidais em solos coesivos, é possível realizar previsões da capacidade de carga utilizando a resistência não drenada medida.

Para levar em consideração o efeito da desestruturação do solo no momento da instalação, Weech (2002) propôs um "índice de desestruturação do solo". Afim de relacionar com a resistência do solo no seu estado intacto e num estado de solo completamente desestruturado, este índice relaciona a taxa de resistência não drenada mobilizada com as tensões verticais efetivas in situ no início do carregamento.

Livneh e Naggar (2008) compararam os resultados de 19 provas de carga em diferentes solos com os resultados de modelagem numérica pelo método dos elementos finitos (MEF). Foi utilizado um fator de torque $K_{T}$ para relacionar a capacidade de carga com o torque de instalação, apresentando um bom ajuste. Naquele trabalho, conseguiu-se uma boa compatibilidade entre os resultados de modelagem numérica e os resultados experimentais. No entanto, segundo esses autores, a capacidade de carga à tração se desenvolveu de maneira um pouco diferente da proposta de Mitsch e Clemence (1985) para solos arenosos. Já em cargas de compressão, o comportamento da curva carga-recalque permitiu confirmar a aplicabilidade deste tipo de fundação para carregamentos de compressão axial.

Segundo Mitsch e Clemence (1985), a superfície de ruptura ocasionada pelo arrancamento de uma estaca helicoidal em um solo arenoso é composta por duas superfícies. Acima da hélice superior, a superfície de ruptura tem formato cônico, cujo ângulo é proporcional ao ângulo de atrito do solo. Abaixo daquela hélice, a superfície de ruptura é aproximadamente cilíndrica. Isso significa que o solo entre as hélices se comporta de modo 
similar ao de uma estaca, com o cisalhamento ocorrendo ao longo da superfície da interface cilindro-solo.

Tappenden, Sego e Robertson (2009) realizaram provas de carga em estacas helicoidais multi-hélice executadas em depósitos de argila glácio-lacustre e areias eólicas. Os ensaios foram instrumentados com medidores de deformação (strain gages) para determinar o comportamento do diagrama de transferência da carga do elemento de fundação para o solo. Segundo os autores, os valores medidos mostraram discrepâncias com o método de ruptura do cilindro usado para a previsão do comportamento. Como conclusão, esses autores sugerem que é necessário um novo modelo de ruptura que contemple a maior contribuição da hélice inferior em relação às demais hélices.

Kurian e Shah (2009) realizaram um estudo paramétrico, com a utilização do MEF, das principais características geométricas da estaca helicoidal. Todavia, quase na totalidade dos casos, o processamento de modelos numéricosrefinados torna a análise inviável. A modelagem considerou um solo de comportamento elástico e não-linear e outro, elastoplástico que segue o modelo constitutivo de Drucker-Prager. Segundo os próprios autores, aquela talvez seria a primeira tentativa de realizar este tipo de análise numérica com estacas helicoidais. Os resultados foram apresentados em forma de curvas carga-recalque nas condições de carregamento de compressão, tração e transversal.

O carregamento lateral em estacas helicoidais atualmente também tem sido objeto de estudos. Prasad e Rao (1996) estudaram o comportamento na ruptura de fundações por estacas helicoidais sob carregamento lateral. Os modelos experimentais foram executados em solos argilosos, revelando que nessas fundações, a resistência lateral é maior do que nas fundações com estacas sem hélices no fuste.

Sakr (2009B) apresenta os resultados de uma campanha de provas de carga em estacas helicoidais instaladas em areia. Os resultados foram comparados com modelo teórico 
proposto por Reese et al. (1974) que estima a resistência lateral por meio de curvas $\mathrm{p}-\mathrm{y}^{3}$. Baseado nos resultados, Sakr (2009B) considera que as estacas helicoidais podem desenvolver considerável resistência lateral, e que essa resistência é quase que exclusivamente controlada pelo diâmetro do fuste.

A grande maioria dos estudos acerca do comportamento de fundações e/ou ancoragens por estacas helicoidais é focada no mecanismo de ruptura do sistema. No entanto não se tem relato de estudos sobre o mecanismo de distribuição de tensões no solo na situação de carga de trabalho. Tal mecanismo é controlado pela interação que ocorre entre a estaca helicoidal e o meio no qual ela está inserida. O estudo da interação que ocorre em fundações por estacas helicoidais é importante para determinar o real comportamento deste sistema, contribuindo para a utilização deste tipo de fundação.

\footnotetext{
${ }^{3}$ Curvas da deformação lateral do solo em função da força (por unidade de comprimento) transferida pela estaca ao longo da profundidade (Gabr et al., 2002). De acordo com Mattlock (1970), a análise de carregamento lateral é um complexo sistema de interação solo-estrutura que é reduzido a curvas p-y. O comportamento da curva p-y é função de muitos fatores: variação das propriedades do solo ao longo da profundidade, deformação da estaca, estado de tensão do solo na zona afetada, história de tensões do solo, etc.
} 


\section{MATERIAIS E MÉTODOS}

Neste capítulo é apresentada a descrição dos materiais e dos métodos utilizados na pesquisa realizada. As análises experimentais desta pesquisa foram desenvolvidas no Departamento de Geotecnia da Escola de Engenharia de São Carlos (EESC) - USP.

\subsection{Materiais}

Um material à base de gelatina e glicerina foi escolhido como material fotoelástico para representar um meio de comportamento elástico-linear coesivo. Esse material foi escolhido por ser um material coesivo e apresentar sensibilidade óptica adequada aos níveis de carregamentos aplicados. Além do mais, tem baixo custo e é simples de preparar e moldar. Vários estudos geotécnicos já utilizaram a gelatina como material fotoelástico, mostrando a eficácia deste material (FARQUHARSON; HENNES, 1940; PHILIPPE; MELLINGER, 1948; RICHARDS JR; MARKS 1966; RICHTER; DEMARS; RICHARDS JR., 1984)

Segundo Farquharson e Hennes (1940), Frocht (1941), Hendry (1966) e Kuske e Robertson (1974), a gelatina apresenta comportamento elástico-linear e limite de proporcionalidade entre tensão e deformação adequados para os níveis de tensão aplicados em estudos fotoelásticos com este material. O material fotoelástico utilizado foi preparado por uma mistura, em peso, de $60 \%$ de água, $25 \%$ de glicerina pura e $15 \%$ de gelatina alimentícia incolor e sem sabor (Figura 3.1). O preparo é realizado com a adição da gelatina à água fria. Após a adição, a mistura é aquecida em banho-maria ${ }^{4}$ até a uma temperatura entre 50 e $60^{\circ} \mathrm{C}$. Para evitar a formação de grumos, a mistura foi deixada em repouso por no mínimo 10 minutos antes do aquecimento. Ao alcançar uma temperatura de 50 ou $60^{\circ} \mathrm{C}$, a glicerina é

\footnotetext{
${ }^{4}$ Método utilizado tanto na cozinha como em laboratórios químicos e na indústria para aquecer lenta e uniformemente qualquer substância líquida ou sólida num recipiente, submergindo-o noutro, onde existe água a ferver ou quase.
} 
adicionada, homogeneizando-se a mistura sem levá-la ao fogo novamente. Como o processo de preparo aprisiona ar, deve-se então levar a mistura para uma câmara de vácuo durante 5 a 10 minutos (Figura 3.2).

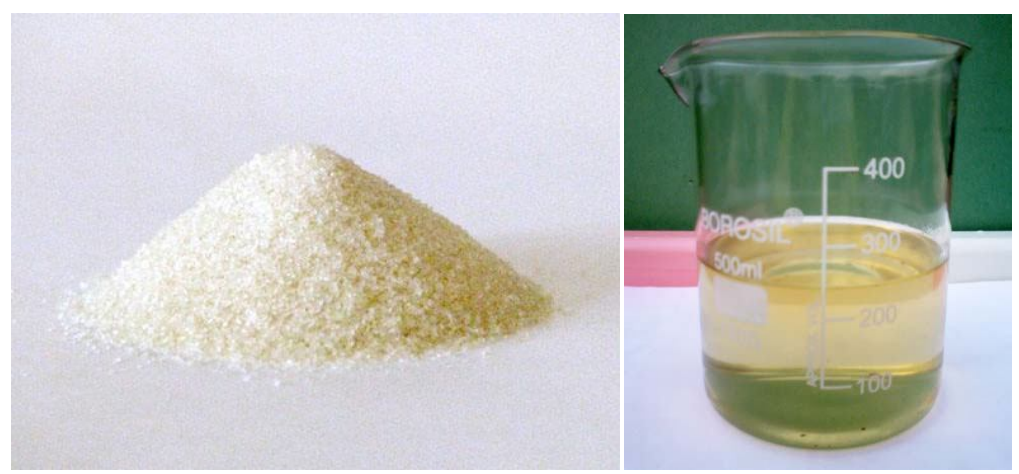

Figura 3.1 - (a) gelatina sem sabor; (b) glicerina pura.

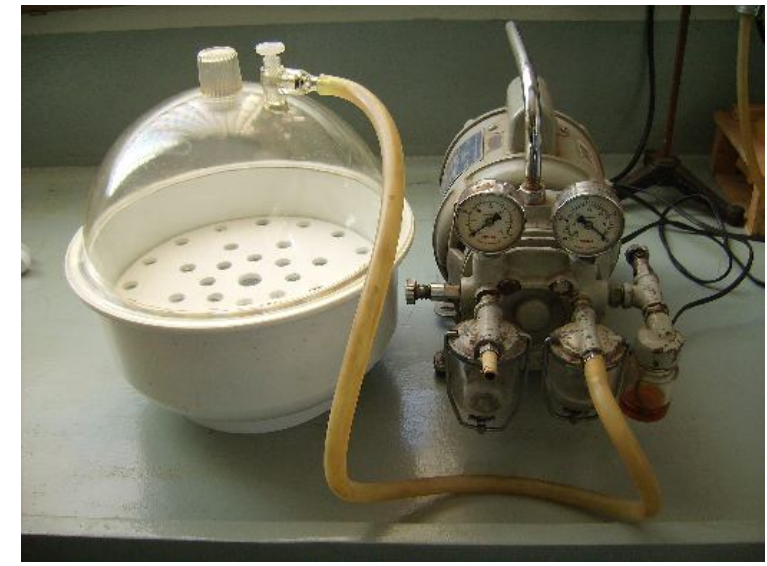

Figura 3.2 - Dessecador conectado à bomba de vácuo utilizados para moldagem dos materiais fotoelásticos.

A gelatina é transferida para o molde por meio de um funil usado para evitar a formação de bolhas de ar na moldagem do modelo. No entanto antes da transferência, é necessário aguardar que a temperatura da mistura abaixe para cerca de $35^{\circ} \mathrm{C}$. Em temperaturas mais altas, o choque térmico poderá ocasionar a ruptura das paredes coladas do molde de acrílico. Se houver a necessidade de eliminar a adesão entre a gelatina e as paredes do molde, 
essas podem ser lubrificadas com graxa de silicone ou outro lubrificante que não provoque reação com a gelatina nem interfira na passagem da luz.

\subsection{Ensaios Fotoelásticos}

Os equipamentos utilizados para todos os ensaios fotoelásticos fazem parte do laboratório de fotoelasticidade do Departamento de Geotecnia da EESC - USP e estão listados a seguir:

- 2 Pares de lentes polarizadoras com diâmetro de 78mm;

- Par de lentes polarizadoras com diâmetro de 205mm;

- Trilho com $90 \mathrm{~cm}$ de extensão;

- Medidor de força Force Gauge® FG 5000A com capacidade máxima de 49,03N;

- Conjunto de pesos em aço;

- Lâmpada fluorescente $45 \mathrm{~W}$;

- Lâmpada incandescente 200W;

- Lâmpada de vapor de sódio 400W;

- Direcionador de feixe de luz;

- Filtro de luz para transformação em luz monocromática verde;

- Filtro de luz para transformação em luz monocromática vermelha;

- Pórtico para aplicação de esforços de tração e compressão;

Alguns dos equipamentos estão mostrados na Figura 3.3.

O laboratório de fotoelasticidade também conta com um polariscópio, produzido pela Photolastic Inc. (Figura 3.4). O equipamento é composto por duas lentes polarizadoras e duas placas quarto de onda. Deste modo, é possível realizar análises com luz polarizada plana e circular. O equipamento conta com um sistema de eixos que vincula as placas quarto de onda, de forma a girar o conjunto de lentes ao mesmo tempo. 
Para a realização de qualquer observação fotoelástica é recomendável vedar qualquer outra fonte de luz que não seja a utilizada no ensaio. Raios de luz não polarizados diminuem a nitidez dos efeitos ópticos e a resolução da fotografia dos parâmetros fotoelásticos, reduzindo precisão da leitura. Os eixos da fonte de luz, das lentes polarizadoras, do modelo fotoelástico e da câmera fotográfica devem ser coincidentes.

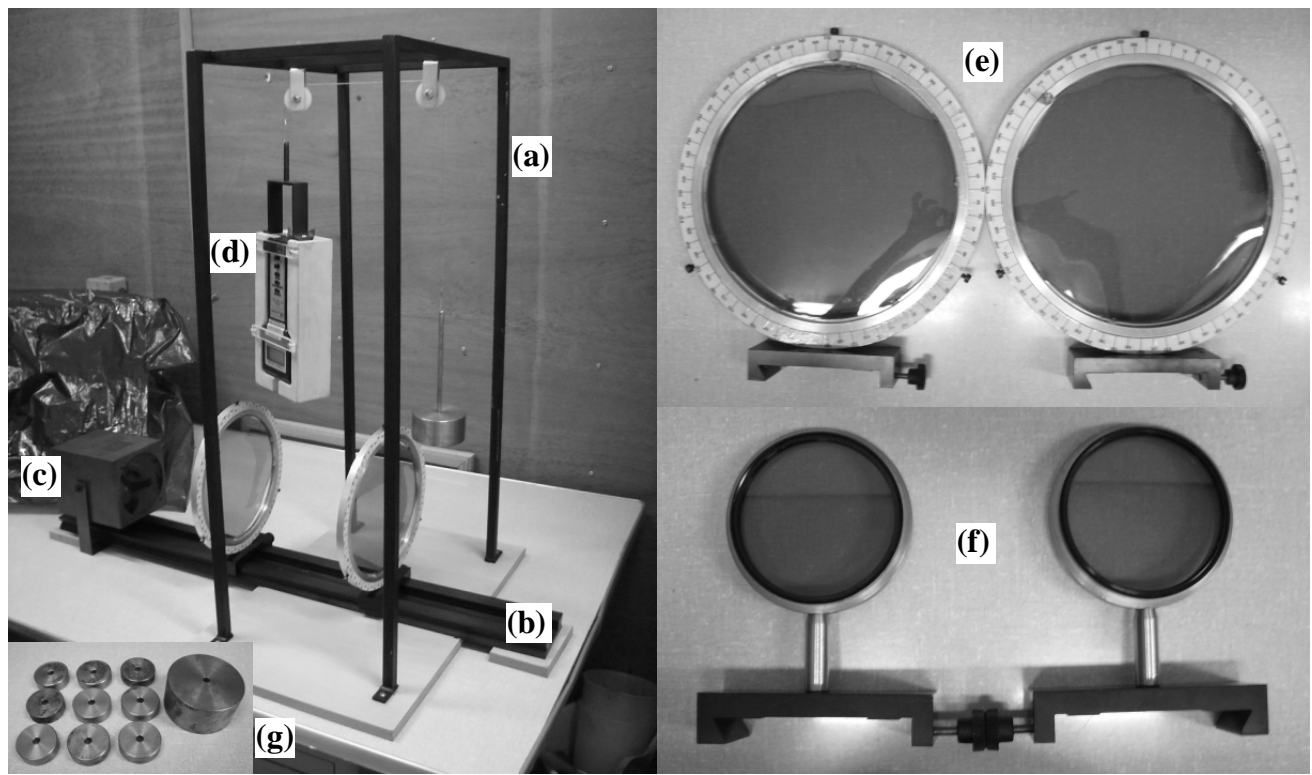

Figura 3.3 - (a) pórtico, (b) trilho, (c) direcionador de luz, (d) medidor de força, (e) polarizadores com $205 \mathrm{~mm}$ de diâmetro, (f) polarizadores com diâmetro de $78 \mathrm{~mm}$ e (g) pesos.
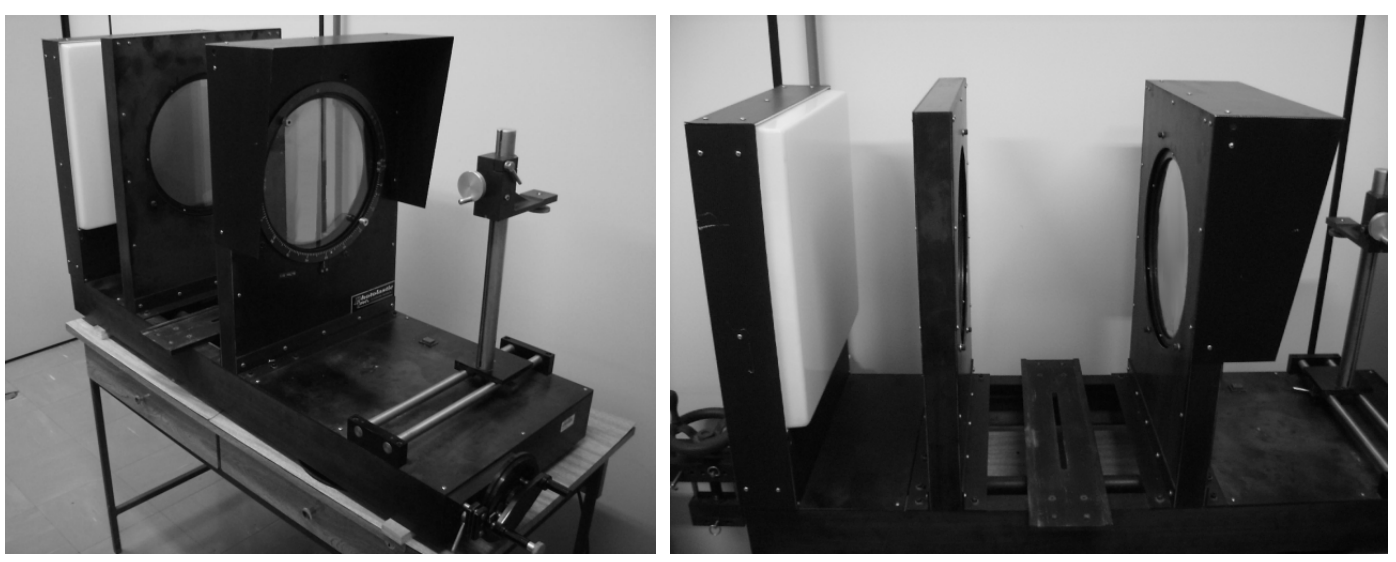

Figura 3.4 - Polariscópio 
Com o objetivo de evitar variações nas propriedades ópticas e mecânicas da gelatina, a temperatura no laboratório fotoelástico foi constantemente monitorada, variando entre 25 e $28^{\circ} \mathrm{C}$. A captura das imagens foi feita através de câmera digital Mitsuca ${ }^{\circledR}$ DC7328BR com luz branca. Os efeitos fotoelásticos de cada nível de carregamento foram registrados após a estabilização visual das isocromáticas que variou de 0 a 2 minutos. As isocromáticas foram fotografadas em campo claro e escuro com luz branca.

As imagens coloridas obtidas dos ensaios foram transformadas em imagens monocromáticas para a leitura das isocromáticas. Para esta transformação utilizou-se o software GNU Image Manipulation Program - GIMP® 2.6.7 de distribuição livre. O programa possibilitou fazer a transformação de uma imagem colorida para uma imagem monocromática com luz verde, e assim utilizar a calibração com a luz monocromática.

As imagens capturadas com luz monocromática por filtro verde e as imagens monocromáticas geradas pelo software foram comparadas afim de verificar se há variação nos lugares geométricos das franjas monocromáticas. Através da comparação, verificou-se que os processos são equivalentes e podem ser utilizados nas análises, pois ambos resultam em valores iguais de calibração.

\subsection{Calibração do Material Fotoelástico}

A calibração necessária para relacionar as isocromáticas observadas com um determinado nível de tensão na gelatina foi realizada conforme o método sugerido por Frocht (1941), Hendry (1966) e Richards Jr. e Mark (1966). O processo consiste em posicionar um bloco do material sobre uma superfície plana e lisa (Figura 3.5). Ao examinar o bloco com o polariscópio, uma série de faixas igualmente espaçadas deverá ser visualizada como resultado da ação do peso próprio do bloco. 


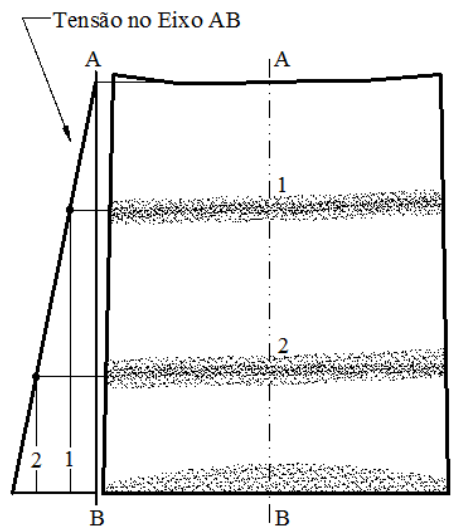

Figura 3.5 - Esquema da calibração (FROCHT, 1941 - modificado).

Com o objetivo de analisar a influência das condições de borda sobre a calibração do material fotoelástico, foram realizadas análises com dois blocos, G1 e G2, geometricamente diferentes. As dimensões dos blocos são apresentadas na Tabela 3.1. A altura dos blocos é limitada devido à instabilidade ao tombamento, que geralmente ocorreu para alturas superiores a 1,5 vezes a largura. A não realização de análises fotoelásticas em modelos fotoelásticos com grandes espessuras se deve, segundo Hendry (1966), à ocorrência de distorções nas leituras das franjas e absorção óptica em modelos de gelatina com espessuras maiores que $50 \mathrm{~mm}$.

Tabela 3.1- Dimensões utilizadas nos blocos de calibração (em mm).

\begin{tabular}{cccc}
\hline Bloco & Altura & Largura & Espessura \\
\hline G1 & 124 & 100 & 50 \\
G2 & 98 & 50 & 50 \\
\hline
\end{tabular}

O molde do bloco G1 foi feito em acrílico de modo que as placas das paredes laterais pudessem ser retiradas por cima (Figura 3.6a). No preparo do bloco G2 utilizou-se um molde feito em borracha de silicone com altura máxima de 100mm (Figura 3.6b). O silicone foi utilizado para verificar a aplicação deste material como molde para esta pesquisa. No entanto 
para moldes maiores, não foi possível utilizar este material pois suas paredes laterais se deformam excessivamente, ocasionando distorções nas medidas dos corpos de prova.

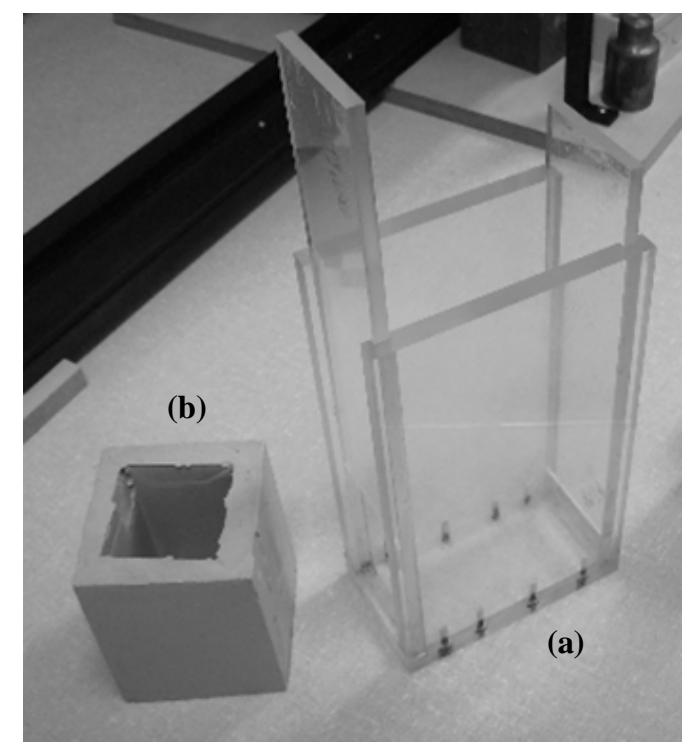

Figura 3.6 - Moldes em (a) silicone, (b) acrílico e (c) aço, para moldagem da gelatina.

A tensão em cada isocromática é calculada dividindo-se o peso de gelatina acima da seção de análise pela área da seção. Através de regressão linear, obtêm-se a equação da reta do tipo $\left(\sigma_{1}-\sigma_{2}\right)=a N$, onde $a$ é o coeficiente angular da reta e $N$ a ordem de franja. A constante óptica $f_{\sigma}$ é então determinada através das Equações (3.1) e (3.2).

$$
\begin{aligned}
& \left(\sigma_{1}-\sigma_{2}\right)=\frac{N \cdot f_{\sigma}}{h} \\
& \tau_{\text {máx }}=\frac{N \cdot f_{\sigma}}{2 h}
\end{aligned}
$$

onde, h é a espessura do modelo. 
As tensões analisadas no bloco geralmente são tomadas no eixo de simetria vertical. Desta forma, as tensões de peso próprio calculadas deverão se equivaler às reais tensões produzidas pelo carregamento do peso próprio.

O mesmo lugar geométrico deve ser observado na franja para que assim seja estabelecido um critério de leitura da isocromática. Ou seja, se as leituras de calibração forem realizadas no centro da franja, as leituras no modelo deverão ser feitas na linha central da isocromática.

Na calibração sugerida por Frocht (1941) e Hendry (1966) é recomendado analisar o efeito das condições de contorno. Deve-se tomar leituras do topo até a uma profundidade em que as condições de apoio não interfiram na distribuição de tensões. Dessa forma é possível admitir que a divisão do peso da gelatina, que está acima da cota do ponto, pela área da seção transversal seria a tensão atuante na cota do ponto.

Para comprovar essa recomendação, foram realizadas simulações com as mesmas dimensões dos corpos de prova utilizados, através do método dos elementos finitos (MEF) com o uso do programa Ansys ${ }^{\circledR}$ v.11. Foram ainda utilizadas duas condições de apoio: uma com restrição em dois graus de liberdade - horizontal e vertical - e outra com restrição apenas na vertical. A intenção foi tentar reproduzir os resultados que se poderia obter, com a fotoelasticidade, quando se lubrificasse a base do corpo de prova (apenas restrição vertical) ou não (restrição vertical e horizontal). Concluiu-se que os valores obtidos pela análise no eixo vertical central poderiam ser utilizados.

É importante controlar a temperatura e a umidade ambiente do laboratório durante o ensaio fotoelástico para que a reprodução do ensaio com os mesmos parâmetros seja possível, uma vez que as propriedades fotoelásticas e mecânicas da gelatina variam sensivelmente com a temperatura. 


\subsubsection{Análises Fotoelásticas das Ancoragens}

Como a gelatina é um material coesivo, a resistência ao cisalhamento da gelatina foi associada à resistência ao cisalhamento não drenada de um solo coesivo. Então, os critérios propostos por Das (Equação (2.65) foram utilizados para que o efeito da profundidade relativa $\left(H / D_{1}\right)_{c r}$ pudesse ser avaliado por meio das análises fotoelásticas.

A resistência não drenada da gelatina foi determinada através de um ensaio de compressão simples. O ensaio foi realizado em corpo de prova cilíndrico com dimensões de $50 \mathrm{~mm}$ de diâmetro e $100 \mathrm{~mm}$ de altura. A tensão de ruptura $\left(\sigma_{\text {rup }}\right)$ no ensaio foi de $14 \mathrm{kPa}$, com uma deformação total de $51 \%$ da altura inicial e superfície de ruptura com uma inclinação de $45^{\circ}$ com a horizontal. Como a gelatina é um material coesivo, adotou-se como resistência ao cisalhamento a sua coesão, ou seja: $c=S_{u}=0,5 \sigma_{\text {rup }}=7 \mathrm{kPa}$. Então, aplicando o critério proposto por Das a este estudo resulta em:

$$
\left(\frac{H}{D_{1}}\right)_{c r}=0,107 S_{u}+2,7=0,107\left(\frac{\sigma_{r u p}}{2}\right)+2,7=3,45
$$

Isto significa que até uma profundidade de hélice igual a 3,45 vezes o diâmetro desta, o comportamento é considerado raso e a superfície deverá atingir a superfície do terreno.

As análises foram realizadas com três modelos de ancoragens: um modelo simplificado com placa metálica plana e dois modelos de estaca helicoidal com diferentes dimensões. As três ancoragens foram usinadas em aço. As dimensões dos modelos são apresentadas na Figura 3.7, com as designações de AP para a ancoragem com placa circular plana, EH1 para a estaca helicoidal maior e EH2 para a menor. 


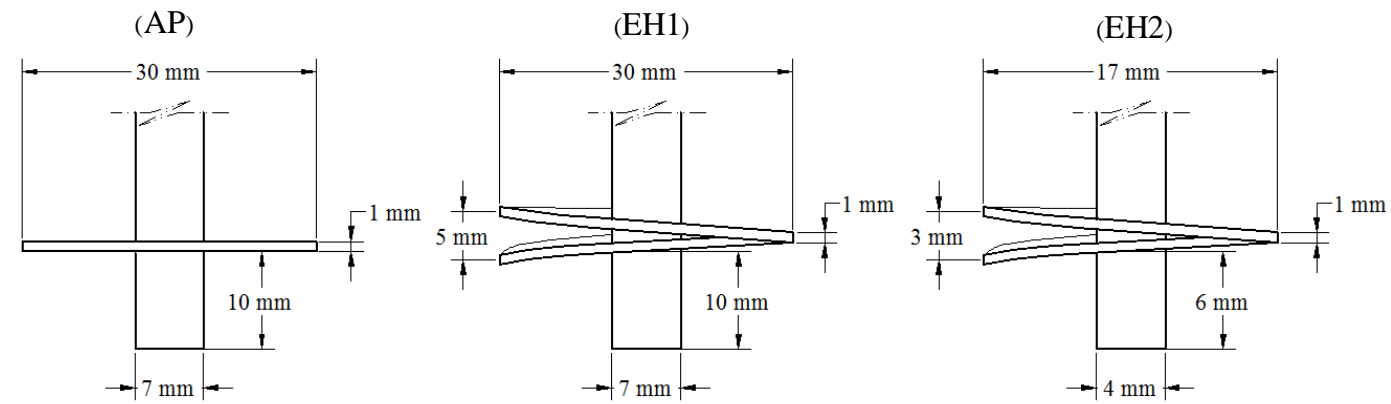

Figura 3.7 - Elementos de ancoragem utilizados.

Foram utilizados dois recipientes de acrílico para a moldagem do modelo fotoelástico, cujas dimensões são apresentadas na Tabela 3.2. Para eliminar a adesão, as paredes do recipiente, normais ao eixo de polarização foram lubrificadas com graxa de silicone. Essa técnica de lubrificação foi proposta por Richter, Demars e Richards Jr (1984).

As ancoragens foram posicionadas no molde sempre com sua haste na vertical e antes da moldagem da gelatina. Após o preparo da gelatina e da retirada das bolhas, a mistura foi colocada no molde de acrílico com o auxílio de um funil. Desta forma, a mistura preencheria o molde do fundo para o topo, envolvendo a ancoragem.

Tabela 3.2 - Dimensões dos moldes de acrílico (em mm).

\begin{tabular}{cccc}
\hline Recipiente & Altura & Largura & Espessura \\
\hline $\mathbf{R 1}$ & 150 & 150 & 50 \\
$\mathbf{R 2}$ & 140 & 140 & 40 \\
\hline
\end{tabular}

\subsubsection{Carregamentos Axiais}

Os carregamentos foram aplicados de maneira a transferir somente esforços axiais, sem induzir flexão ou torção. O sistema de aplicação dos carregamentos de tração e compressão consiste de um pórtico de reação com duas roldanas, cabo e um trilho para fixação do modelo (Figura 3.8a e b). Utilizou-se um dinamômetro digital Force Gauge ${ }^{\circledR}$ FG 5000A com capacidade de $49 \mathrm{~N}$ (Newton) e resolução de 0,01 N (Newton) para medir os esforços aplicados na cabeça da ancoragem (Figura 3.8c). Os dispositivos utilizados para 
transferir a carga do medidor para a ancoragem são fornecidos juntamente com o dinamômetro.

(a)

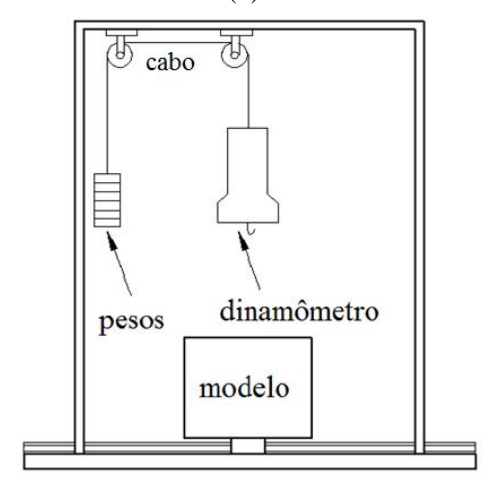

(b)

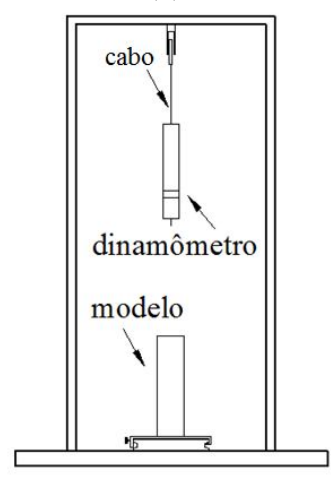

(C)

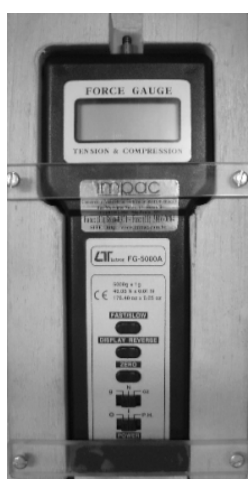

Figura 3.8 -Esquema de carregamento axial: (a) vista frontal e (b) lateral; (c) dinamômetro digital

A sequência de carregamento e descarregamento foi realizada em intervalos da ordem de $1 \mathrm{~N}$ em todos os modelos. Os ensaios foram realizados com graxa de silicone como lubrificante para proporcionar deslocamento relativo entre as partes metálicas e gelatina. Com o uso da lubrificação pretende-se eliminar a adesão da gelatina à haste com a finalidade de avaliar as tensões induzidas unicamente pela lâmina. Por apresentarem maior concentração de tensões, as seções EE e DD foram adotadas para as análises (Figura 3.9a). Tais designações foram escolhidas por representar a seção à esquerda e à direita da ancoragem.

Os traçados das seções para obtenção dos parâmetros das isocromáticas e seus contornos podem ser feitos sobre a própria imagem através de programas CAD (ComputerAided Design). O método utilizado para determinar a profundidade de cada isocromática é exemplificado na Figura 3.9. A determinação da localização $(z)$ da interseção de uma dada isocromática com a seção em estudo é exemplificado na Figura 3.9b. O valor de z / Y na superfície do modelo é zero e no fundo do recipiente tem-se o valor de z / Y $=1$. Desta forma na seção em estudo, o valor de $z$ é determinado por semelhança de triângulos.. 
(b)
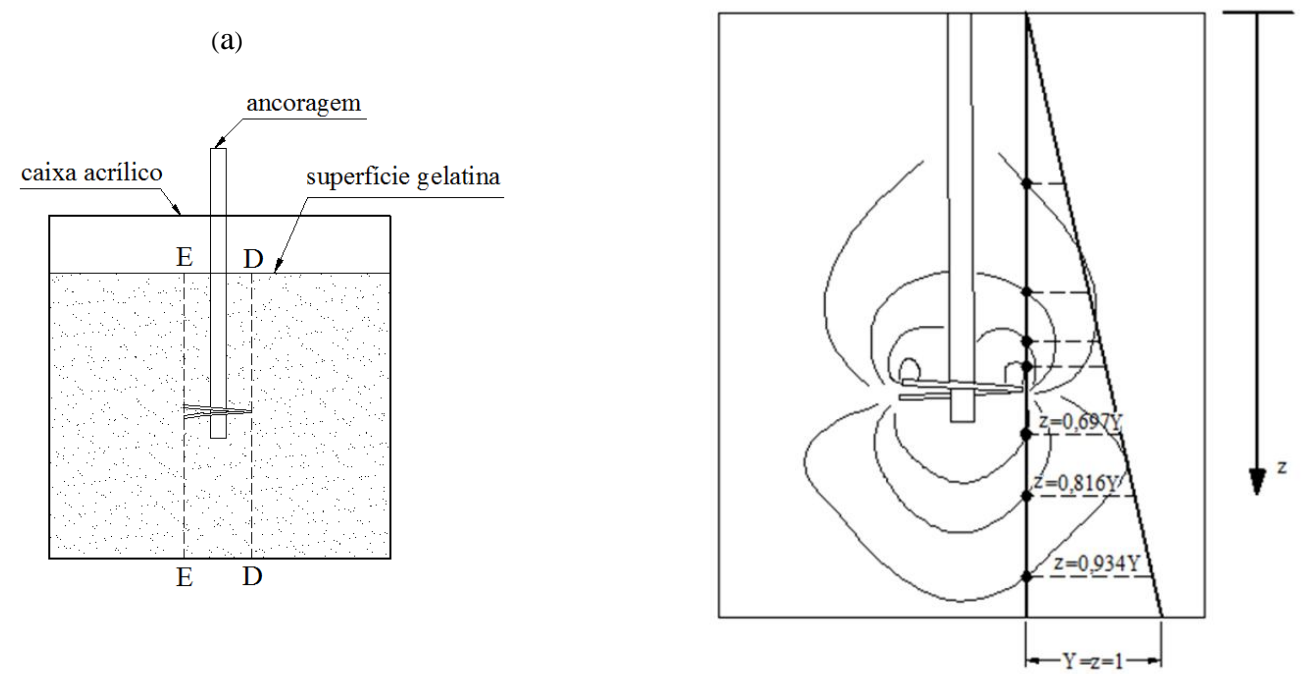

Figura 3.9 - (a) seções adotadas para análise; (b) determinação da profundidade das isocromáticas.

\subsubsection{Análises Numéricas}

Os resultados das análises fotoelásticas foram comparados com os resultados obtidos com as simulações numéricas para o modelos que utilizam a ancoragem AP. As análises numéricas foram realizadas com o programa Ansys® v11, que utiliza o método dos elementos finitos (MEF). O programa Ansys ${ }^{\circledR}$ v11 possui em seu banco de dados o elemento PLANE82, que foi utilizado em todas as modelagens numéricas deste trabalho. O PLANE82 é um elemento bi-dimensional de quatro nós. Esse elemento proporciona resultados mais precisos para malhas automáticas e pode tolerar formas irregulares com pouca ou nenhuma perda de precisão. O elemento PLANE82 permite realizar análises axi-simétricas, análises com estado plano de tensão e estado plano de deformação. Portanto, foram realizadas análises numéricas por axi-simetria e análises com estado plano de tensões.

As características geométricas do modelo foram as mesmas consideradas para a modelagem experimental de AP. A Figura 3.10 mostra o sistema de ancoragem modelado numericamente.

O módulo de elasticidade da gelatina $\left(E_{\text {gelat }}\right)$ e o coeficiente de Poisson ( $\left.v_{\text {gelat }}\right)$ utilizados foram de $100 \mathrm{kPa}$ e 0,495, respectivamente, conforme consta da literatura. Os 
valores adotados para o módulo de elasticidade $\left(\mathrm{E}_{\text {aço }}\right)$ e coeficiente de Poisson $\left(v_{\text {aço }}\right)$ do aço foram de $2 \times 10^{8} \mathrm{kPa}$ e 0,3 , respectivamente.

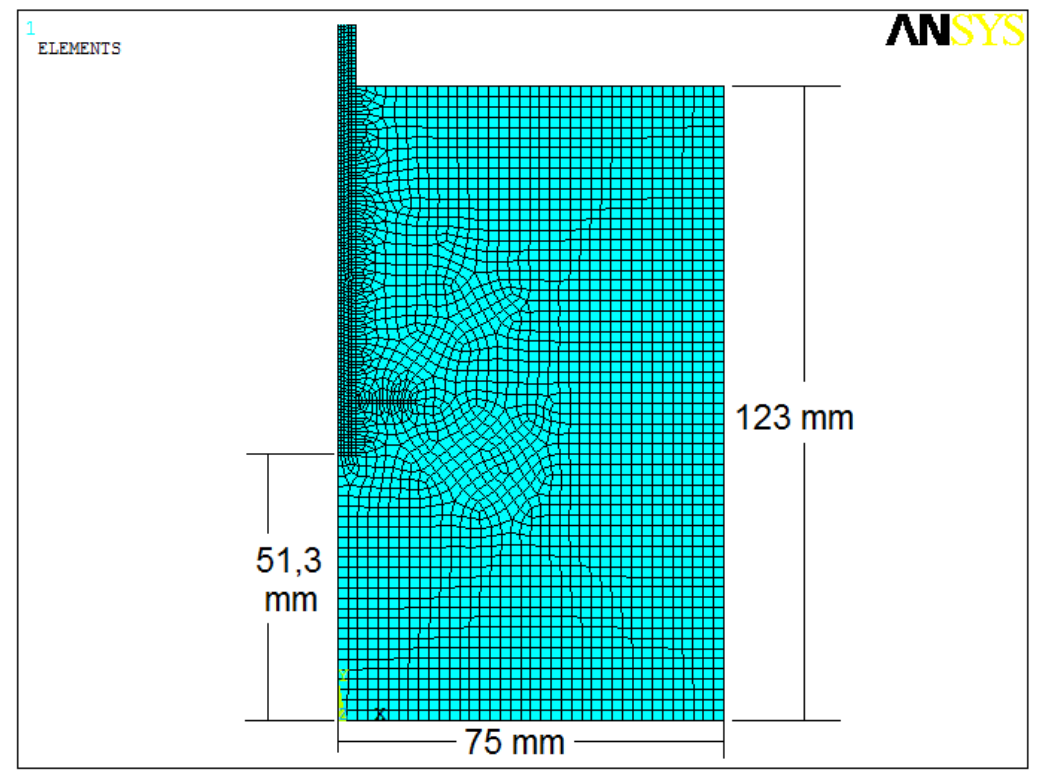

Figura 3.10 - Modelo numérico.

Com o objetido de verificar a influência da variabilidade dos valores propostos para o módulo de elasticidade da gelatina, realizou-se uma análise paramétrica variando-se os valores de $E_{\text {gelat }}$ Um modelo numérico de um sistema de ancoragem em placa circular plana foi analisado. Essa análise foi realizada com a utilização de um modelo com simetria em torno de seu eixo vertical (axi-simetria) e geometria idêntica à AP. Variou-se módulo de elasticidade da gelatina $\left(E_{\text {gelat }}\right)$ entre 10 e $300 \mathrm{kPa}$.

Os resultados obtidos com a análise realizada mostraram que os valores das tensões principais variaram apenas $3 \%$ entre os valores extremos considerados para o módulo de elasticidade da gelatina. As tensões são pouco influenciadas pelo módulo de elasticidade da gelatina, pois a rigidez da gelatina é muito menor que a do aço da ancoragem. Desta forma, o intervalo de variação do módulo de elasticidade não é suficiente para promover mudanças significativas na intensidade das tensões. 


\section{RESULTADOS E DISCUSSÕES}

Neste capítulo são apresentados os resultados e a discussão dos ensaios fotoelásticos com carregamento axial. Também são apresentadas as comparações dos resultados experimentais com os resultados numéricos da ancoragem AP.

Foram executadas 22 moldagens para os experimentos fotoelásticos. Dessas moldagens, foi possível realizar 39 ensaios fotoelásticos. Dentre esses ensaios, realizaram-se 8 ensaios de calibração e 31 ensaios de carregamento axial. Ao todo, criou-se um banco de dados com mais de 1500 imagens dos ensaios fotoelásticos realizados.

Dos 31 ensaios, dois foram descartados. Um por se tratar do primeiro experimento fotografado com a técnica. Este ensaio teve o objetivo de promover o contato inicial com a técnica, por isso seus resultados não foram registrados para utilização na pesquisa. O outro foi descartado devido quantidade excessiva de bolhas de ar aprisionadas. Este modelo foi levado então à ruptura da gelatina durante o carregamento para posteriores análises (Figura 4.1).

(a)

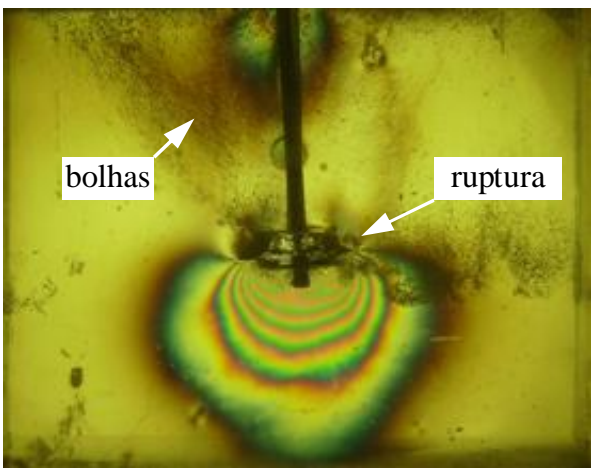

(b)

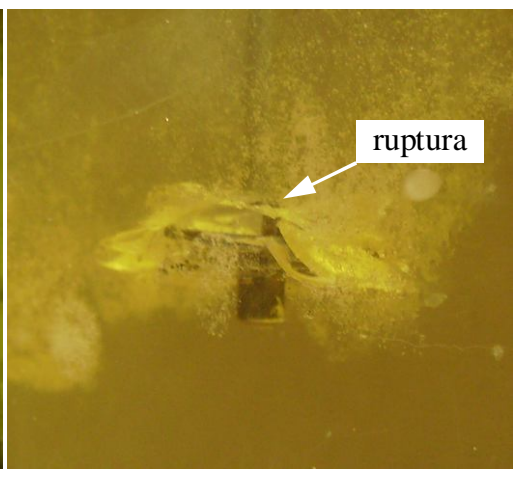

Figura 4.1 - (a) Modelo com bolhas e ruptura; (b) detalhe da ruptura da gelatina. 


\subsection{Calibração da Gelatina}

As massas específicas $(\rho)$ das gelatinas moldadas para a calibração fotoelástica foram de $1,108 \mathrm{~g} / \mathrm{cm}^{3}$ e $1,111 \mathrm{~g} / \mathrm{cm}^{3}$ para os corpos de prova G1e G2, respectivamente. Esses parâmetros foram considerados na determinação das tensões de peso próprio para calibração da gelatina.

A sequência de carregamento com G1 é apresentada na Figura 4.2. Para visualizar franjas de ordem superior a $\mathrm{N}=2$, foi necessário aplicar carregamentos uniformemente distribuídos $(\sigma)$ por meio de pesos e uma placa de acrílico lubrificada na face em contato com o corpo de prova utilizada para distribuir a carga. Com o corpo de prova G1, foi possível registrar franjas de ordem $(N)$ igual 3.

Através da concentração de isocromáticas na base do corpo de prova, pôde-se constatar a influência das condições de contorno e restrição do deslocamento na base. Para o caso do corpo de prova G2, a maior ordem de franja $(N)$ visualizada também foi igual a 3 (Figura 4.3).
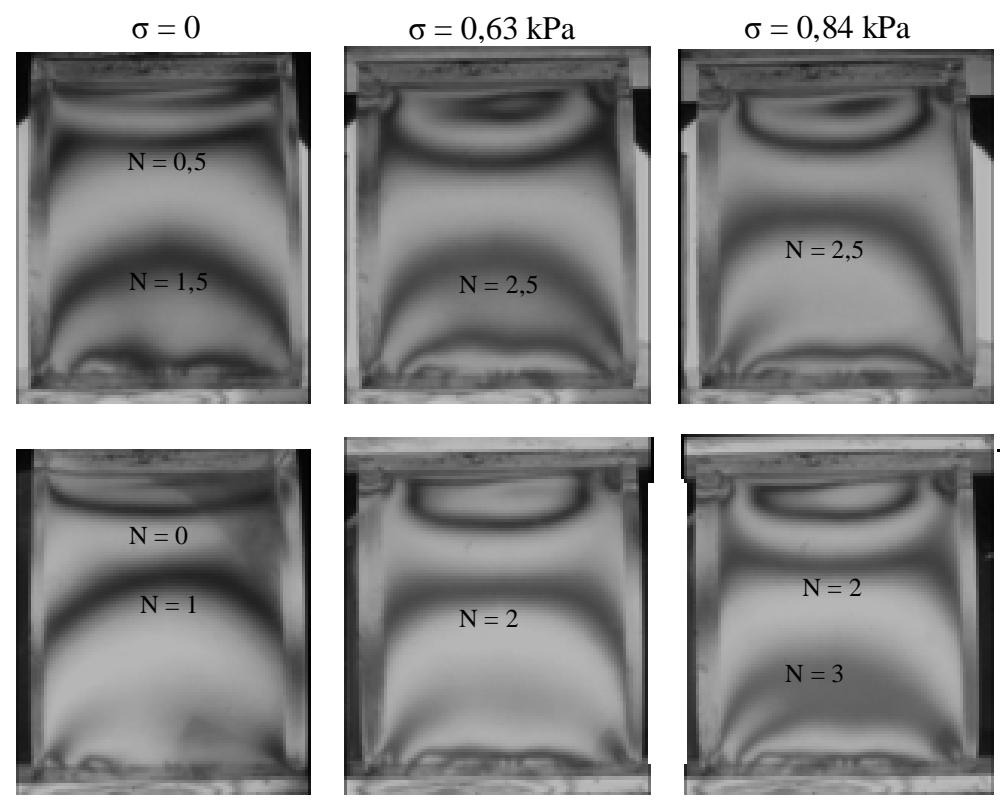

Figura 4.2 - Carregamentos em G1 com campo claro (acima) e escuro (abaixo) com luz verde ( $\lambda=5461 \AA$ ). 

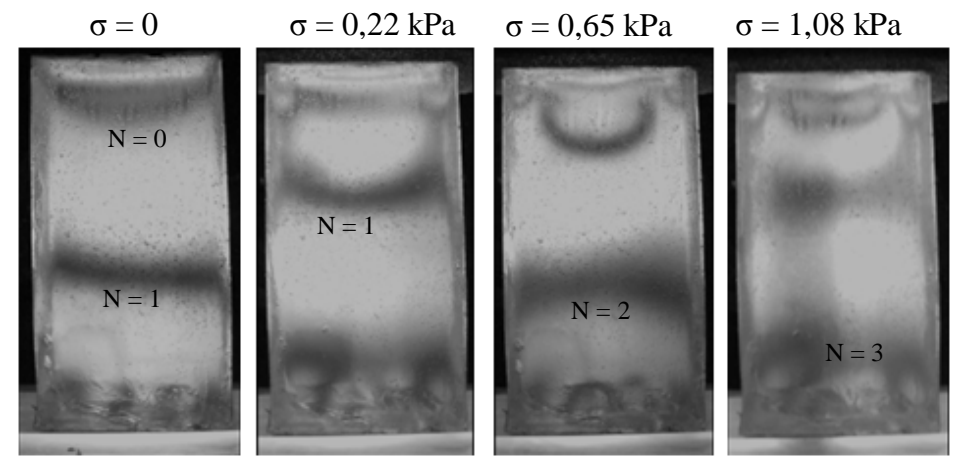

Figura 4.3 - Carregamentos em G2 com campo escuro com luz verde $(\lambda=5461 \AA)$.

Os pontos obtidos com as leituras em G1 e G2 e as retas de ajustes são apresentados na Figura 4.4. Os coeficientes angulares das retas de ajuste são iguais à constante óptica dividida pela espessura do modelo $\left(f_{\sigma} / h\right)$. Portanto, os valores de $f_{\sigma}$ são obtidos pela multiplicação do coeficiente angular da reta com a espessura do modelo. Foram realizadas três regressões: uma regressão para os pontos de G1, uma para os pontos de G2 e outra utilizando todos os pontos de G1 e G2 em conjunto. Os valores obtidos das constantes ópticas são apresentados na Tabela 4.1.

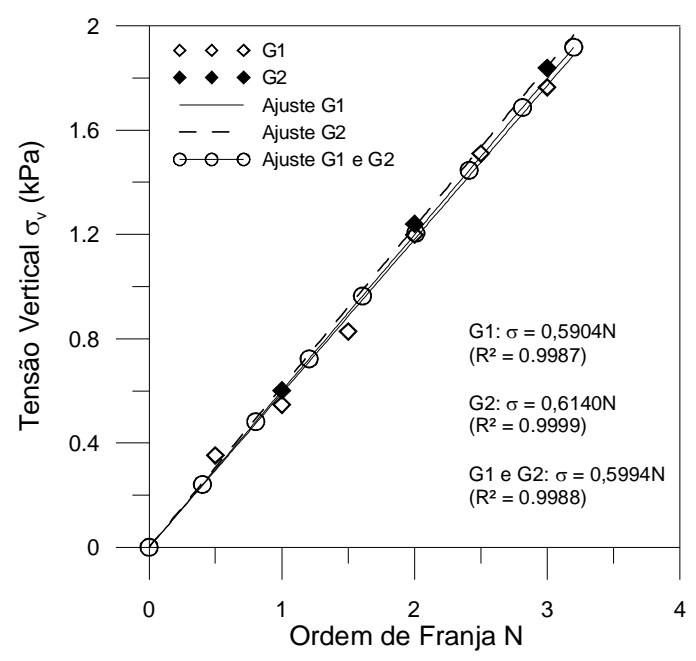

Figura 4.4 - Curva de calibração da gelatina. 
Tabela 4.1 - Valores de $f_{\sigma}$ determinados por meio de calibração.

\begin{tabular}{cccc}
\hline Pontos & G1 & G2 & G1 e G2 \\
\hline $\mathrm{f}_{\sigma}(\mathrm{N} / \mathrm{m})$ & 29,5 & 30,7 & 30,0 \\
\hline
\end{tabular}

Para a utilização do método de calibração proposto por Frocht (1941), utilizado neste trabalho, admite-se que a influência das condições de borda seja desprezível. Portanto, mediante observação e análise das isocromáticas de G1 e G2, concluiu-se que o valor da constante óptica $\left(f_{\sigma}\right)$ a ser utilizado é $29,5 \mathrm{~N} / \mathrm{m}$, obtido pelo ensaio com o corpo de prova G1. Esse corpo de prova apresentou menor influência das condições de borda sobre as isocromáticas.

\subsection{Ensaios Fotoelásticos}

São apresentados os resultados dos experimentos fotoelásticos em carregamento de tração e compressão. A comparação entre os resultados obtidos por modelagem experimental e por modelagem numérica da ancoragem AP também é apresentada. Os itens são divididos entre as geometrias das ancoragens e posição da profundidade da ancoragem em relação à superfície da gelatina.

Por meio das observações durante os ensaios fotoelásticos, notou-se perda de adesão entre a gelatina e a haste, mesmo sem lubrificação da haste. Portanto, considerou-se que a transferência de carga não ocorreria através da haste. As tensões obtidas como resultados são apresentadas com suas unidades no Sistema Internacional de Unidades e também normalizadas pelo valor da resistência ao cisalhamento (coesão) da gelatina ( $c=7 \mathrm{kPa}$ ) e ora normalizadas pela tensão aplicada pela placa $\left(\sigma_{p}\right)$ (Equação (4.1).

$$
\sigma_{p}=p / A_{p}
$$

onde, $p$ é a força aplicada na cabeça da estaca ou ancoragem e $A_{p}$ é a área da projeção em planta da lâmina da estaca helicoidal ou da ancoragem. 


\subsubsection{Ancoragem de Placa Circular Plana "AP" na profundidade igual a 2,5D} (Ancoragem Rasa)

Para iniciar os estudos fotoelásticos com estacas helicoidais, primeiramente foi confeccionado um modelo de estaca helicoidal simplificado, considerando uma ancoragem plana. Com essa simplificação, o problema analisado se tornou simétrico em relação ao eixo de vertical de simetria. Isso permite uma fácil modelagem numérica com grande aproximação das condições experimentais.

Em todos os carregamentos houve o desenvolvimento de vácuo na região do contato lâmina-gelatina. Mesmo sabendo que ocorreria perda de adesão na interface dos elementos devido à deformação da gelatina, optou-se por lubrificar a haste com graxa de silicone e aplicar uma rotação na haste de $360^{\circ}$ em torno de seu eixo vertical para impedir a adesão entre os materiais. Desta forma, teve-se a certeza de que as tensões de tração no material fotoelástico seriam unicamente devidas ao efeito da formação de vácuo. Apesar de a gelatina ser muito deformável, o vácuo não permitiu descolamento da interface gelatina-estaca sob esforços normais, havendo compatibilidade de deslocamentos.

A formação de vácuo ocorre pelo fato de não haver comunicação com o ambiente externo (sob pressão atmosférica) na região de contato placa-gelatina. Não havendo comunicação com o ambiente exterior, não há possibilidade de entrada de ar naquele local. Nos experimentos fotoelásticos, houve o fenômeno de vácuo tanto no arrancamento quanto na compressão dos modelos. Durante o arrancamento, as tensões de tração surgiram na região abaixo da placa, enquanto que na compressão houve o vácuo na área superior à lâmina (Figura 4.5).

Nestas análises, as tensões devidas ao vácuo podem representar o efeito da sucção nas ancoragens. No estudo de ancoragens, é necessário esclarecer que o termo sucção é tratado por diversos autores diferentemente daquele da Mecânica dos Solos Não-saturados. No caso 
de ancoragens em solos moles e/ou orgânicos, por exemplo, é chamado de sucção o fenômeno que confere alguma resistência ao arrancamento devido à pressão negativa que surge na cavidade que se forma na região abaixo da placa de ancoragem.

(a)

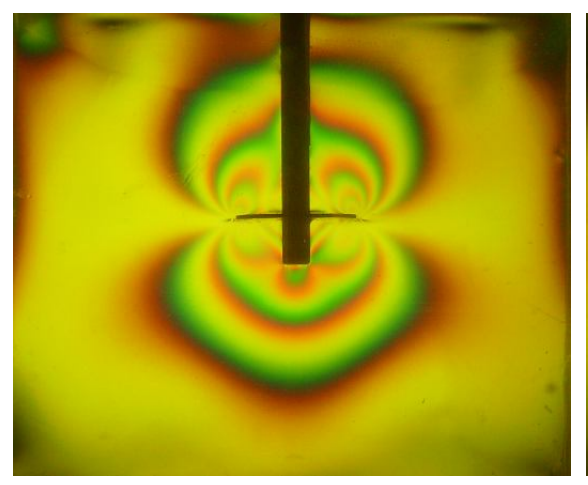

(b)

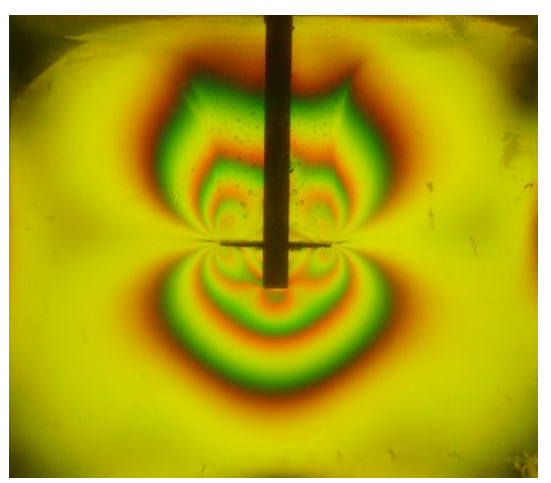

Figura 4.5 - Isocromáticas em campo escuro com AP lubrificada com graxa de silicone em: (a) arrancamento por 15,4 N $\left(\sigma_{p}=3,11 c\right)$; (b) compressão de 10,0 N $\left(\sigma_{p}=2,02 c\right)$.

Em ensaios de arrancamento de ancoragens em placa ou estacas helicoidais, o efeito da sucção no fundo da lâmina tem sido observado por vários autores. Mooney, Amdczak e Clemence (1985) mediram valores de sucção de até 20,7 kPa na região abaixo da placa de todas estacas helicoidais em ensaios de arrancamento de curto-prazo realizados em laboratório com modelos reduzidos instalados em argila marinha. Baba, Gulhati e Datta (1989) constataram que a força de sucção aumenta com o incremento da velocidade do arrancamento da ancoragem. Em baixas velocidades de arrancamento $(0,2 \sim 1,0 \mathrm{~mm} / \mathrm{min})$ houve pequena diferença entre as forças de arrancamento com e sem a eliminação da sucção no fundo das placas de ancoragem.

Das et al. (1994) realizaram ensaios de arrancamento de placas circulares imersas em argila marinha saturada e em diversas misturas de solos. Os ensaios foram realizados com e sem o contato do fundo da placa com o solo. Verificou-se que, para os materiais estudados, as forças de sucção diminuem com o aumento da profundidade relativa. Em modelagens físicas 
em centrífuga com estacas helicoidais tracionadas, Tsuha (2007) constatou em areia não saturada, por meio da superfície de ruptura formada na região abaixo da lâmina helicoidal, a ocorrência resistência a tração abaixo da lâmina. Este fenômeno é creditado ao efeito da sucção matricial em um solo não saturado.

O fenômeno de vácuo também foi observado em Richter, Demars e Richards, Jr. (1984), que analisaram fundações por estacas sob carregamento transversal por meio da técnica da fotoelasticidade. Para determinar a influência da graxa de silicone na adesão estaca-gelatina, os autores verificaram que a graxa permitiu o deslocamento relativo na interface do fuste estaca-gelatina nos quatro testes realizados. Todavia, constataram que não ocorreu separação entre a ponta e a gelatina, gerando alguma tensão no material fotoelástico. Possivelmente, parcela daquela tensão na ponta da estaca seria resultado da formação de vácuo na interface ponta-gelatina.

Sabe-se que o efeito da sucção contribui para o incremento da capacidade de carga da ancoragem. Entretando, segundo Das (1990), pouco se sabe da magnitude deste efeito e sugere-se negligenciar esta contribuição em estimativas da capacidade de carga.

As isocromáticas que representam distribuição de tensões devido à máxima tração aplicada na ancoragem são apresentadas na Figura 4.6. A dificuldade em determinar o traçado das isocromáticas é maior na região da extremidade da placa, pois é um local de concentração de tensões e, quanto maior a ordem da franja, menor a resolução da mesma. O aparecimento de isocromáticas de ordem até $N=1$, próximo aos limites laterais indica restrição ao deslocamento lateral exercida pelo recipiente, o que indica interferência das condições de contorno lateral. 
(a)

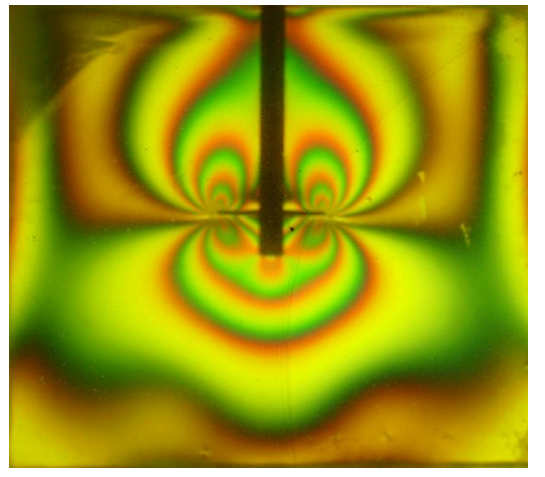

(b)

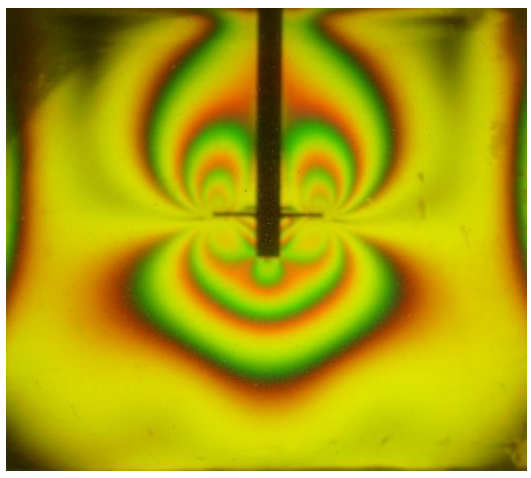

Figura 4.6 - Isocromáticas em campo (a) claro e (b) escuro em carregamento de tração de $-18,1 \mathrm{~N}\left(\sigma_{p}=3,66 c\right)$.

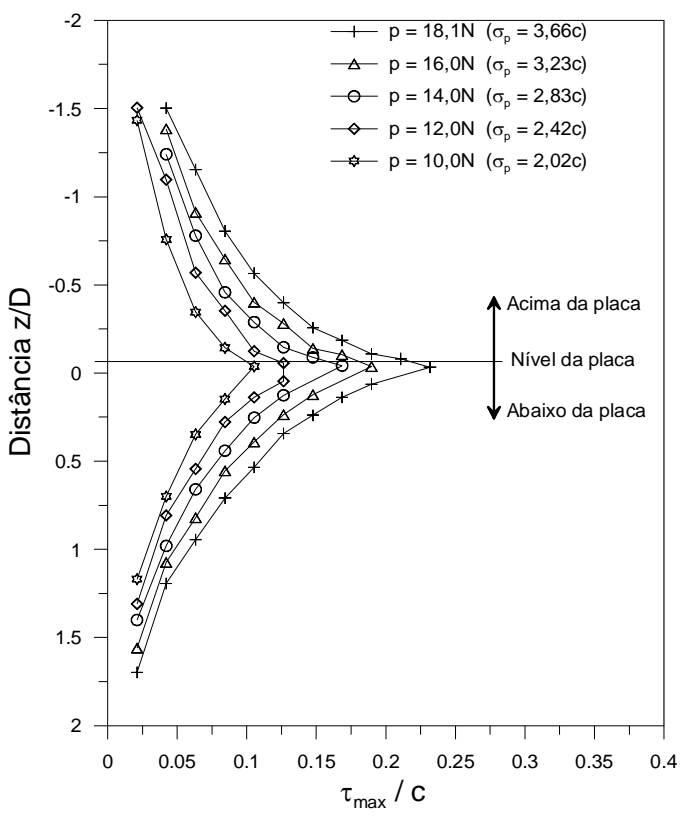

Figura 4.7 - Carregamentos de tração analisados na seção EE para ancoragem AP.

Cabe ressaltar que a ocorrência da máxima tensão de cisalhamento em um estado plano de tensão como dado pela Equação (2.57) ocorrerá somente se a espessura do modelo tender a zero. Portanto, o parâmetro $\tau_{\text {máx }}$ será utilizado para uma indicar uma dada tensão de cisalhamento obtida da leitura das isocromáticas que pode não ser a máxima no sistema pois a espessura do modelo pode não ser desprezível. 
Nos níveis de carregamento de tração com tensão aplicada pela placa igual a $\sigma_{p}=$ $2,63 c(p=13,0 \mathrm{~N})$ e a $\sigma_{p}=3,66 \mathrm{c}(p=18,1 \mathrm{~N})$, as franjas de ordem $N=0,5$ não interceptaram a seção de estudo na área acima da placa de ancoragem. Entretanto, não se pode afirmar que em níveis de menores de carregamento as tensões não atingiriam a superfície.

Apesar de ancoragens em placa plana não serem destinadas a cargas de compressão, neste estudo foram aplicados carregamentos de compressão em AP para que mais resultados das análises fotoelásticas pudessem ser comparados com os resultados numéricos. Os experimentos com cargas de compressão na haste foram conduzidos até $\sigma_{p}=2,20 c(p=10,9$ N) (Figura 4.8). Esta limitação de carregamento se deve ao desvio de verticalidade da haste com a aplicação da carga. Com o aumento do nível de carga, houve maior concentração de tensões na região da placa. A franja de ordem $N=0,5$ foi interceptada pela seção de estudo na região acima da ancoragem até a carga $\sigma_{p}=1,61 c(p=8,0 \mathrm{~N})$.

O traçado dos contornos de máxima tensão cisalhante $\left(\tau_{m a ́ x}\right)$ foi realizado a partir da obtenção dos valores de $\left(\sigma_{1}-\sigma_{2}\right)_{\exp }$ de cada isocromática observada. No mais elevado carregamento de compressão aplicado, ocorreu maior concentração de tensões à distâncias máximas de $1 D$ (uma vez o diâmetro) a partir da placa de ancoragem (Figura 4.8). Por meio do traçado das isoclínicas (Figura 4.9a) foi possível determinar a direção das tensões principais (Figura 4.9b). Houve uma concentração das isoclínicas nas duas extremidades da placa, retratando a concentração de tensões já observada na análise das isocromáticas. 


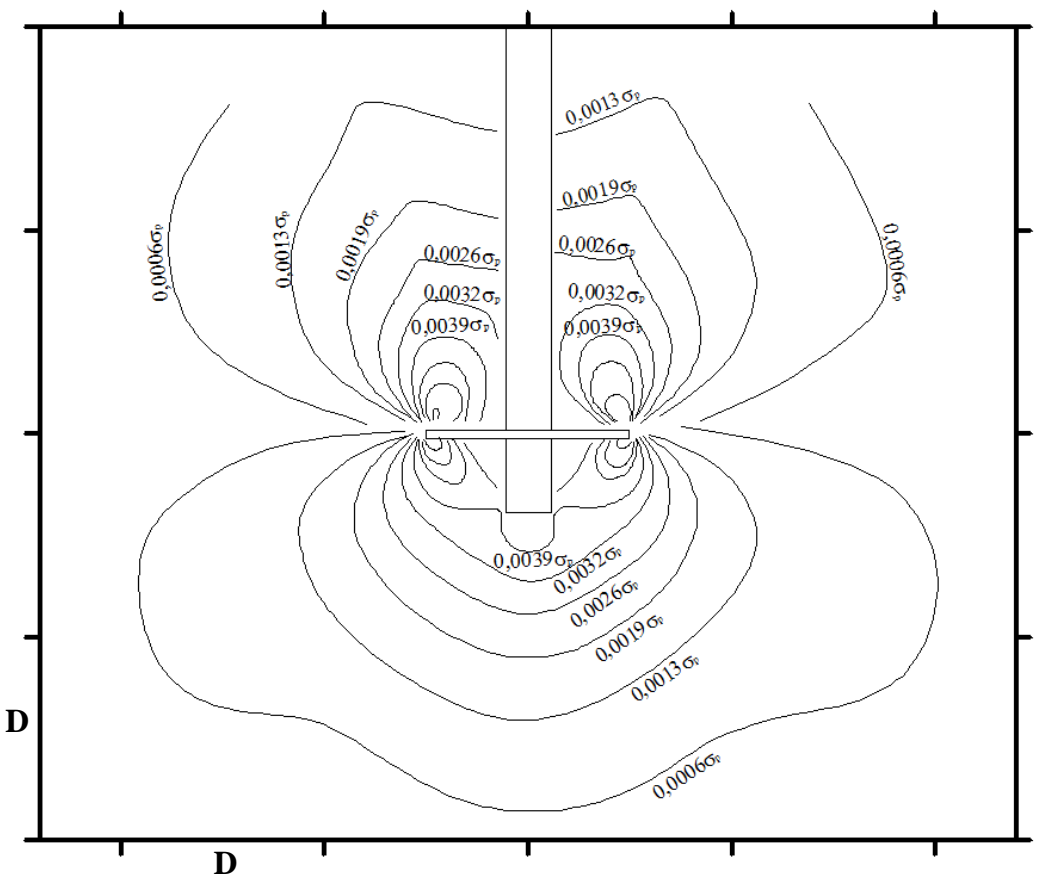

Figura 4.8 - Ancoragem AP $\operatorname{com} \tau_{\max }=0,15 \mathrm{kPa}\left(\tau_{\max }=0,02 c\right)$ por contorno sob carga de compressão de $10,9 \mathrm{~N}$ $\left(\sigma_{p}=2,20 c\right)$.

(a)

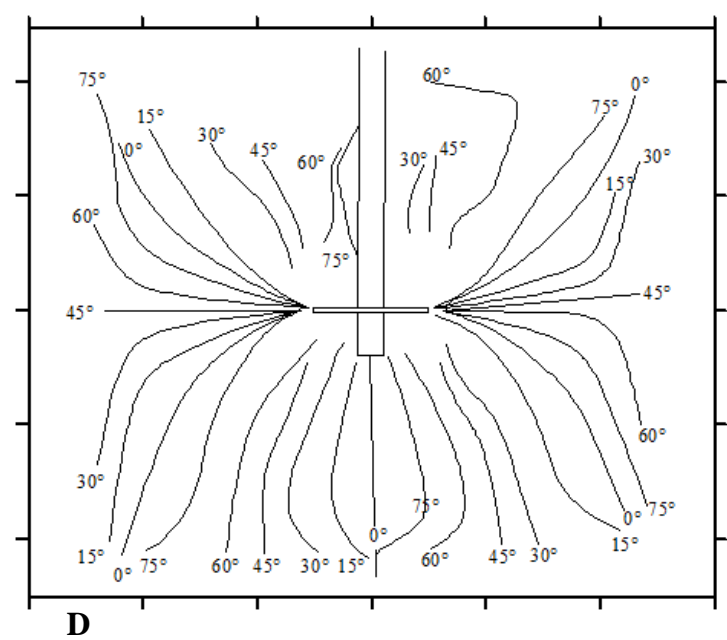

(b)

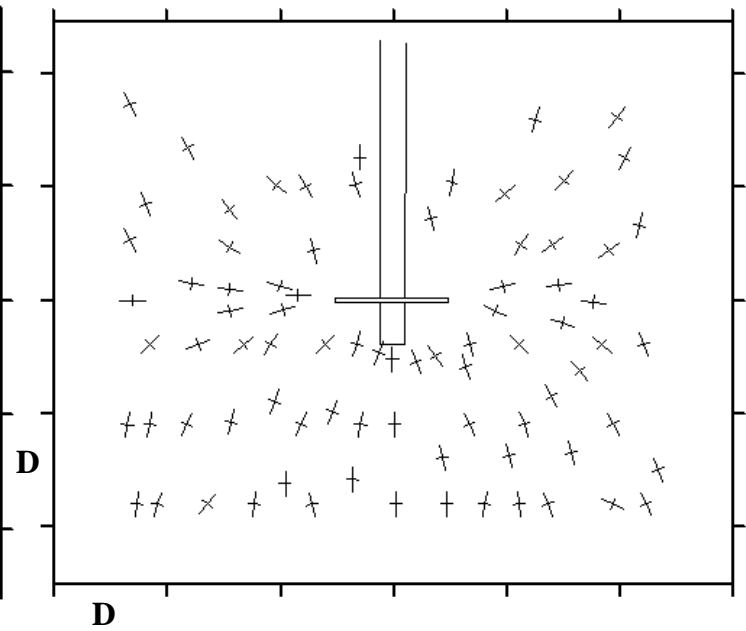

Figura 4.9 - (a) Família de isoclínicas e (b) direção das tensões principais sob carregamento de compressão.

Os contornos da tensão cisalhante máxima $\left(\tau_{m a ́ x}\right)$ também foram traçados na situação de máximo carregamento de tração aplicado (Figura 4.10). Neste nível de carregamento, maiores gradientes de tensão atingiram a superfície. Diferente do ocorrido na máxima compressão de AP, na máxima tração, os maiores níveis de tensão se propagaram a uma 
distância da placa maior que $1 D$. O traçado da família de isoclínicas (Figura 4.11a) e da direção das tensões principais (Figura 4.11b) mostrou comportamento semelhante ao da direção das tensões principais no carregamento de compressão.

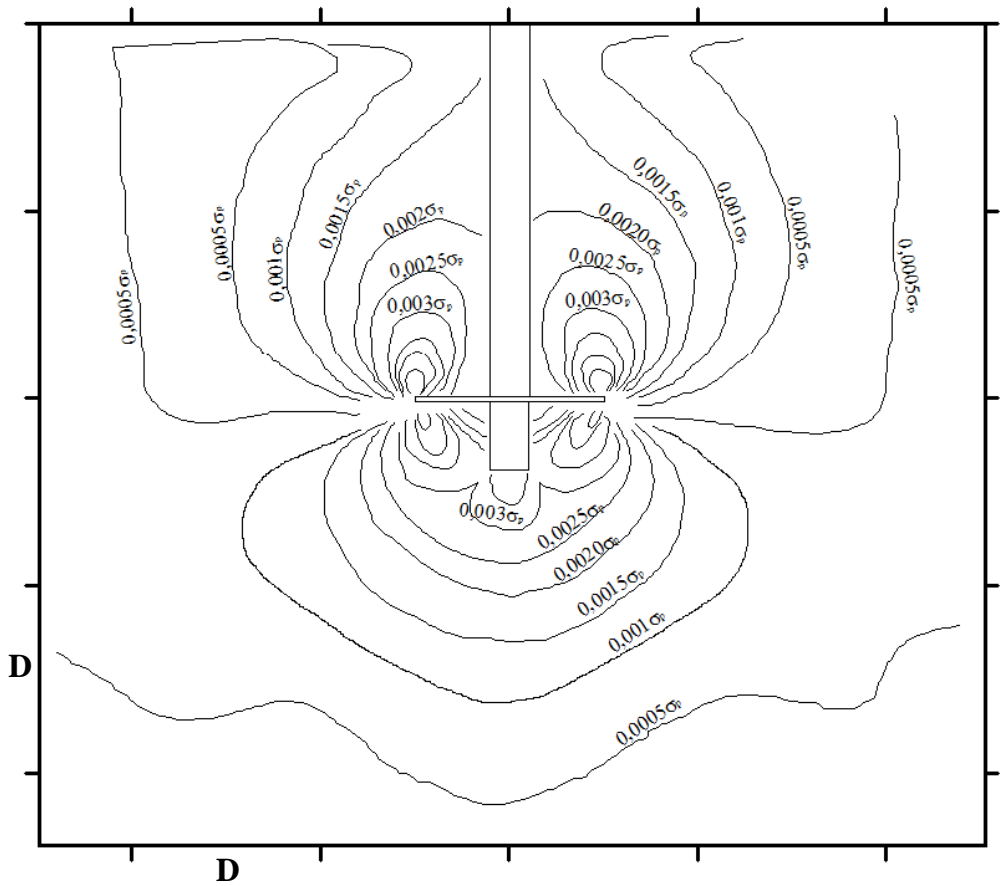

Figura 4.10 $-\tau_{\max }=0,15 \mathrm{kPa}\left(\tau_{\max }=0,02 c\right)$ por contorno sob carga de tração de $18,1 \mathrm{~N}\left(\sigma_{p}=3,66 c\right)$ em AP.

(a)

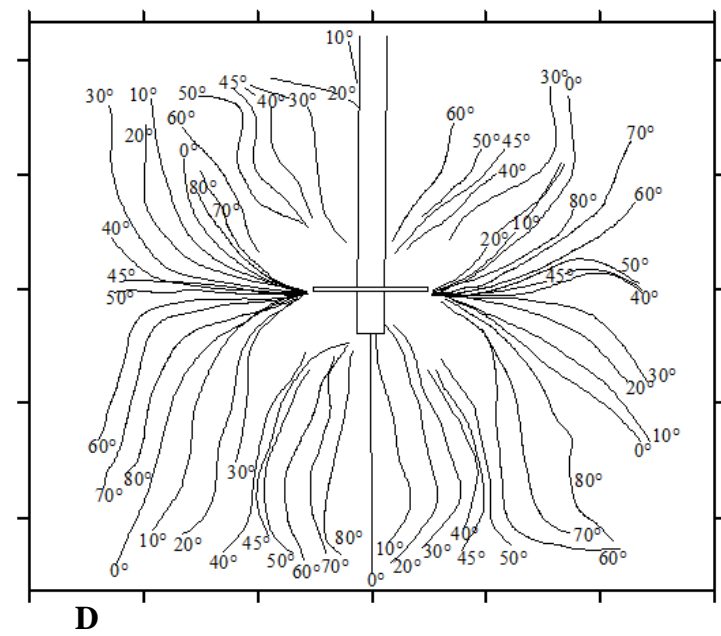

(b)

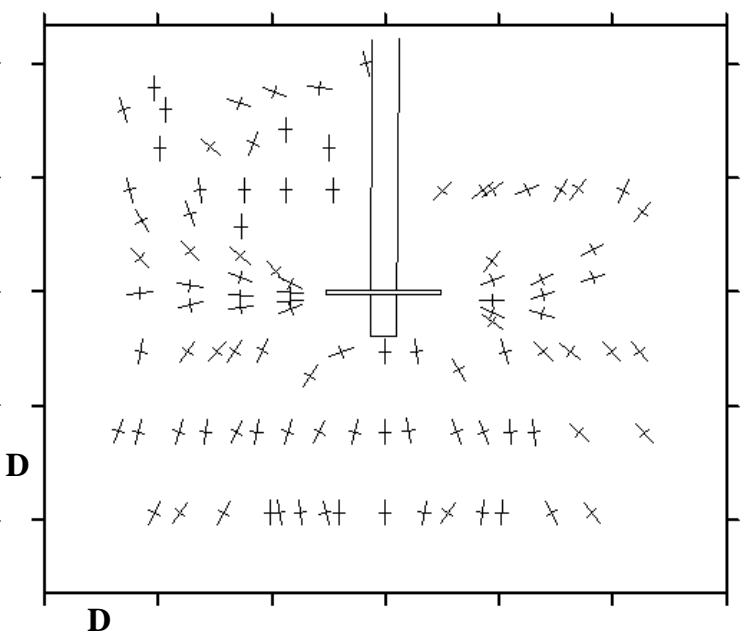

Figura 4.11 - (a) Família de isoclínicas e (b) direção das tensões principais sob carregamento de tração. 


\subsubsection{Modelagem Numérica Assumindo Estado Plano de Tensões}

Sabe-se que a análise fotoelástica plana fornece as tensões em um sistema bidimensional. Contudo, a modelagem experimental em estudo utiliza um elemento de ancoragem tridimensional para induzir o carregamento no meio elástico, representado pela gelatina. São apresentadas comparações com resultados das modelagens numéricas pelo método dos elementos finitos para determinar se as tensões resultantes da aplicação da carga na ancoragem representam um estado plano de tensões.

Foram realizadas simulações numéricas para comparação de um experimento realizado com a ancoragem AP inserida em um modelo de gelatina com espessura de $33 \mathrm{~mm}$. Com essa redução da espessura, esperava-se encontrar resultados experimentais mais próximos de um estado plano de tensões, uma vez que a espessura do modelo teria aproximadamente a mesma ordem de grandeza do diâmetro da placa.

Foram consideradas duas formas de carregamento:

a) carregamento aplicado por meio de uma força que atua no centro da seção transversal circular do topo da haste de ancoragem;

b) carregamento aplicado por meio de uma tensão numericamente igual a uma força dividida pela área da seção transversal da haste $\left(A_{p}\right)$. Essa tensão atua no topo da haste de ancoragem, com seção transversal circular.

Para a comparação em termos de tensões de cisalhamento máximas, foi proposta a utilização dos resultados numéricos fornecidos pela seguinte expressão:

$$
\tau_{\max }=\frac{\left(\sigma_{1}-\sigma_{2}\right)+\left(\sigma_{1}-\sigma_{3}\right)+\left(\sigma_{2}-\sigma_{3}\right)}{3}
$$

Foram analisados dois carregamentos experimentais, um de tração da ancoragem por $p=15,5 \mathrm{~N}\left(\sigma_{p}=3,13 c\right)$ (Figura 4.12a) e outro com carga $p=13,3 \mathrm{~N}\left(\sigma_{p}=2,69 c\right)$ (Figura 4.12b) 
de compressão em AP. Entretanto, os níveis de tensão obtidos pela modelagem numérica, admitindo-se um estado plano de tensões, foram cerca de 50 vezes maiores que aquelas obtidas com a análise experimental para o caso de carregamento aplicado pela forma $a$ (Figura 4.13). Para o caso de carregamento aplicado da forma $b$, os níveis de tensão foram em torno de 20 vezes maiores que aqueles obtidos experimentalmente (Figura 4.14).

(a)

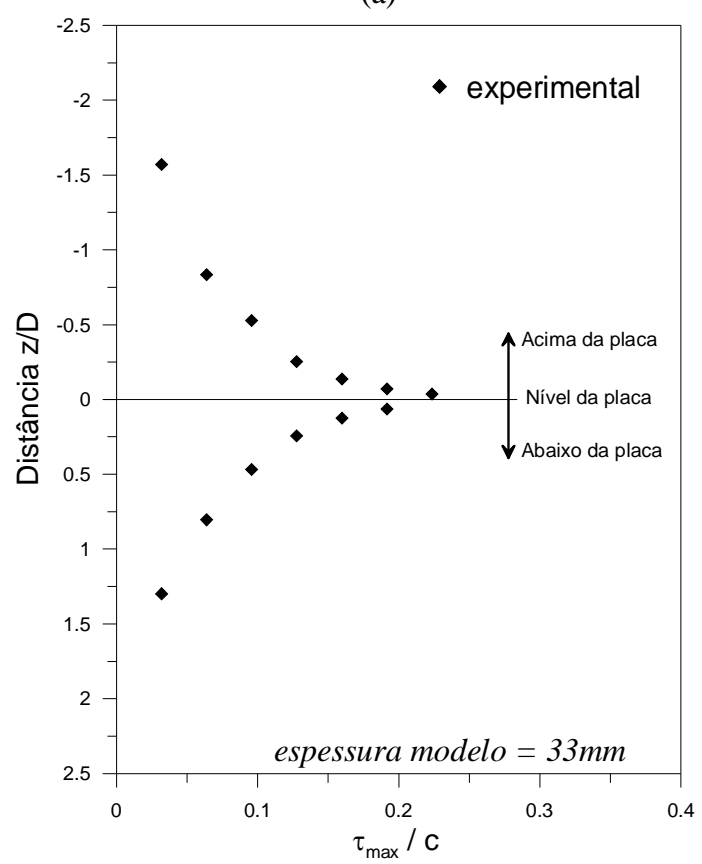

(b)

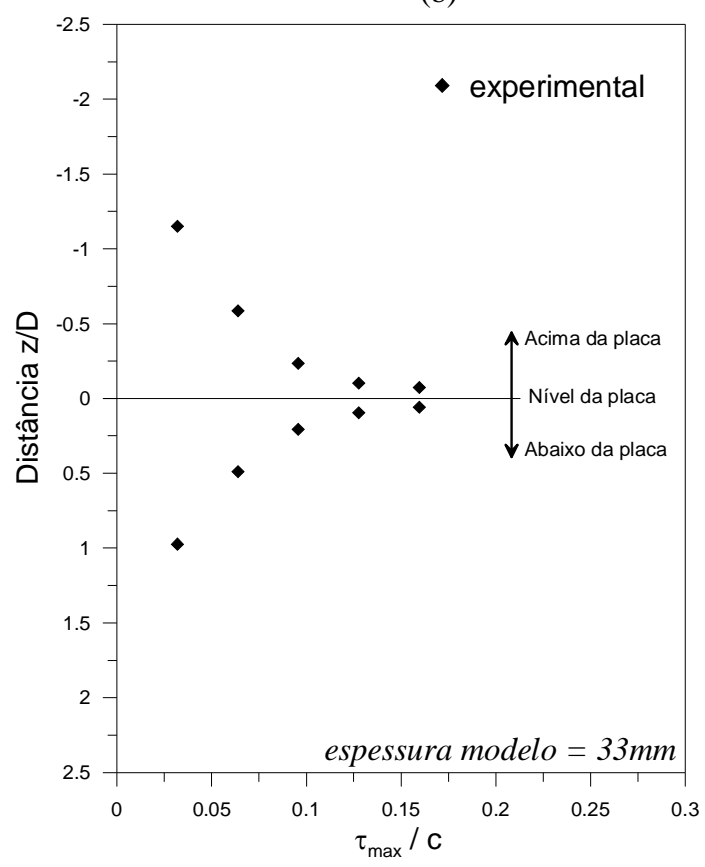

Figura 4.12 - (a) arrancamento de AP com 15,5 N $\left(\sigma_{p}=3,13 c\right)$ e (b) compressão com $p=13,3 \mathrm{~N}\left(\sigma_{p}=2,69 c\right)$.

Comparando-se os resultados numéricos e experimentais é possível notar que os resultados da modelagem experimental não foram compatíveis com uma análise por estado plano de tensões. Portanto, as análises fotoelásticas de AP com um modelo de espessura de $50 \mathrm{~mm}$ não fornecem tensões correspondentes a uma análise por estado plano de tensões. 
(a)

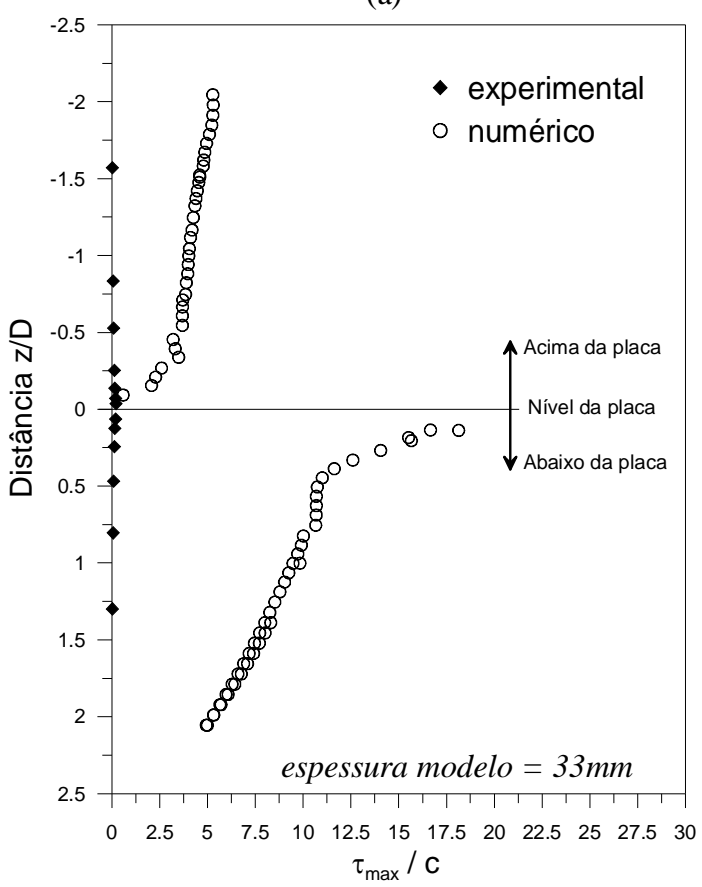

(b)

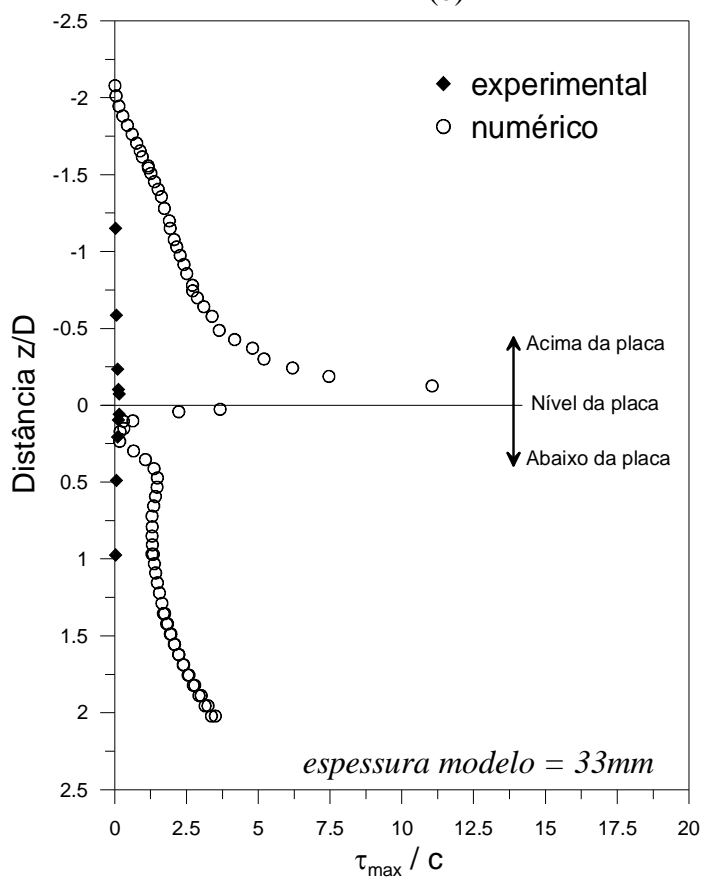

Figura 4.13 - (a) arrancamento de $\mathrm{AP} \operatorname{com} 15,5 \mathrm{~N}\left(\sigma_{p}=3,13 c\right)$ e (b) compressão com $p=13,3 \mathrm{~N}\left(\sigma_{p}=2,69 c\right)$.

Carregamento "a".

(a)

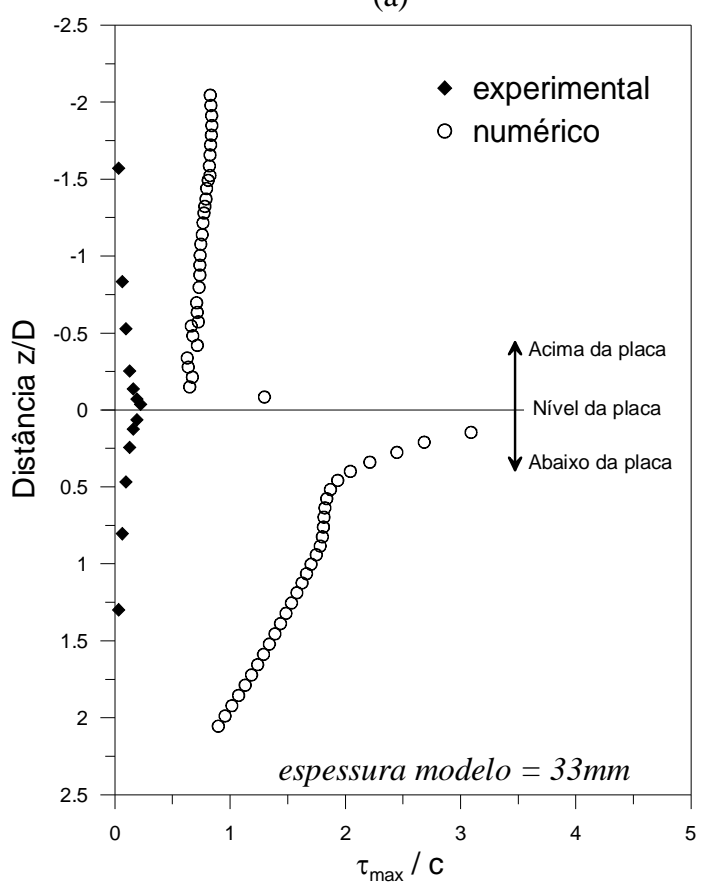

(b)

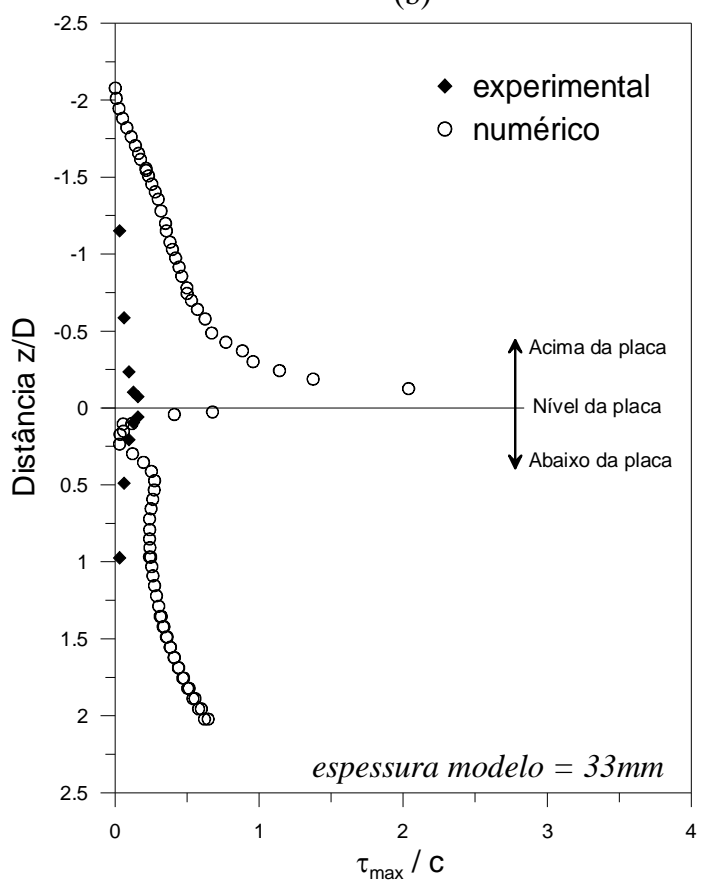

Figura 4.14 - (a) arrancamento de AP com 15,5 N $\left(\sigma_{p}=3,13 c\right)$ e (b) compressão com $p=13,3 \mathrm{~N}\left(\sigma_{p}=2,69 c\right)$.

Carregamento "b". 


\subsubsection{Modelagem Numérica Axi-simétrica}

Também foi realizada uma análise numérica axi-simétrica, obtendo-se as três tensões principais. Os resultados foram então comparados com os resultados obtidos com as análises fotoelásticas. A comparação dos resultados obtidos com o método experimental e com a análise numérica axi-simétrica, considerando o máximo carregamento de tração, é apresentada na Figura 4.15. A Figura 4.16 mostra os resultados das análises numérica e experimental para o carregamento experimental máximo de compressão.

Os valores de $\left(\sigma_{1}-\sigma_{2}\right)$ correspondentes à análise experimental mostraram maior coerência com os valores obtidos com a análise numérica na região tracionada acima da placa de ancoragem. O comportamento das tensões cisalhantes máximas se apresentou semelhante para as duas modelagens, porém com menores intensidades na análise experimental.

(a)

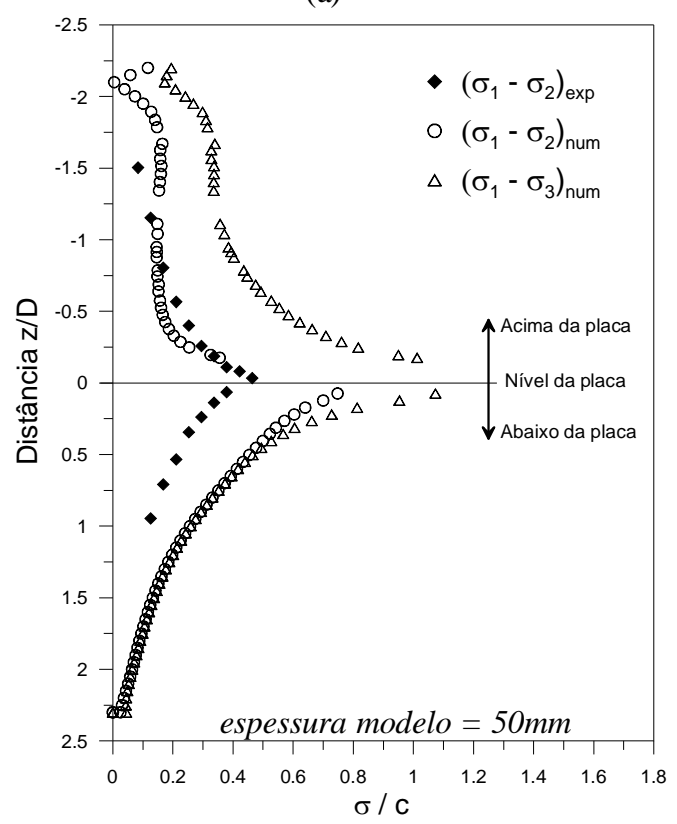

(b)

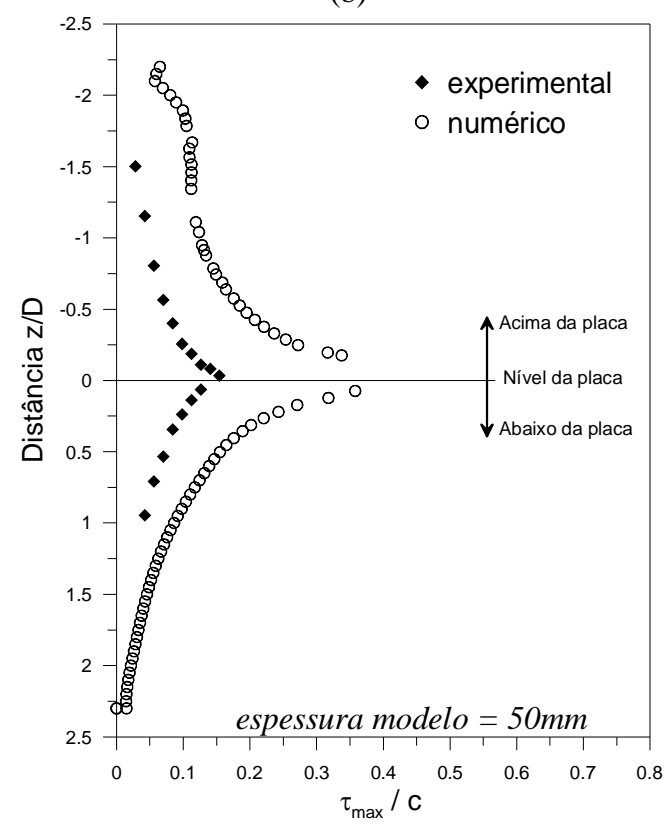

Figura 4.15 - Análise experimental e numérica na seção EE no arrancamento de AP com 18,1 N $\left(\sigma_{p}=3,66 c\right)$ em termos da (a) diferença das tensões principais e (b) tensões cisalhantes máximas.

No ensaio de compressão, os valores experimentais de $\left(\sigma_{1}-\sigma_{2}\right)$ praticamente coincidiram com os valores numéricos de $\left(\sigma_{1}-\sigma_{2}\right)$ na região acima da ancoragem. Contudo, 
houve menor concordância entre as modelagens na área abaixo da ancoragem, da mesma forma que no ensaio de tração. Em termos de tensão cisalhante máxima, as duas modelagens apresentaram valores semelhantes (Figura 4.16b).

(a)

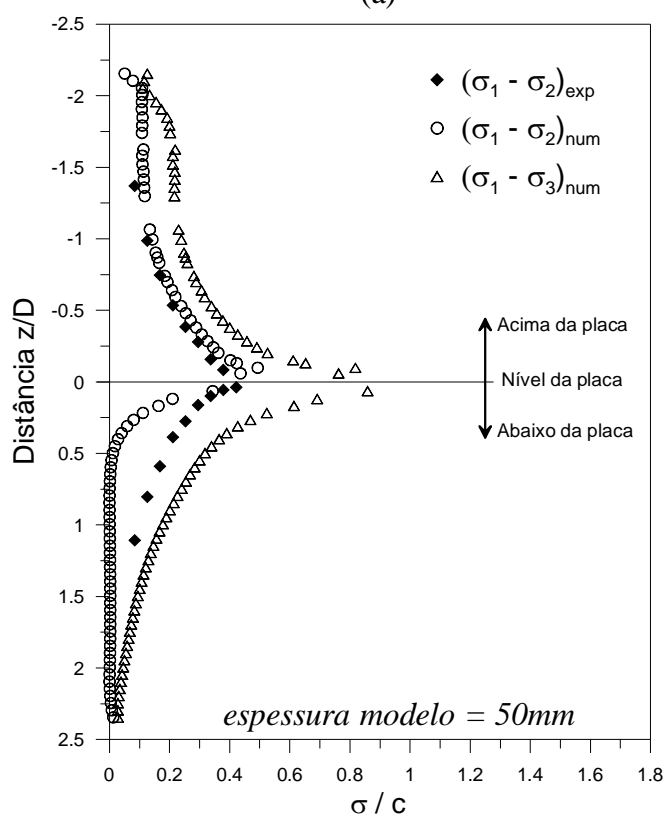

(b)

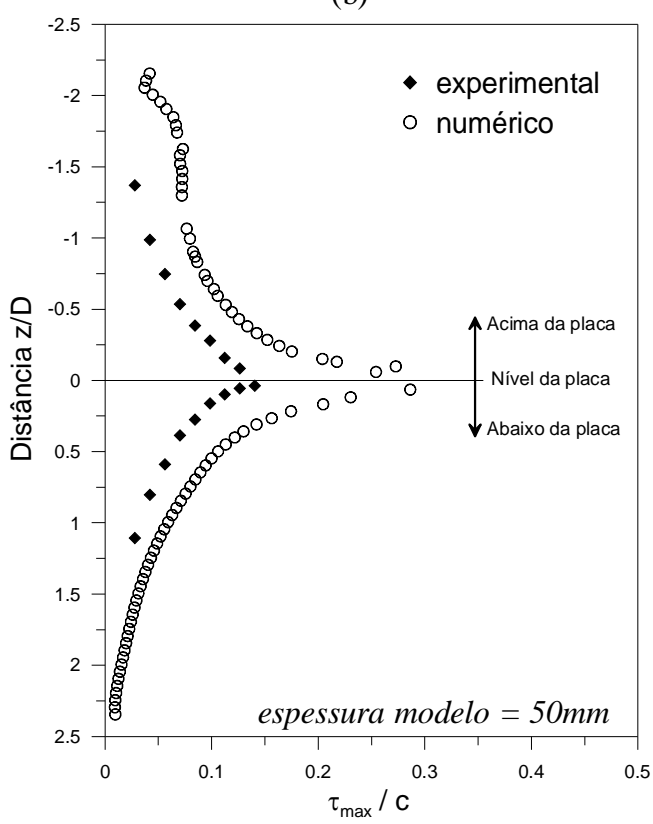

Figura 4.16 - Análise experimental e numérica na seção EE com carga de compressão de 10,9 $\mathrm{N}\left(\sigma_{p}=2,20 c\right)$ em AP em termos da (a) diferença das tensões principais e (b) tensões cisalhantes máximas.

Através das comparações realizadas nos carregamentos de tração e compressão, constatou-se que os resultados experimentais em termos da diferença das tensões principais $\left(\sigma_{1}-\sigma_{2}\right)$, na região superior à placa, são próximos dos resultados numéricos. A aproximação dos pontos das análises em termos de $\tau_{\max }$ indica que a aplicação da análise fotoelasticidade é válida para o problema analisado.

De acordo com a comparação realizada na tração e compressão da haste, os valores numéricos e experimentais sempre mostraram melhor concordância na região superior à placa. Contudo, essa melhor concordância se deu apenas na comparação entre ambos os valores de $\left(\sigma_{1}-\sigma_{2}\right)$. Já os valores de $\left(\sigma_{1}-\sigma_{3}\right)_{\text {num }}$ mostraram um maior distanciamento dos valores experimentais. 
Foi preparado um modelo com uma espessura reduzida para $33 \mathrm{~mm}$. Essa redução poderia modificar o comportamento das tensões obtidas experimentalmente com o modelo de menor espessura. Portanto, o objetivo dessa redução foi o de avaliar se haveria alterações no comportamento das tensões obtidas experimentalmente.

Os resultados com o modelo com 33mm de espessura foram semelhantes aos obtidos com modelos com 50mm de espessura. No entanto, em termos de intensidade de tensões, os resultados obtidos com modelos experimentais de menor espessura apresentaram ainda, tensões mais baixas do que na comparação com o modelo de $50 \mathrm{~mm}$ de espessura. Possivelmente, uma parcela expressiva do carregamento aplicado pela ancoragem foi resistido pelas paredes laterais do molde. Essa transferência de carga para as laterais do recipiente foi maior do que a ocorrida no modelo com $50 \mathrm{~mm}$ de espessura.

No carregamento de tração de AP, o comportamento da distribuição de tensões obtidas pelo modelo experimental mostrou maior aproximação de $\left(\sigma_{1}-\sigma_{2}\right)_{n u m}$ (Figura 4.17a). Na análise em termos de tensões máximas $\left(\tau_{\max }\right)$, da mesma forma como nos modelos de maior espessura, ocorreu a tendência dos comportamentos se coincidirem (Figura 4.17b).

Quando analisadas as tensões originadas pelo carregamento de compressão, o pontos experimentais obtidos sempre mostraram intensidades menores, mas comportamento parecido. Observando a diferença das tensões principais na compressão de AP, é possível perceber que os pontos de $\left(\sigma_{1}-\sigma_{2}\right)_{\exp }$ apresentaram a mesma tendência do modelo com 50mm de espessura (Figura 4.18a), mas intensidade menor. Isso reforça a suposição de que a fotoelasticidade pode proporcionar a leitura de tensões que retratam um sistema espacial, já que na análise por tensões cisalhantes máximas $\left(\tau_{\max }\right)$, o traçado da distribuição de tensões experimentais é parecido com as tensões obtidas numericamente (Figura 4.18b). 
(a)

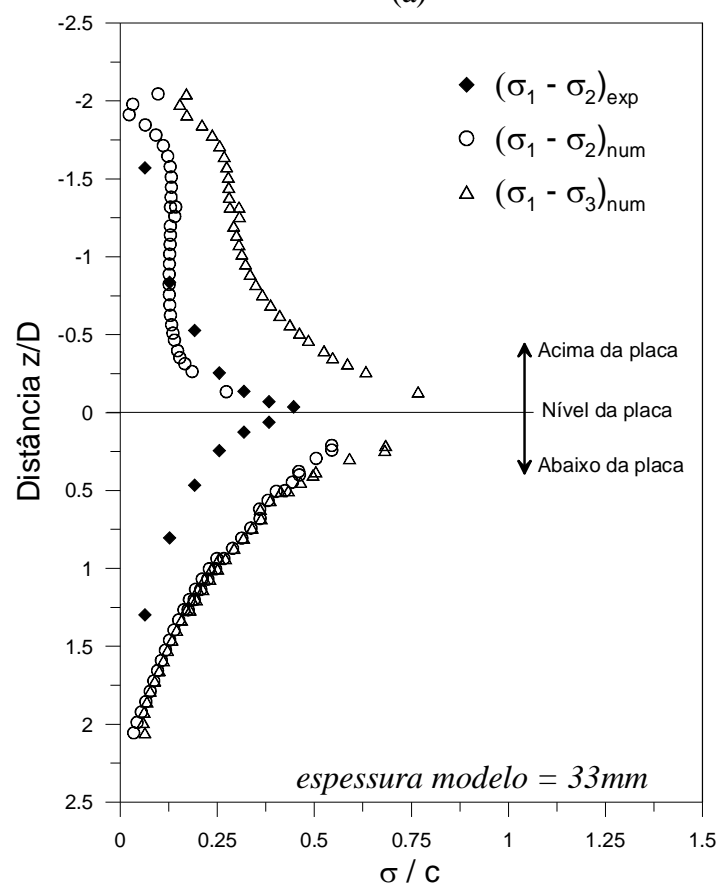

(b)

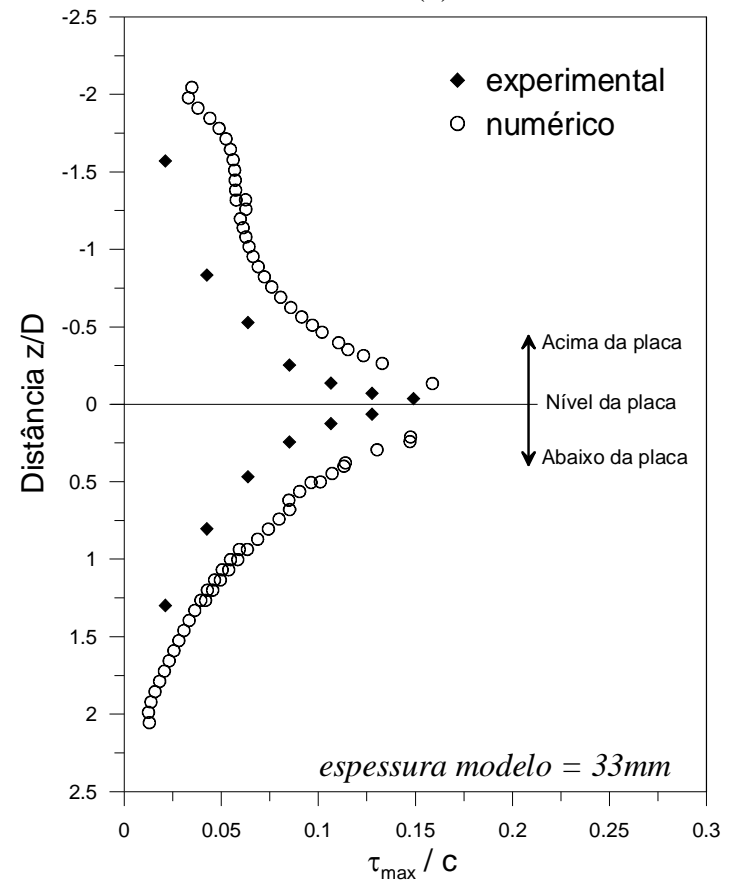

Figura 4.17 - Análise experimental e numérica na seção EE no arrancamento de AP com 15,5 N $\left(\sigma_{p}=3,13 c\right)$ em termos da (a) diferença das tensões principais e (b) tensões cisalhantes máximas.
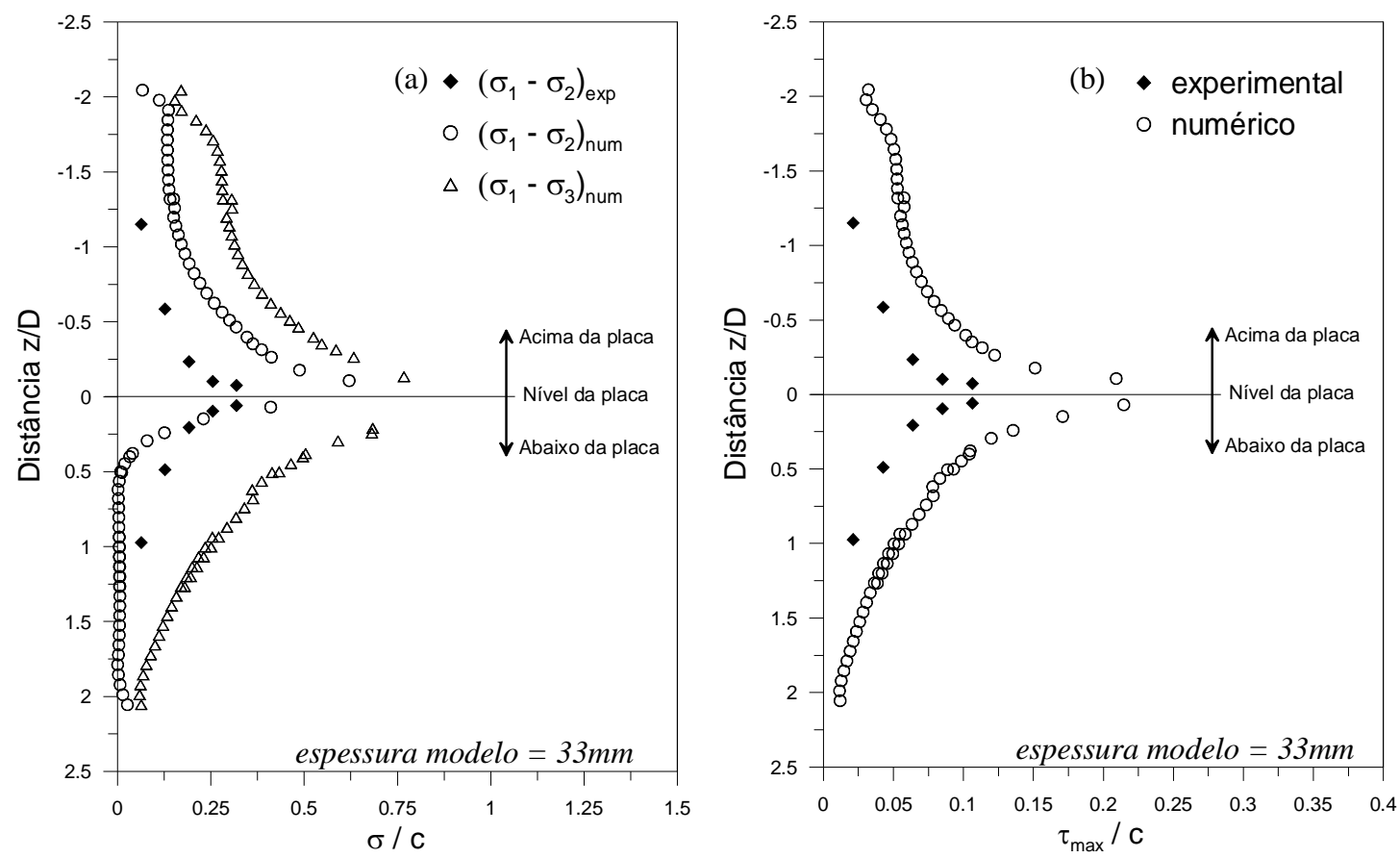

Figura 4.18 - Análise experimental e numérica na seção EE com carga de compressão de 13,3 N $\left(\sigma_{p}=2,69 c\right)$ em AP em termos da (a) diferença das tensões principais e (b) tensões cisalhantes máximas. 
Uma das aplicações da técnica da fotoelasticidade é a de fornecer parâmetros para o ajuste de modelos numéricos. O fato de $\left(\sigma_{1}-\sigma_{2}\right)_{\text {exp }}$ se aproximar mais de $\left(\sigma_{1}-\sigma_{2}\right)_{\text {num }}$ não implica em dizer que as tensões observadas por meio da técnica da fotoelasticidade representam os valores de $\left(\sigma_{1}-\sigma_{2}\right)$ do sistema tridimensional. $\mathrm{O}$ modelo fotoelástico em estudo foi concebido com o objetivo de proporcionar uma análise simplificada das tensões de um sistema espacial. Esta análise transformaria o estado tridimensional de tensões em um estado plano "simplificado". Assim, o resultado da análise fotoelástica deverá representar, de alguma forma, uma composição daquelas tensões originadas pelo carregamento naquele sistema tridimensional. Por isso é que ao se considerar o resultado em termos de tensões cisalhantes máximas, os pontos da análise experimental e numérica mostram razoável ajuste.

\subsubsection{Estaca Helicoidal "EH1” na profundidade igual a 2,5D (Ancoragem Rasa)}

Os ensaios realizados comparam os níveis de tensão originados por situações de carregamento na ancoragem plana e na estaca helicoidal. Foram analisadas as duas seções verticais EE e DD, devido à assimetria da estaca helicoidal. Todos os modelos foram preparados com o molde de acrílico R1, com 50mm de espessura. A Figura 4.19 mostra as isocromáticas obtidas com carregamento de tração e compressão com EH1.
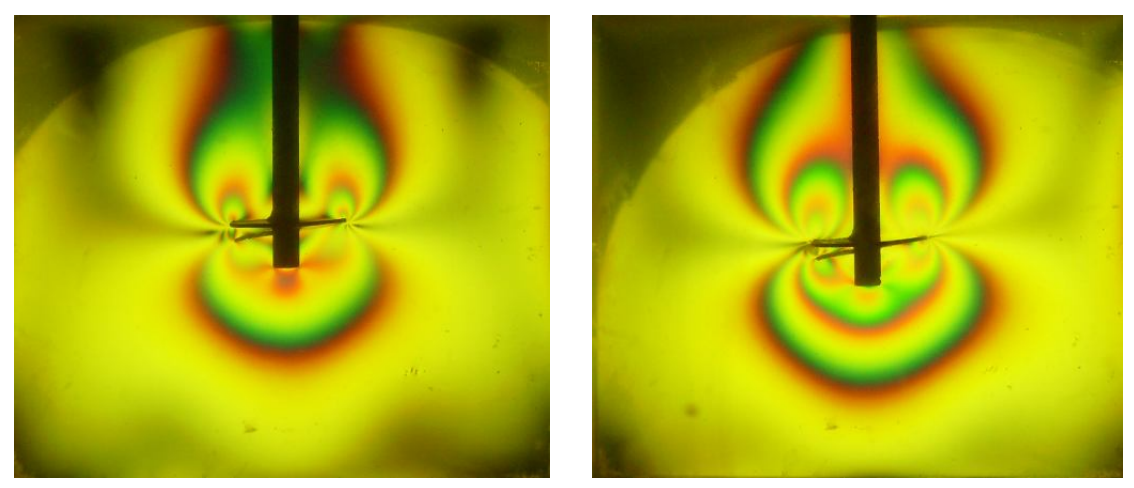

Figura 4.19 - Isocromáticas em carregamento de: (a) tração com 9,0 N e (b) compressão com 9,2 N com EH1. 
A Figura 4.20 mostra uma comparação da distribuição de tensões ao longo da seção em estudo, para avaliar a influência da geometria espacial da lâmina. Através da técnica da fotoelasticidade, constatou-se que os níveis de $\left(\sigma_{1}-\sigma_{2}\right)$ gerados pelo carregamento de EH1 foram em torno de $30 \%$ maiores a uma distância $1,5 \mathrm{D}$ da lâmina e $12 \%$ maiores à distância de $0,05 D$ da lâmina quando comparados com os valores obtidos com AP. Em comparação com a análise numérica de AP, a modelagem experimental da estaca EH1 apresentou menores valores de tensão na região abaixo da lâmina, assim como na análise fotoelástica de AP.

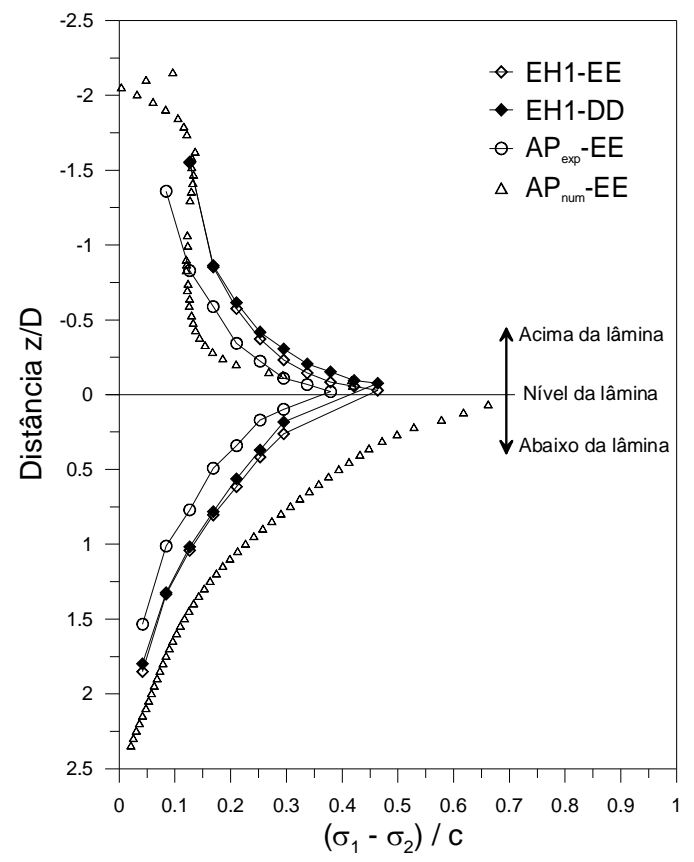

Figura 4.20 - Análise experimental e numérica em carregamento de $-15,0 \mathrm{~N}\left(\sigma_{p}=3,03 c\right)$ em AP e EH1.

Apesar da não-simetria vertical, a análise plana de tensões permitiu observar que as intensidades de tensão nas seções EE e DD são coincidentes na estaca helicoidal (Figura 4.21). Há variação apenas na posição geométrica das tensões em relação à referência adotada. Assim como na ancoragem AP, o ensaio com carga de compressão na estaca helicoidal EH1 foi conduzido com carregamentos mais baixos em relação aos ensaios de tração. O 
desvio de verticalidade, neste caso, passou a interferir nos resultados em cargas maiores que $9,0 \mathrm{~N}\left(\sigma_{p}=1,82 c\right)$.

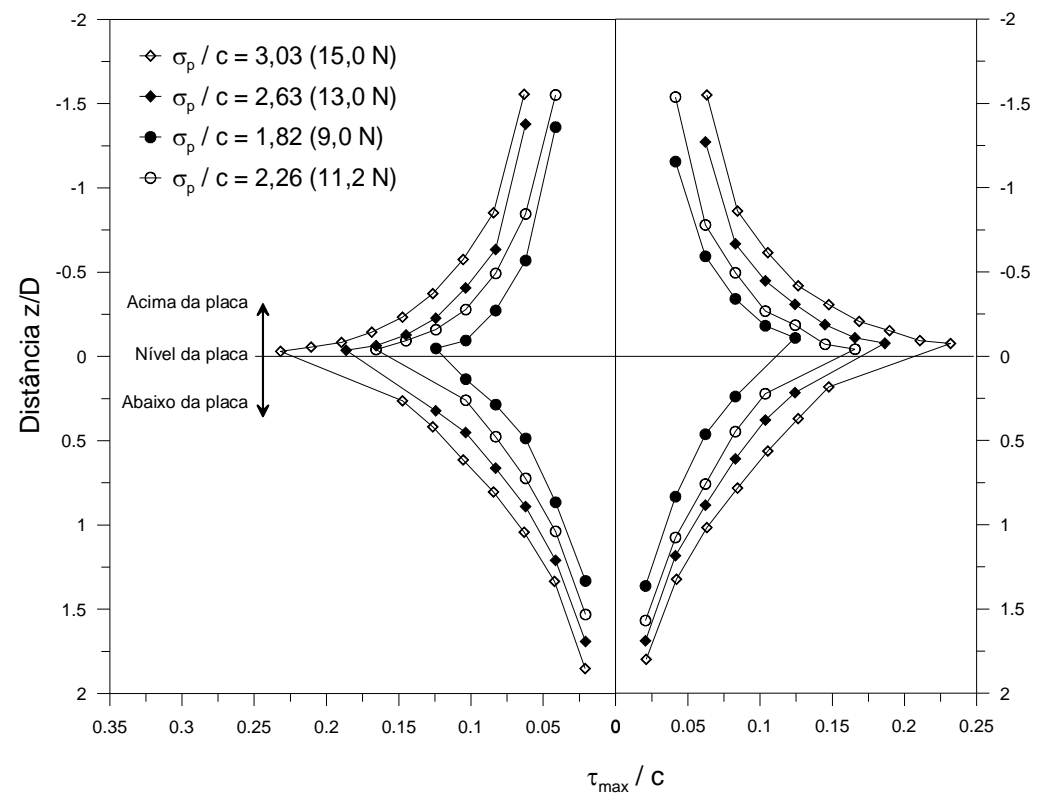

Figura 4.21 - Tração de EH1 com variação da ordem de $2 \mathrm{~N}\left(\Delta \sigma_{p}=0,40 c\right)$ e nas seções EE e DD, respectivamente.

Diferente do ocorrido no carregamento à tração, o comportamento sob compressão da estaca helicoidal EH1 foi semelhante ao comportamento na compressão de AP em uma distância maior que $0,25 D$ em relação à lâmina (Figura 4.22). A diferença do nível de tensões entre EH1 e AP na região próxima à lamina se deve à baixa resolução das isocromáticas no ensaio de EH1 naquela região, e não necessariamente a menores níveis de tensão. Desta forma, é possível considerar um elemento de ancoragem em forma de placa plana nas análises de estacas helicoidais em compressão.

Esta afirmativa é confirmada por meio de uma comparação realizada em uma seção horizontal imediatamente abaixo da extremidade de EH1 e AP. A sobreposição dos pontos mostra que a distribuição de tensões em um carregamento de compressão numa placa circular é equivalente à distribuição de tensões do mesmo carregamento em uma estaca helicoidal (Figura 4.23). 


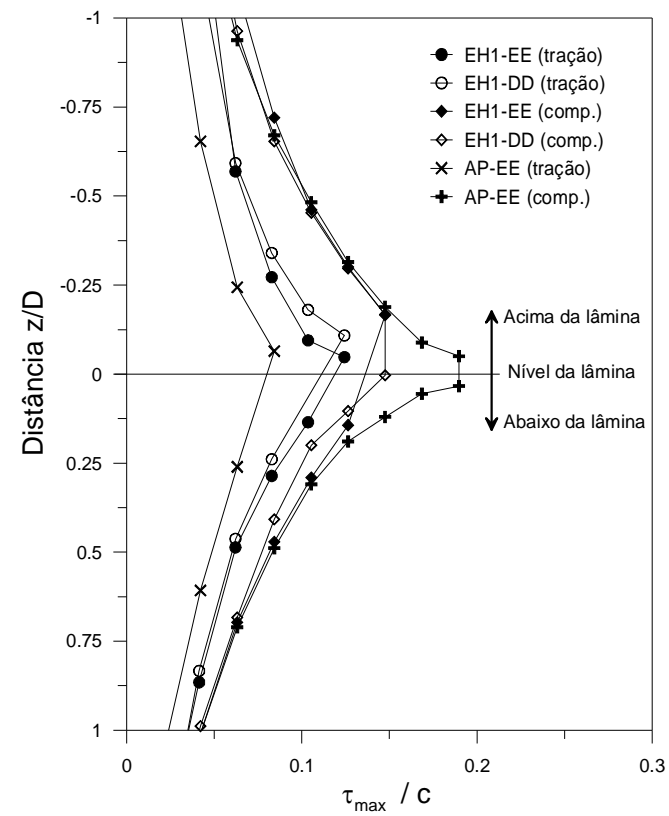

Figura 4.22 - Comparação entre AP e EH1, nas seções EE e DD em carregamento de $9,0 \mathrm{~N}\left(\sigma_{p}=1,82 c\right)$ de tração e compressão.

A diferença dos valores de tensões ocasionadas pela posição, em termos de rotação, também foi investigada. Uma comparação foi feita entre os resultados com a estaca EH1 moldada na posição ilustrada na Figura 3.7 e moldada com rotação uma de $90^{\circ}$ em relação ao seu eixo vertical.

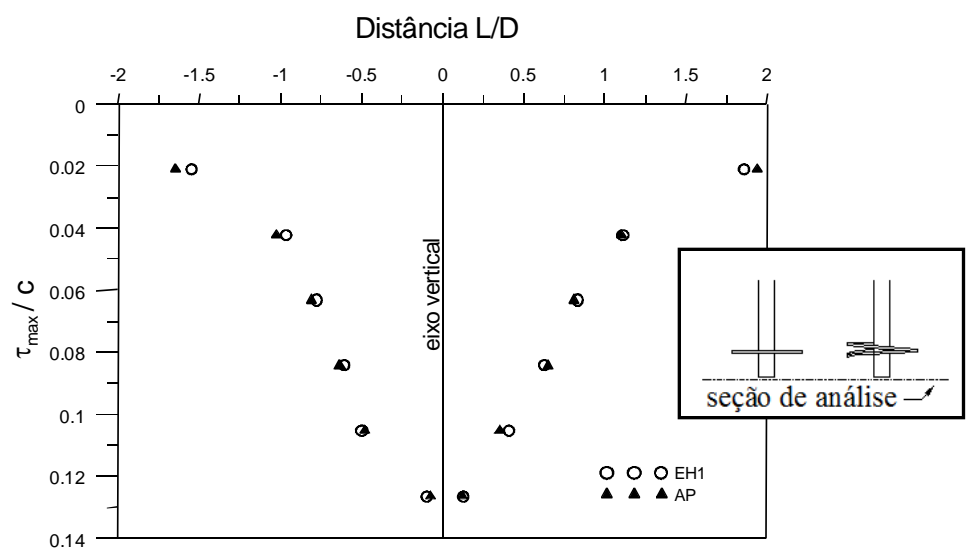

Figura 4.23 - Análise fotoelástica de tensões em seção horizontal nab compressão de $9,0 \mathrm{~N}\left(\sigma_{p}=1,82 c\right)$ das ancoragens, onde o ponto $(0,0)$ é o centro da ponta da haste. 
Entre as duas configurações, a posição em $0^{\circ}$ forneceu maiores intensidades de tensão (Figura 4.24). Para uma mesma posição de EH1, o nível máximo de tensão coincidiu entre as seções EE e DD. Quando a geometria da estaca helicoidal é tornada plana devido à análise fotoelástica, as extremidades da lâmina variam em relação a uma dada seção vertical. Por isso que se tem diferença na posição vertical das tensões máximas na extremidade da hélice.

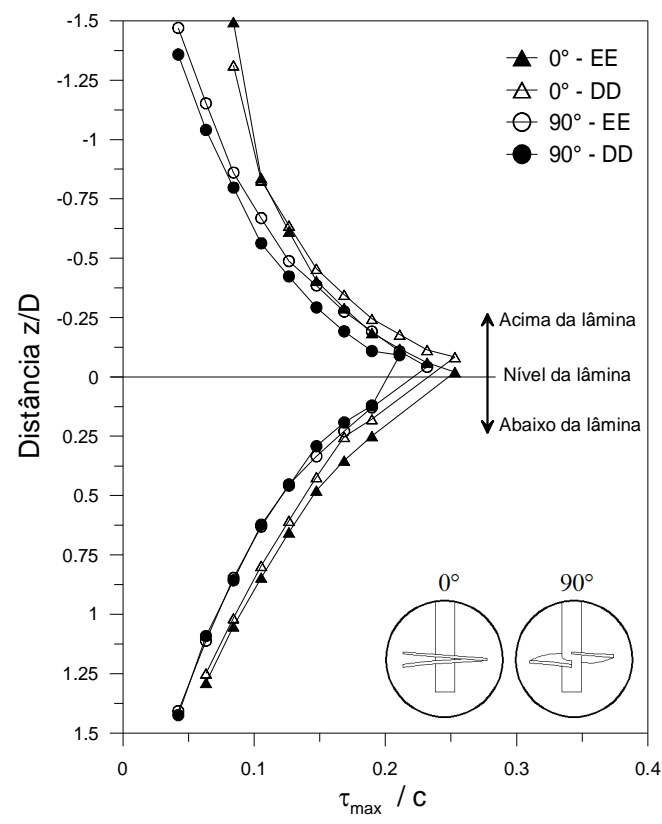

Figura 4.24 - Análise fotoelástica da estaca EH1 na posição a $0^{\circ}$ tração de $15,9 \mathrm{~N}\left(\sigma_{p}=3,21 c\right)$ e $90^{\circ}$ com tração de $15,7 \mathrm{~N}\left(\sigma_{p}=3,17 c\right)$.

\subsubsection{Estaca Helicoidal “EH2” na profundidade igual a 1,6D (Ancoragem Rasa)}

Como foi possível observar nos experimentos com AP e EH1, as isocromáticas originadas pelo carregamento alcançaram as bordas do modelo. Isso promoveu uma alteração nas configurações das franjas próximas àquela região. Utilizou-se então modelos com dimensões reduzidas para que a influência das condições de contorno fosse minimizada. Todos os modelos foram preparados com o molde de acrílico R1com espessura de 50mm.

Foram preparados dois modelos com gelatina para realizar os ensaios de tração. Nessas moldagens, foi possível observar a ocorrência de tensões residuais ocasionadas pela 
perda de água da gelatina. Tal fenômeno, abordado em 2.2.1.7, é chamado de efeito de borda e é muito difícil de ser evitado na gelatina, pois este material tem grande suscetibilidade à perda de água por evaporação. Desta forma, o controle da umidade e temperatura durante a moldagem e ensaios fotoelásticos deveria ser mais bem avaliado para minimizar o efeito de borda. Devido então à perda de água, registraram-se ordens de franjas de até $N=2$. No entanto estas tensões residuais parecem não afetar a distribuição de tensões no sistema.

A propagação de tensões até a superfície é resultado de sistemas de ancoragens rasas (Figura 4.25). A primeira isocromática a surgir é a de ordem $N=0$, juntamente com as manchas negras $N=0$ próximas à superfície inferior do modelo. Tais pontos indicam o lugar geométrico onde $\sigma_{1}$ é igual a $\sigma_{2}$. Ao evoluir o nível de carregamento de tração da haste, aparecem franjas de ordem superior. Com variação de $2,6 \mathrm{~N}\left(\sigma_{p}=1,63 c\right)$ para $3,8 \mathrm{~N}\left(\sigma_{p}=\right.$ $2,39 c$ ) de carregamento de tração, a isocromática $N=1$ intercepta a superfície.

O comportamento de uma ancoragem em função da profundidade crítica relativa $\left(H / D_{l}\right)_{c r}$ se refere ao mecanismo de propagação da superfície de ruptura e consequentemente, à propagação das tensões e deformações no instante em que o sistema rompe. No entanto, o estudo do mecanismo de propagação das tensões provocadas pelas cargas de serviço permite, por exemplo, avaliar as regiões críticas e regiões sob tensão no sistema de ancoragem com o incremento de carga. Tais regiões variam com a profundidade relativa.

Os contornos das isocromáticas de ordem inteira e meia ordem são mostrados na Figura 4.26 para carga de compressão de 7,9 N $\left(\sigma_{p}=4,97 c\right)$. De forma geral, as tensões geradas pela tração da estaca não ultrapassaram uma distância horizontal de $3 D$ na superfície. Cada contorno representa um nível de tensão $\tau_{\max }=0,02 c\left(\tau_{\operatorname{máx}}=0,15 \mathrm{kPa}\right)$. O valor da tensão de cisalhamento máxima $\tau_{\text {máx }}$ ao atingir a superfície foi de $\tau_{\max }=0,14 c(0,98 \mathrm{kPa})$. 
$\sigma_{p}=0(p=0)$
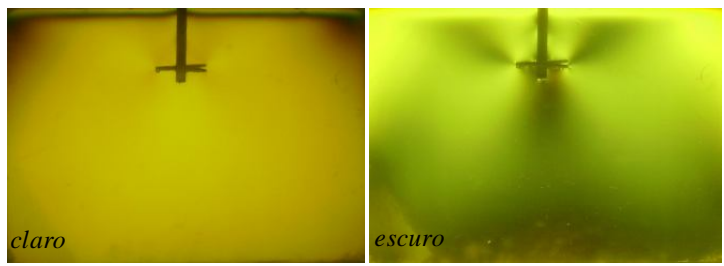

$\sigma_{p}=1,65 c(p=2,6 \mathrm{~N})$

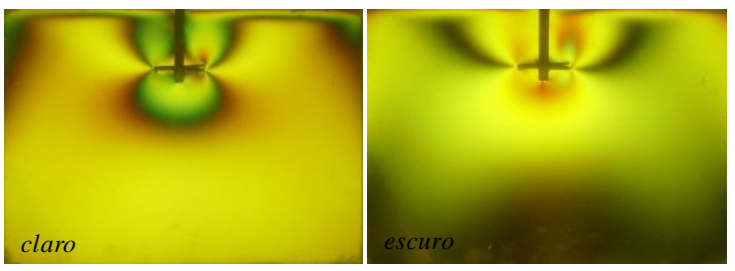

$\sigma_{p}=2,88 c(p=4,6 \mathrm{~N})$
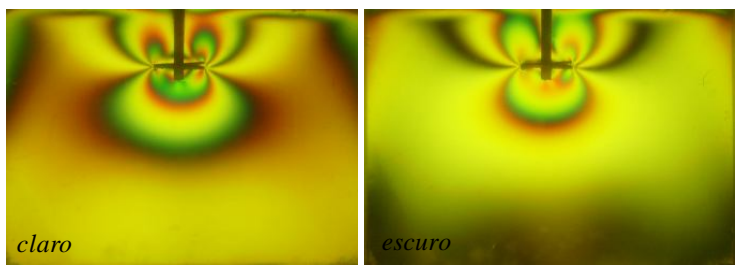

$\sigma_{p}=4,25 c(p=6,8 \mathrm{~N})$

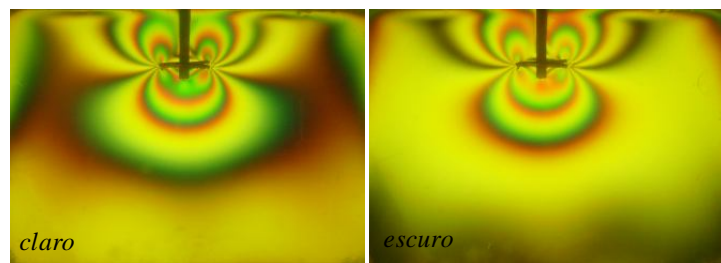

$\sigma_{p}=0,99 c(p=1,6 \mathrm{~N})$

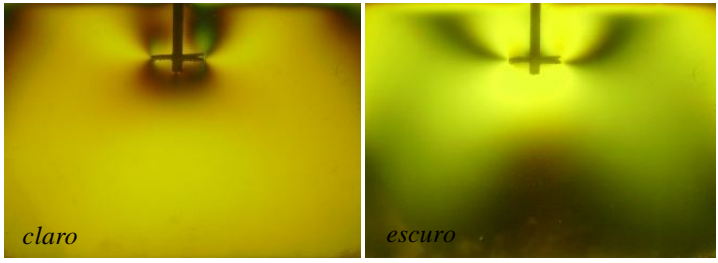

$\sigma_{p}=2,42 c(p=3,8 \mathrm{~N})$

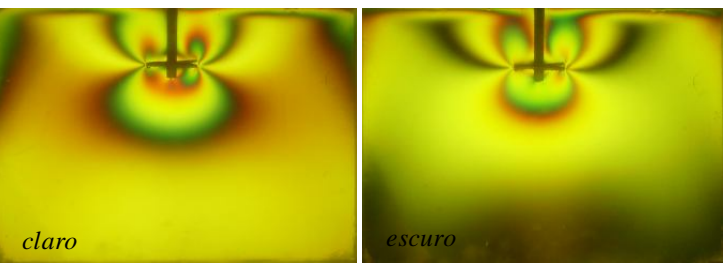

$\sigma_{p}=3,71 c(p=5,9 \mathrm{~N})$

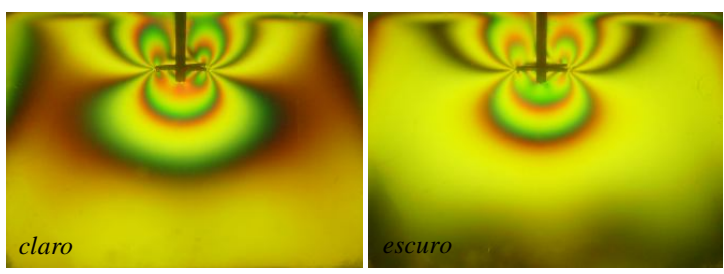

$\sigma_{p}=4,97 c(p=7,9 \mathrm{~N})$

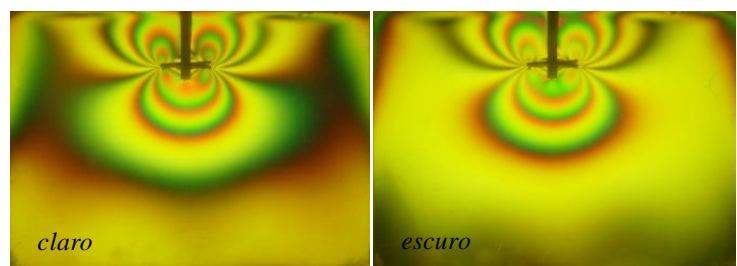

Figura 4.25 - Sequência do carregamento de tração da haste de EH2 com isocromáticas em campo claro e escuro.

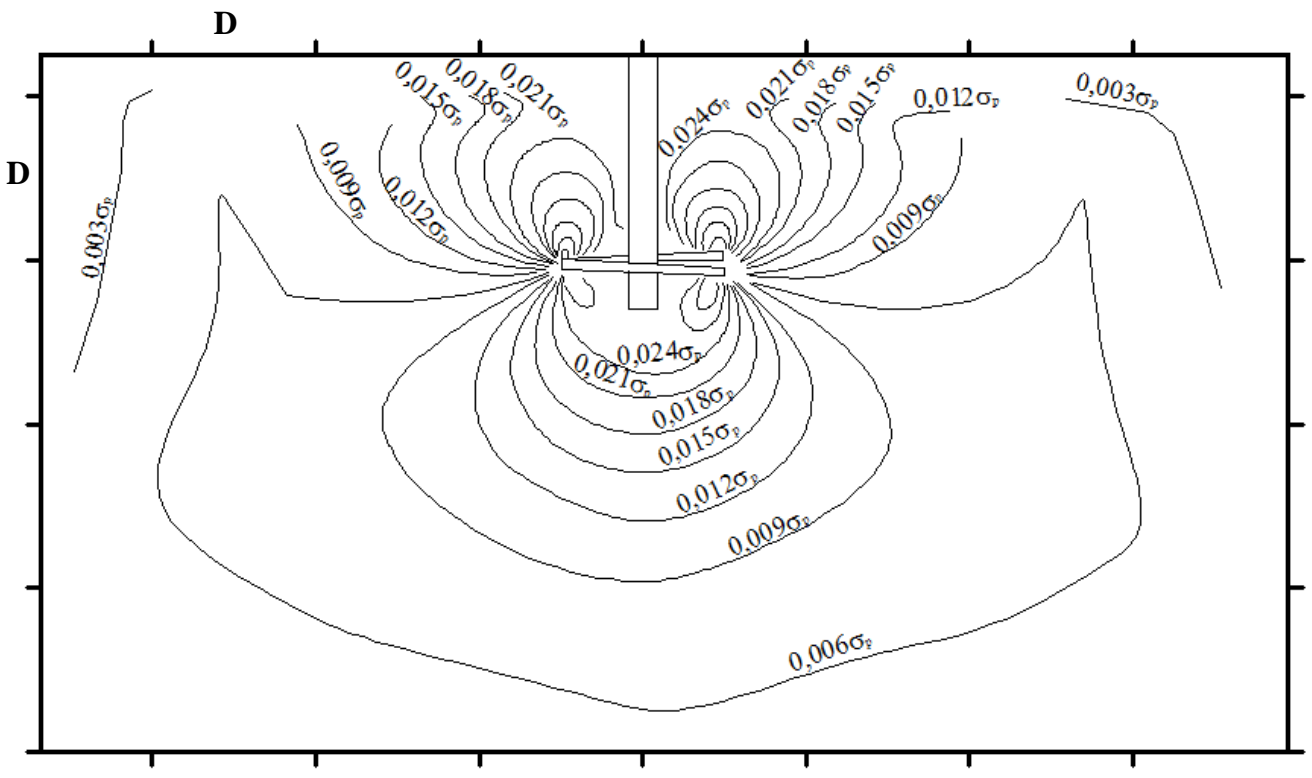

Figura 4.26 $-\tau_{\operatorname{maxx}}=0,15 \mathrm{kPa}\left(\tau_{\max }=0,02 c\right)$ por contorno na tração de $\mathrm{EH} 2 \operatorname{com} 7,9 \mathrm{~N}\left(\sigma_{p}=4,97 c\right)$. 
Ao analisar os modelos fotoelásticos descarregados observa-se que o peso próprio da gelatina moldada não produz isocromáticas. $\mathrm{O}$ molde de acrílico que confina a gelatina moldada recebe parte do carregamento de peso próprio da gelatina. Desta forma, o peso próprio deste material fotoelástico provocava uma mínima influência na distribuição de tensões do sistema.

\subsubsection{Estaca Helicoidal "EH2” na profundidade igual a 5,5D (Ancoragem Profunda)}

Na condição estudada de ancoragem profunda $5,5 D$, foi constatado que houve uma perda gradual de adesão na haste com início na superfície do terreno, representado pela gelatina. Se o intervalo de tempo entre a aplicação da carga e a captura da imagem não for suficiente para que ocorra o total deslizamento relativo na interface gelatina-haste, a distribuição de tensões do sistema será influenciada pela transferência de carga ocorrida pela adesão parcial da haste. Como resultado, a resistência de haste poderia ser superestimada. Entretanto, neste trabalho a captura das imagens foi realizada somente após a completa estabilização do deslocamento relativo na interface haste-gelatina.

A comparação das tensões $\tau_{\text {máx }}$ após a aplicação da carga e após a estabilização das isocromáticas é mostrada na Figura 4.27. Notou-se que a variação da adesão na interface gelatina-haste não provoca influencia na distribuição de tensões da lâmina helicoidal, pois os contornos na região da lâmina são idênticos. Este efeito somente foi observado na profundidade de $5,5 D$.

Com a utilização da estaca helicoidal EH2, com dimensões menores que a estaca helicoidal EH1, objetivou-se minimizar os efeitos das condições de contorno lateral. No entanto, mesmo com a utilização de EH2 e do molde R2, foi possível observar próximo aos limites laterais, valores de tensão da ordem de $10 \%$ dos valores de tensão observados em regiões bem próximas à lâmina. 
(a)

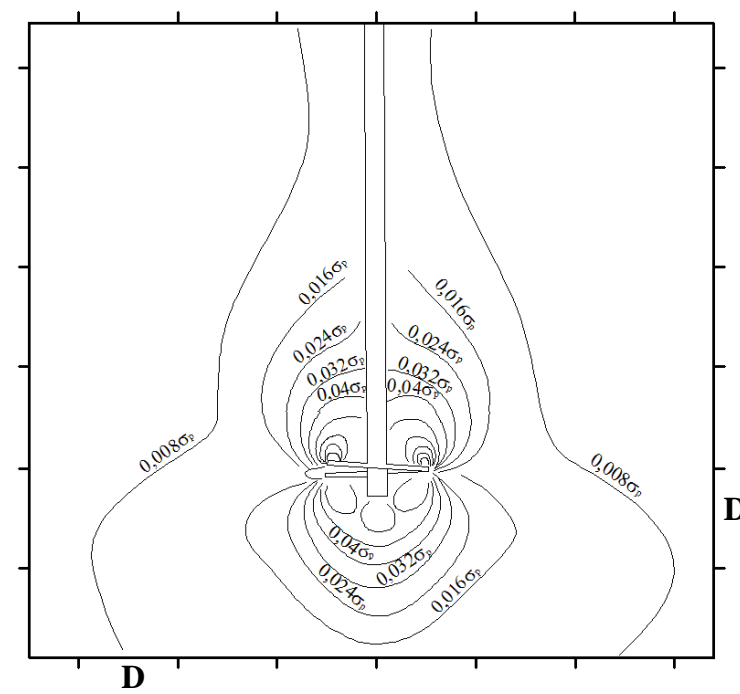

(b)

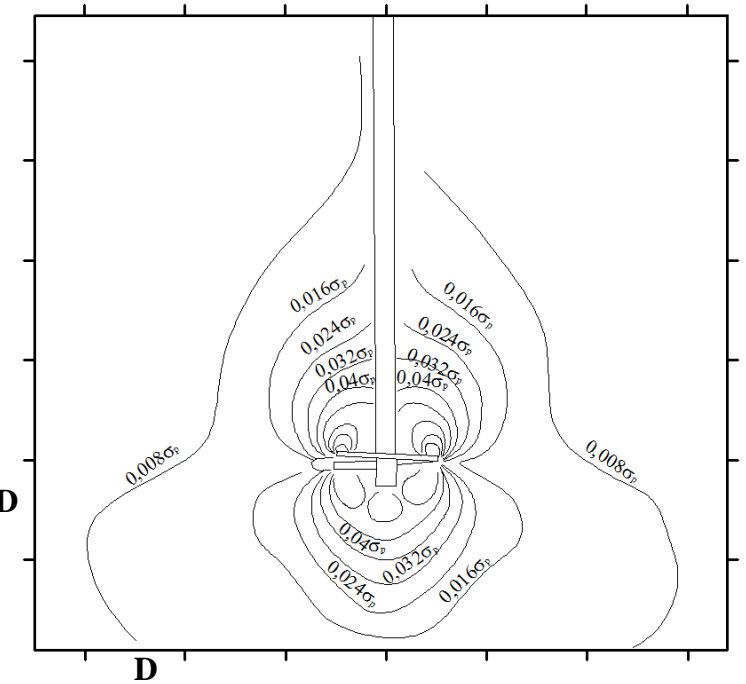

Figura 4.27 - Arrancamento por 10,5 N $\left(\sigma_{p}=6,61 c\right) \operatorname{com} \tau_{\max }=0,05 c\left(\tau_{\operatorname{máx}}=0,37 \mathrm{kPa}\right)$ por contorno. Captura da imagem (a) imediatamente após aplicação da carga e (b) após estabilização de isocromáticas, respectivamente.

Para avaliar o desenvolvimento das tensões no maciço, uma sequência de carregamento de tração é apresentada na Figura 4.28. Como esperado, pode-se observar a evolução das tensões e o efeito do vácuo na região inferior da lâmina, da mesma forma como foi observado por Baba, Gulhati e Datta (1989) e Das et al. (1994) em argilas marinhas. As isocromáticas de ordem inteira não interceptam a superfície do terreno. Então como na ruptura, este sistema tem comportamento de ancoragem profunda. A região mobilizada pelo carregamento não se prolongará até a superfície. 


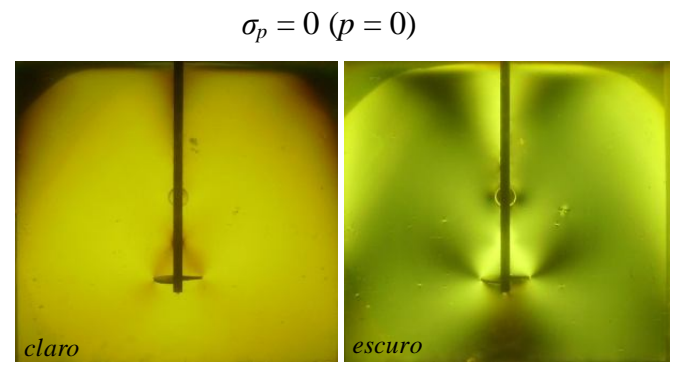

$\sigma_{p}=1,82 c(p=2,9 \mathrm{~N})$

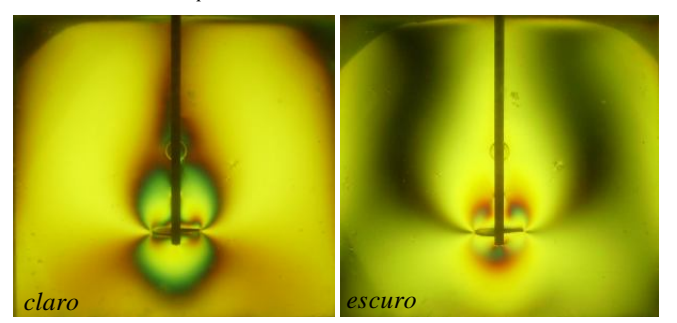

$\sigma_{p}=3,13 c(p=5,0 \mathrm{~N})$

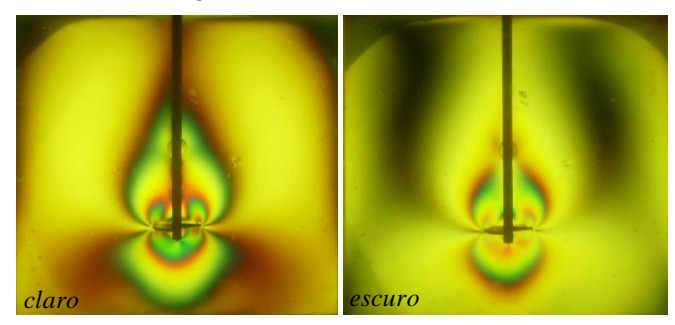

$\sigma_{p}=4,41 c(p=7,0 \mathrm{~N})$

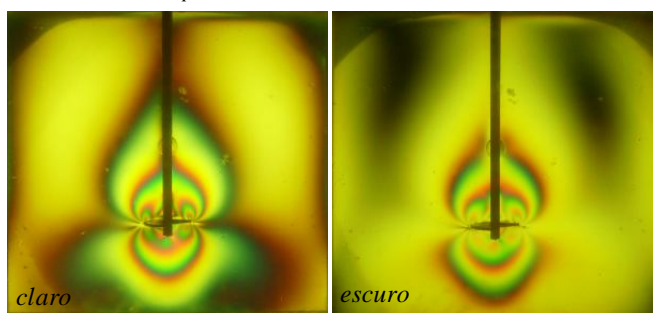

$\sigma_{p}=1,29 c(p=2,0 \mathrm{~N})$

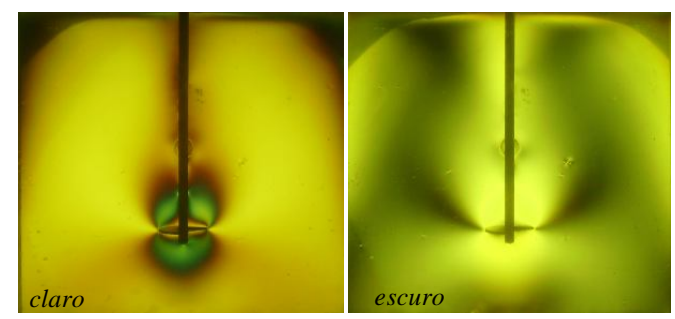

$\sigma_{p}=2,50 c(p=4,0 \mathrm{~N})$

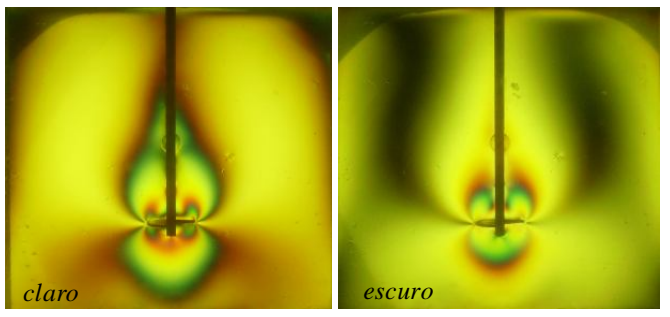

$\sigma_{p}=3,75 c(p=6,0 \mathrm{~N})$

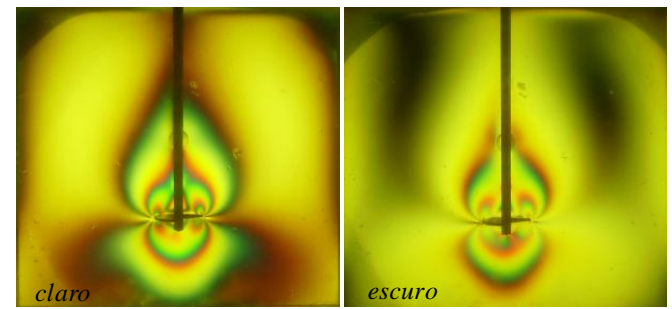

$\sigma_{p}=5,00 c(p=8,0 \mathrm{~N})$

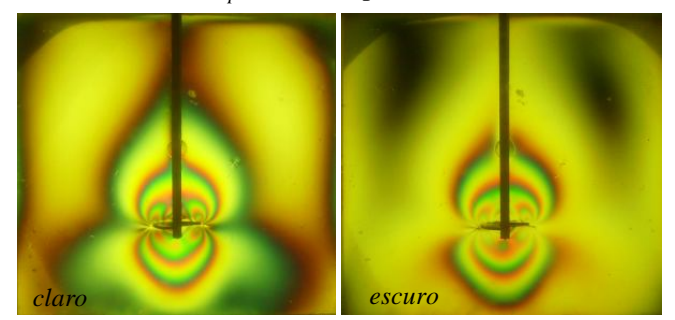

Figura 4.28 - Isocromáticas em ensaio de tração de EH2.

Foi feita uma comparação entre as distribuições de tensões para as duas profundidades de ancoragem. A carga transferida para a gelatina por meio da resistência de interface hastegelatina foi desprezível em ambos os casos (Figura 4.29). Na ancoragem a 1,6D de profundidade, a borda delimitada pela superfície acima da ancoragem promoveu uma maior propagação horizontal das tensões. Fato que não ocorre na ancoragem profunda pois a condição de borda superior não interfere na distribuição de tensões, concentrando tais tensões na região da hélice. Portanto, as tensões geradas foram maiores no carregamento da ancoragem em maior profundidade. 


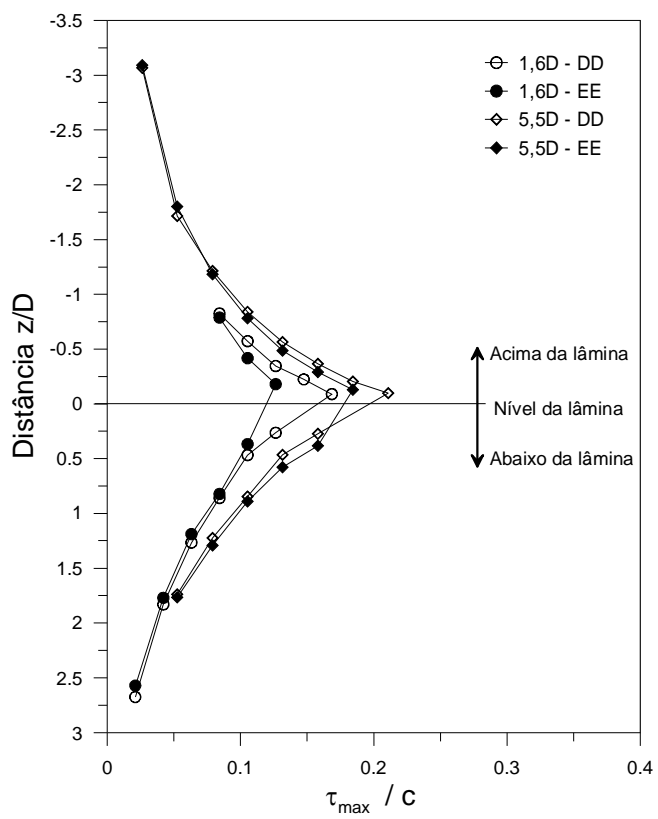

Figura 4.29 - EH2 nas profundidades iguais a 1,6 e 5,5D com 8,0 N $\left(\sigma_{p}=5,03 c\right)$ de tração .

A família de isoclínicas e a direção das tensões principais em carregamento de tração em EH2 são mostradas na Figura 4.30a. Foi possível visualizar todas as franjas capturadas a cada rotação de $15^{\circ}$ do conjunto de lentes no sentido horário. Os dois pontos singulares onde ocorre a concentração das isoclínicas não indicam um ponto isotrópico. A variação na inclinação das tensões principais pode indicar concentração de carga pela ancoragem (Figura 4.30b). Na vizinhança dos pontos de aplicação de carga concentrada, a direção das tensões principais varia de 0 a $180^{\circ}$, por isso as isoclínicas convergem a um único ponto.

(a)

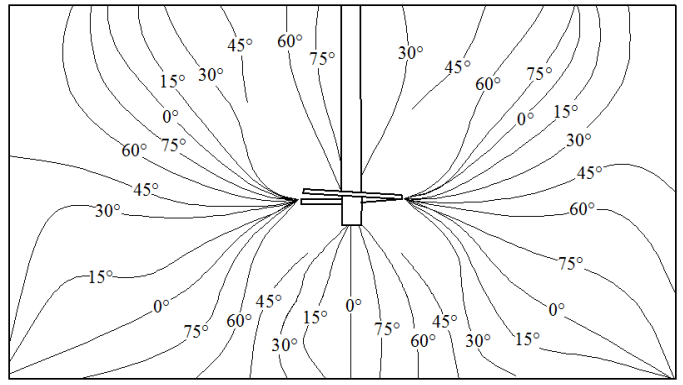

Figura 4.30 - (a) Família de isoclínicas e (b) direção das tensões principais sob carregamento de tração. (b)

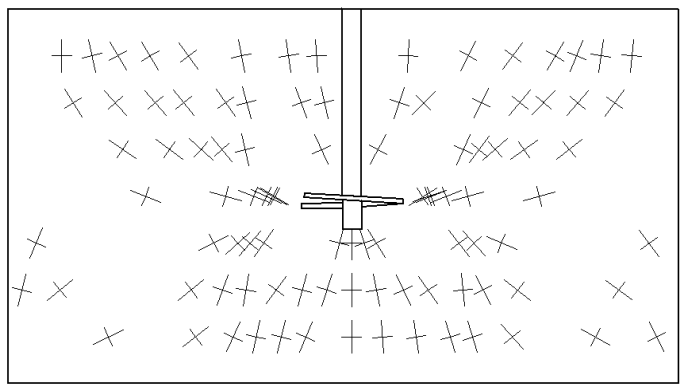




\section{CONCLUSÃO}

Neste trabalho é apresentada uma técnica experimental de análise de tensões de campo completo. Por meio da técnica da fotoelasticidade foi realizado um estudo experimental da distribuição de tensões geradas por uma ancoragem em placa e por estacas helicoidais (rasa e profunda) sob carregamento de tração e compressão em um meio elástico contínuo que representa um solo puramente coesivo de comportamento elástico-linear.

A partir deste estudo foi possível validar a técnica da fotoelasticidade para sua aplicação em análises de sistemas geotécnicos no Departamento de Geotecnia da EESC. Foram estabelecidos procedimentos experimentais para o uso da gelatina na representação do solo, de modo que análises experimentais de tensão pudessem ser realizadas. A partir da utilização dos conceitos expostos neste trabalho, novas pesquisas poderão ser realizadas com o uso da técnica da fotoelasticidade.

Esta técnica permitiu avaliar de forma simples e com boa precisão a distribuição de tensões em sistemas com geometria complexa. A análise numérica desses sistemas só poderia ser realizada com poderosos programas que utilizam o método dos elementos finitos, demandando muito tempo para a sua preparação e pesados recursos computacionais. Portanto, a técnica da fotoelasticidade é uma poderosa ferramenta que pode ser utilizada como alternativa, ou mesmo aliada, nas análises de tensões, corroborando os resultados obtidos experimentalmente com os resultados das análises numéricas.

A comparação entre as tensões obtidas por meio da análise experimental e numérica possibilitou validar os resultados obtidos com a técnica da fotoelasticidade neste estudo. Mostrou-se que as tensões observadas por meio da fotoelasticidade apresentam correspondência com os valores de tensão obtidos pela modelagem numérica quando são considerados os mesmos parâmetros elásticos dos materiais experimentais. Portanto, a análise 
fotoelástica pode fornecer, de maneira simplificada, uma composição de tensões originadas pelo carregamento em uma fundação com elemento de geometria complexa.

No estudo de fundações por estacas helicoidais, o presente trabalho permitiu comparar o efeito da geometria da placa de ancoragem com a estaca helicoidal. Com isso, foi possível determinar as diferenças entre as distribuições de tensões geradas pela ancoragem plana e pela ancoragem helicoidal, bem como as diferenças entre sistemas de ancoragem rasa e profunda na situação de carregamento de serviço. As análises permitiram estabelecer simplificações em análises de projeto, contribuindo para a melhoria do conhecimento do comportamento em serviço das fundações por estacas helicoidais

\subsection{Sugestões para Trabalhos Futuros}

Mediante a revisão bibliográfica realizada observou-se que a utilização da fotoelasticidade é limitada ao estudo da diferença das tensões principais ou tensões cisalhantes máximas. Estudos mais aprofundados que utilizem a técnica exigem o emprego de métodos numéricos e/ou técnicas mais complexas para separação das tensões principais. Constatou-se também que alguns estudos com fotoelasticidade tridimensional já foram desenvolvidos com o uso da gelatina como material fotoelástico. Com base nestes argumentos, sugere-se a realização dos seguintes estudos futuros:

- Aplicar um método que proporcione a separação das tensões principais, seja pela utilização dos métodos propostos na literatura, algoritmos e métodos numéricos.

- Realizar análises fotoelásticas tridimensionais utilizando a gelatina ou outro material.

- Avaliar o efeito do espaçamento entre as hélices e a distância entre ancoragens.

- Tendo em vista trabalhos que trazem curvas carga-recalque de ancoragens analisadas por meio de métodos numéricos, realizar análises fotoelásticas com o registro dos deslocamentos das ancoragens para comparação com análises numéricas. 


\section{REFERÊNCIAS}

A.B. CHANGE CO. JULY 2010. Produced by Hubbell Power Systems, Inc. Disponível em: <http://www.abchance.com/helical/>. Acesso em: 10 ago. 2010.

AGARWAL, B. D.; CHATURVEDI, S. K. Development and Characterization of Optically Superior Photoelastic Composite Materials. International Journal of Mechanical Sciences. Great Britain, Vol. 20, No. 7, p. 407-414, 1978.

ALLERSMA, H. G. B. Optical analysis of stress and strain around the tip of a penetration probe. In: International Conference on Penetration Testing, 1, 1988, Orlande, Florida. Anais... Orlande, 1988, p. 615-620.

ARAÚJO, C. A. Módulo I: Mecânica Aplicada. Uberlândia: Universidade Federal de Uberlândia, 2006. (apostila). 45 p.

ARAÚJO, C. A. Módulo II: Fotoelasticidade de transmissão plana. Uberlândia: Universidade Federal de Uberlândia, 2006. (apostila). 58 p.

ARAÚJO, C. A.; NEVES, F. D.; BERNARDES, S. R. Análise de tensões em implantes dentários utilizando a técnica fotoelástica. In: Congresso Nacional de Engenharia Mecânica, 3, Belém, Brasil. Anais... Belém, 2004, 13 p. 
ASHFORD, S. A.; SITAR, N. Effect of Element Size on the Static Finite Element Analysis of Steep Slopes. International Journal for Numerical and Analytical Methods in Geomechanics, Vol. 25, No. 14, p. 1361-1376, 2001.

ASUNDI, A. KISHEN, A. Stress Distribution in the Dento-Alveolar System Using Digital Photoelasticity. Journal of Engineering in Medicine. Professional Engineering Publishing Ltd., Vol. 214, No. 6, p. 659-667, 2000.

BABA, H. U.; GULHATI, S. K.; DATTA, M. Suction effect in plane anchors in soft clay. In: International Conference on Soil Mechanics and Foundation Engineering, 12, Rio de Janeiro, Anais... Rio de Janeiro, 1989, p. 409-412.

BERNARDES S. R.; ARAÚJO, C. A.; FERNANDES NETO, A. J.; GOMES, V. L. Análise fotoelástica da união de pilara implantes de hexágonos externo e interno. Implant News. Vol. 3, No. 4, p. 355-359, 2006.

BHOWMIK, A. K. On Photoelastic Stress Measurements in Optically Absorbing Medium. Optics Communications. Elsevier Science B.V., Vol. 210, No. 3-6, p. 165-172, 2002.

BURKI, N. K.; RICHARDS JR, R. Photoelastic Analysis of a Cofferdam. Journal of the Geotechnical Engineering Division. ASCE, Vol. 101, No. GT2, p. 129-145, 1975.

CHAKRABARTY, J. Theory of Plasticity. 3a Ed. U.S.A.: McGraw-Hill Book Co. 2006. 895 p. 
CHANDRASHEKHARA, K.; ANTONY, S. J. Theoretical and Experimental Investigation of Framed Structure-Layered Soil Interaction Problems. Computers and Structures, Great Britain, Vol. 48, No. 2, p. 263-271, 1993.

CHANDRASHEKHARA, K.; ANTONY, S. J. Interaction Analysis of Strip Footing Resting on a Non-homogeneous Elastic Medium. Computers and Structures, Great Britain, Vol. 60, No. 1, p. 79-86, 1996.

CHANDRASHEKHARA, K.; JACOB, K. A. Photoelastic Analysis of Composite Action of Walls Supported on Beams. Building and Environment, Great Britain, Vol. 11, No. 2, p. 139-144, 1976.

CLEMENCE, S.P. Uplift Behavior of anchor Foundations in Soil. In: A session sponsored by the Geotechnical Engineering Division of the American Society of Civil Engineers in conjunction with the ASCE Convention, Detroit, Michigan. Anais... Detroit: American Society of Civil Engineers, 1985, p. 126.

CLEMENCE, S.P.; CROUCH, L.K., STEPHENSON, R.W. Prediction of uplift capacity for helical anchors in sand. $2^{\text {nd }}$ Geotechnical engineering Conference, Vol.2, Cairo, Egito. Anais... Cairo, 1994, p. 332-343.

Da ROCHA, A. M. Teoria da Elasticidade. 1a Ed. Rio de Janeiro: Cia Brasileira de Artes Gráficas. 1950. 137 p. 
DAMACENO, A. R. D. Análise Fotoelástica da Influência de Intermediários Protéticos na Distribuição de Tensões Induzidas por Infra-estrutruas Implanto-Suportadas Submetidas à Soldagem a Laser. 2007, 108 p., Tese de Doutorado, Faculdade de Odontologia de Piracicaba, Universidade Estadual de Campinas, Piracicaba, 2007.

DALLY, J. W.; RILLEY, W. F. Experimental Stress Analysis. 3a Ed. U.S.A.: McGraw-Hill Book Co. 1991. 639 p.

DAS, B. M. Model tests for uplift capacity of foundations in clay. Soils and Foundation. Vol. 18, No.2, p. 17-24, 1978.

DAS, B. M. A procedure for estimation of ultimate uplift capacity of foundations in clay. Soils and Foundations. Vol. 20, No. 1, p. 77-82, 1980.

DAS, B. M. Earth Anchors. Elsevier Science, First edition, Amsterdam, 1990, p. 252.

DAS, B. M.; SEELEY, G. R. Breakout resistance of horizontal anchors. Jounal of Geotechnical Engineering Division. ASCE, Vol. 101, No.9, p. 999-1003, 1975.

DIJKSTRA, J.; BROERE, W.; VAN TOL, A. F.; Measurement of Stress and Strain Development Around a Pile in a Photoelastic Granular Material. In: International Symposium on Geomechanics and Geotechnics of Particulate Media. 2006, Ube, Yamaguchi, Japan. Anais... London, 2006, p. 335-338. 
DRESCHER, A.; De JONG, G. J. Photoelastic Verification of a Mechanical Modelo for the Flow of a Granular Material. Journal of the Mechanics and Physics of Solids. Great Britain, Vol. 20, No. 5, p. 337-351, 1972.

DURELli, A. J.; PARKS, V. J.; NORGARD, J. S. Photoelastic Solution of Stresses in the Elastic Foundation Supporting a Plate. International Journal of Solids Structures. Great Britain, Vol. 9, No. 2, p. 193-202, 1973.

EPSTEIN, J. S., LLOYD, W. R. Refined Methods in Photoelastic Stress Analysis with Applications to Fracture Mechanics. Optics and Lasers in Enginering. Vol. 14, No. 3, p. 185-202, 1991.

FAKHOURI, S. F. Distribuição de Tensões de Parafusos do Sistema de Fixação Vertebral Submetidos a Arrancamento Utilizando Fotoelasticidade de Transmissão Plana. 2008, 158 p. Tese de Doutorado, Faculdade de Medicina de Ribeirão Preto, Universidade de São Paulo, Ribeirão Preto, 2008.

FAKHOURI, S. F.; SIQUEIRA, D. P. P.; ARAÚJO, C. A.; DEFINO, H. L. A.; SHIMANO, A. C. Análise fotoelástica de parafuso de sistema de fixação vertebral. Acta Ortopédica Brasileira. Vol. 17, No. 4, p. 207-210, 2009.

FARQUHARSON, F.B.; HENNES, R.G. Gelatin Models for Photoelastic Analysis of Stress on Earth Masses. Civil Engineering. Vol. 10, No. 4, p. 211-214, 1940. 
FÉODOSIEV, V. Resistência dos Materiais. K. Asryantz. Porto: Edições Lopes da Silva, 1977, 591 p.

FIALHO, J. L. Análise Experimental de Tensões, 1a Ed. Vol.2. Lisboa: LNEC., 1979, 179p.

FLEURY, S. V. Análise Da Distribuição De Tensões Em Descontinuidades De Rocha Utilizando A Técnica Da Fotoelasticidade. 2001. 147 p. Dissertação de Mestrado, Universidade de Brasília, Brasília, 2001.

FLEURY, S. V.; ASSIS, A. P. Análise da Distribuição de Tensões em Descontinuidades de Rocha Utilizando a Técnica da Fotoelasticidade. In: XII Congresso Brasileiro de Mecânica dos Solos e Engenharia Geotécnica, I Congresso Luso-Brasileiro de Geotecnia e III Simpósio Brasileiro de Mecânica das Rochas, 2002, São Paulo, Anais... 2002. v. Único. p. 79-90.

FROCHT, M. M. Photoelasticity, 1a Ed. Vol. 1. U.S.A.: John Wiley \& Sons, Inc. 1941. 411 p.

GABR, M. A.; BORDEN, R. H.; CHO, K. H.; CLARK, S.; NIXON, J. B. P-y Curves for Laterally Loaded Drilled Shafts Embedded in Weathered Rock. North Carolina: North Carolina State University - Department of Civil Engineering, 2002, 289 p. (Technical Report).

GOMES, J.F.S. Análise Experimental de Tensões por Fotoelasticidade. 1a Ed. Laboratório Nacional de Engenharia Civil, Lisboa, 1984, 234 p. 
GOMIDE, H.A. Desenvolvimento de um material para fotoelasticidade tridimensional. In: Congresso Brasileiro de Engenharia Mecânica, 3, 1975, Rio de Janeiro, Anais... 1975, p. 27 42.

GOMIDE, H. A.; OLIVEIRA, S. A. G. . Materiais para Fotoelasticidade de Reflexão. RBCM-Revista Brasileira de Ciências Mecânicas, Rio de Janeiro, Vol. 11, No. 1, p. 87$100,1989$.

GOMIDE, H. A.; SMITH NETO, P. Materiais de Rápida Obtenção para Fotoelasticidade Tridimensional. In: VI CBECIMAT - Congresso Brasileiro Engenharia e Ciências dos Materiais, 1984, Rio de Janeiro. Anais... Rio de Janeiro: CBECIMAT - Rio de Janeiro, 1984. Vol. 1, p. 303-306.

GRECULA, M. J.; MORRIS, R. P. LAUGHLIN, H. C.; BUFORD, W. L. JR; PATTERSON, R. M. Femoral surface strain in intact composite femurs: a custom computer analysis of the photoelastic coating technique. IEEE Transactions on Biomedical Engineering. Institute of Electrical and Electronics Engineers Inc., Vol. 47, No. 7, p. 926-933, 2000.

GUAGLIANO, M.; SANGIRARDI, M.; VERGANI, L. Photoelastic Methods to determine K $\mathrm{K}_{\mathrm{I}}, \mathrm{K}_{\mathrm{II}}$ and $\mathrm{K}_{\mathrm{III}}$ of internal cracks subjected to mixed mode loading. International Journal of Fatigue. Elsevier Ltd, Vol. 28, No. 5-6, p. 576-582, 2006.

HENDRY, A. W. Photoelastic Analysis. 1a Ed. London: Pergamon Press Ltd. 1966. 155 p. 
HOFFMAN, O.; SACHS, G. Introduction to the theory of plasticity for engineers. $1 \mathrm{a}$ Ed. U.S.A.: McGraw-Hill Book Co. 1953. 290 p.

HOYT, R. M.; CLEMENCE, S.P. 1989. Uplift Capacity of Helical Anchors in Soil. In: International Conference on Soil Mechanics and Foundation Engineering, 12., 1989, Rio de Janeiro, Anais... Rio de Janeiro, Vol. 2, p. 1019-1022.

JONES, L. C.; HUNGERFORD, D. S. Measurement of Strain in the Fresh Human Femur Using the Photoelastic Coating Technique. Transactions of the Eleventh Annual Meeting of the Society for Biomaterials. In: Conjunction with the Seventeenth International Biomaterials Symposium, 1985, San Diego. Anais... Society for Biomaterials, 1985. Vol. 8, p. 199.

KHANA, S. K.; ELLINGSEN, M. D., WINTER, R. M. Investigation of fracture in transparent glass fiber reinforced polymer composites using photoelasticity. Journal of Engineering Materials and Technology, Transactions of the ASME. ASME, Vol. 126, No. 1, p. 1-7, 2004.

KULHAWY, F. H. Uplift Behavior of Shallow Soil Anchors. In: A session sponsored by the Geotechnical Engineering Division of the American Society of Civil Engineers in conjunction with the ASCE Convention, Detroit, Michigan. Anais...1985, p. 1-25.

KURIAN, N.P.; SHAH, S.J. Studies on the behaviour of screw piles by the finite element method. Canadian Geotechnical Journal. Vol. 46, No.6, p. 627-638, 2009.

KUSKE, A.; ROBERTSON, G. Photoelastic Stress Analysis. 1a Ed. U.S.A.: John Wiley \& Sons, Inc. 1974. 519 p. 
LI, Y. Compressive Behaviour of Grouted Helical Foundations. 2006. 238 p. Tese (Doutorado em Engenharia Civil) - Universidade de Siracusa, 2006.

LIVNEH, B. AND EL NAGGAR, M.H. Axial load testing and numerical modeling of square shaft helical piles. Canadian Geotechnical Journal. Vol. 45, No. 8, 2008, p.1142-1155.

MAHMOUD, M. A.; HOSSEINI, A. Assessment of Stress Intensity Factor and Aspect Ratio Variability of Surface Cracks in Bending Plates. Engineering Fracture Mechanics. Vol. 24, No. 2, p. 207-221, 1986.

MATLOCK, H. Correlations for Design of Laterally Loaded Piles in Soft Clay, In: Offshore Technology Conference, 2., Dallas, Texas, Anais... Dallas, Vol. 1, 1970, p. 577-594.

MEASUREMENT GROUP, INC. Introduction to stress analysis by photostress method. Tech Note TN-702, Raleigh, USA, 12 p. 1981.

MEGUID, S. A.; GONG, S. X.; Stress Concentration Around Interacting Circular Holes: A Comparison Between Theory and Experiments. Engineering Fracture Mechanics. Great Britain, Vol. 44, No. 2, p. 247-256, 1993.

MERIFIELD, R. S.; LYAMIN, A. V.; SLOAN, S. W.; YU, H. S. Three-Dimensional Lower Bound Solutions for Stability of Plate Anchors in Clay. Journal of Geotechnical and Geoenvironmental Engineering. ASCE, Vol. 129, No. 3, p. 243-253, 2003.

MERIFIELD, R. S.; SLOAN, S. W.; YU, H. S. Stability of plate anchors in undrained clay. Géotechnique. Vol. 51, No. 2, p. 141-153, 2001. 
MERIFIELD, R. S.; SMITH, C. C. The ultimate uplift capacity of multi-plate strip anchors in undrained clay. Computer and Geotechnics, doi:10.1016/j.compgeo.2010.02.004, 2010.

MEYERHOFF, G.; ADAMS, J. I. The ultimate uplift capacity of foundations. Canadian

Geotechnical Journal. v. 5:4, p. 225-244, 1968

MINDLIN, R. D. A Mathematical Theory of Photo-Viscoelasticity. Journal of Applied Physics. New York, Vol. 20, No. 2, p. 206-216, 1949.

MITSCH, M. P.; CLEMENCE, S. P. The uplift capacity of helix anchors in sand. In: A session sponsored by the Geotechnical Engineering Division of the American Society of Civil Engineers in conjunction with the ASCE Convention, Detroit, Michigan. Anais..., 1985, p. $26-47$.

MOONEY, J. S., ADAMCZAK, S. JR.; CLEMENCE, S. P. Uplift capacity of helix anchors in clay and silt. Proc. of a session sponsored by the Geotechnical Engineering Division of the American Society of Civil Engineers in conjunction with the ASCE Convention in Detroit, Michigan. Anais... 1985, p. 48-72.

MORRIS, L.; O’DONELL, P.; DELASSUS, P.; MCGLOUGHLIN, T. Experimental assessment of stress patterns in abdominal aortic aneurysms using the photoelastic method. Strain. British Society for Strain Measurement, Vol. 40, No. 4, p. 165-172, 2004.

MÜLLER, G. U. Photoelastic Determination of Contact Stresses of Foundations. Journal of Geotechnical Engineering; ASCE, Vol. 122, No. 8, p. 692-696, 1996. 
OLIVEIRA, A. G. Estudo da Transmissão e Distribuição de Tensões Aplicadas à Resina Acrílica Convencional e Acrescida de Fibras Através do Método Fotelástico. 2007, 204 p. Tese de Doutorado, Faculdade de Medicina de Ribeirão Preto, Universidade de São Paulo, Ribeirão Preto, 2007.

PATTERSON, E.; BRAILLY, P.; TARONI, M. High frequency quantitative photoelasticity applied to jet engine components. Experimental Mechanics. Springer Verlag, Vol. 46, No. 6, p. 661-668, 2006.

PENG, S.S. A photoelastic coating technique for rock fracture analysis. International Journal of Rock Mechanics and Mining Sciences \& Geomechanics Abstracts. Vol. 13, No. 6, p. 173-176

PEREIRA, G. P. M.; SMITH NETO, P.; ALMEIDA, D. L. Avaliação de Franjas Fotoelásticas Simuladas no Matlab e Software de Elementos Finitos. In: Congresso Iberoamericano de Engenharia Mecânica, 8, 2007, Cusco, Anais... Federação Iberoamericana de Engenharia Mecânica, 2007, 8 p.

PHILIPPE, R.R.; MELLINGER, F.M. A study of photoelastic models of foundations. In: International Conference on Soil Mechanics And Foundation Engineering, ISSMFE, 2, 1948, Rotterdam, Anais... Vol. 5, 1948, p. 58-63.

PHILIPS, ARIS. Introduction to Plasticity. 1a Ed. The Ronald Press Company, New York, U.S.A. 1956. 239 p. 
PRABHAKARAN, R.; SAWYER, W. A Photoelastic Investigation of Asymmetric Four Point Bend Shear Test for Composite Materials. Composite Structures. Great Britain, Vol. 5, No. 3, p. 217-231, 1986.

PRASAD, Y. V. S. N.; RAO, S. N. Lateral Capacity of Helical Piles in Clays. Journal of Geotechnical Engineering, Vol. 122, No.11, p. 938-941, 1996.

RAO, S.N.; PRASSAD, M. D.; SHETTY, M. D.; JOSHI, V. V. Uplift capacity of screw pile anchors. Geotechnical Engineering. Vol. 20, No. 2, p. 35-50, 1989.

RAVI, S. Development of Transparent Composite for Photoelastic Studies. Advanced Composite Materials. Ah Zeist, Holanda, Vol. 7, No. 1, p. 73-81, 1998.

REESE, L. C., COX, W. R., KOOP, F. D. Analysis of Laterally Loaded Piles in Sand. In: Offshore Technology Conference, 6, 1974, Houston, Anais... Houston, 2009, Vol. 2, p. 473483.

RICHARDS JR, R.; MARK, R. Gelatin Models for Photoelastic Analysis of Gravity Structures. Experimental Mechanics. Springer Boston, Vol. 6, No. 1, p. 30-38, 1966.

RICHTER, J. A.; DEMARS, K. R.; RICHARDS JR, R. Photoelastic Analysis of Laterally Loaded Rigid Piles. Journal of Geotechnical Engineering. ASCE, Vol. 110, No. 4, p.548$551,1984$. 
ROSSMANITH, H. P.; SHUKLA, A. Photoelastic investigation of dynamic load transfer in granular media. Acta Mechanica. Springer Wien, Vol. 42, No. 3-4, p. 215,225, 1982.

ROWE, R. K.; DAVIS, E. H. The behaviour of anchor plates clay. Géotechnique. Vol. 32, No. 1, p. 9-23, 1982.

SAKR, M. Performance of helical piles in oil sand. Canadian Geotechnical Journal. Vol. 46, No.9, p. 1046-1061, 2009.

SAKR, M. Lateral Resistance of Helical Piles in Oil Sands. In: 2009 International Foundation Congress and Equipment Expo, 1, 2009, Orlando, Florida, Anais... Orlando, 2009, p. 464471.

SCHIMIDT, R.; NASR, M. Screw Piles... Uses and Considerations. Structure Magazine. June, p. 29-31. 2004

SHUKLA, A.; CHALIVENDRA, V. B.; PARAMESWARAN, V.; LEE, K. H. Photoelastic Investigation of Interfacial Fracture Between Orthotropic and Isotropic Materials. Optics and Lasers in Engineering. Elsevier Ltd., Vol. 40, No. 4, p. 307-324, 2003.

SIMAMOTO JÚNIOR, P. C. Análise das Tensões na Estrutura de Suporte em Protocolos Implanto-Suportados com Alterações do Número e Diâmetros das Fixações. 2008, 119 p., Tese de Doutorado, Faculdade de Odontologia de Piracicaba, Universidade Estadual de Campinas, Piracicaba, 2008. 
SIMPADYAN, D. T. Photoelastic Study of Density Effects Under Footings in Granular Media. 1970, 76 p. Dissertação de Mestrado, Universidade de Wyoming, Laramie, Wyoming, 1970.

SMITH, F. W. Polymer Applications in Three Dimensional Linear Mechanics Analysis. Polymer Engineering and Science. Vol. 19, No. 2, p. 979, 1979.

STOLLE, D.; GUO, P. A Look at the Use of an Equivalent Homogeneous Medium. Canadian Geotechnical Journal. National Research Council of Canada, Vol. 44, No. 5, p. 507-519, 2007.

TAPPENDEN, K; SEGO, D.; ROBERTSON, P. Load Transfer Behavior of Full-Scale Instrumented Screw Anchors. In: 2009 International Foundation Congress and Equipment Expo, 1, 2009, Orlando, Florida, Anais... Orlando, 2009, p. 472-479.

TIMOSHENKO, S.P.; GOODIER, J.N. Teoria da Elasticidade. 3a Ed. Guanabara Dois S.A., Rio de Janeiro. 1980. 545 p.

TSUHA, C. H. C. Modelo teórico para capacidade de carga à tração de estacas metálicas helicoidais em solo arenoso. 2007. 275 p. Tese (Doutorado em Geotecnia) - Departamento de Geotecnia, Escola de Engenharia de São Carlos, Universidade de São Paulo, São Carlos, 2007.

VASCONCELOS, A. C. V. “Engenharia”, Vol. 7, IPT, São Paulo. 1947. p. 295-359-487. 
VESIC A. S. Cratering by explosives as an earth pressure problem. In: International conference of soil mechanics and foundation engineering, 6, 1965, Montreal, Quebec, Anais... Montreal, 1965. p. 427-431

VESIC, A. S. Breakout resistance of objects embedded in ocean bottom. Journal of Soil Mechanics and Foundation Division. ASCE, Vol. 97 No.7, p. 1183-1205, 1971.

VILAR, O. M.; BUENO, B. S. Mecânica dos Solos - Volume II. São Carlos: Departamento de Geotecnia da Escola de Engenharia de São Carlos da Universidade de São Paulo, 2004. (apostila). $154 \mathrm{p}$.

WEECH, C. N. Installation and load testing of helical piles in a sensitive fine-grained soil. 2002. 335 p. Dissertação (Master of Applied Science) - Departamento de Engenharia Civil, Universidade de Britsh Columbia, Britsh Columbia, 2002.

WIKIPEDIA 27 JUNE 2010. Wikimedia Foundation, Inc. Disponível em: <http://upload.wikimedia.org/wikipedia/commons/9/9d/Octahedral_stress_planes.png>. Acesso em: 05 jul. 2010. 